\title{
The concept of flavor styles to classify flavors
}

Citation for published version (APA):

Klosse, P. R. (2004). The concept of flavor styles to classify flavors. [Doctoral Thesis, Maastricht University]. Academie voor Gastronomie. https://doi.org/10.26481/dis.20040324pk

Document status and date:

Published: 01/01/2004

DOI:

10.26481/dis.20040324pk

Document Version:

Publisher's PDF, also known as Version of record

\section{Please check the document version of this publication:}

- A submitted manuscript is the version of the article upon submission and before peer-review. There can be important differences between the submitted version and the official published version of record.

People interested in the research are advised to contact the author for the final version of the publication, or visit the DOI to the publisher's website.

- The final author version and the galley proof are versions of the publication after peer review.

- The final published version features the final layout of the paper including the volume, issue and page numbers.

Link to publication

\footnotetext{
General rights rights.

- You may freely distribute the URL identifying the publication in the public portal. please follow below link for the End User Agreement:

www.umlib.nl/taverne-license

Take down policy

If you believe that this document breaches copyright please contact us at:

repository@maastrichtuniversity.nl

providing details and we will investigate your claim.
}

Copyright and moral rights for the publications made accessible in the public portal are retained by the authors and/or other copyright owners and it is a condition of accessing publications that users recognise and abide by the legal requirements associated with these

- Users may download and print one copy of any publication from the public portal for the purpose of private study or research.

- You may not further distribute the material or use it for any profit-making activity or commercial gain

If the publication is distributed under the terms of Article $25 \mathrm{fa}$ of the Dutch Copyright Act, indicated by the "Taverne" license above, 


\section{of revor sujles to elessify fllevors}




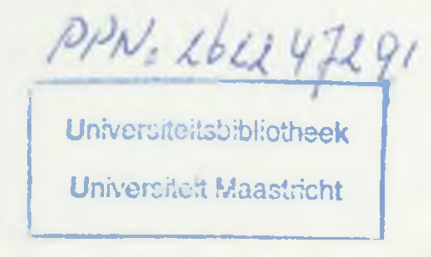

\section{Colofon}

Omslagontwerp: [ Studio Evers Haarlem BV ]

Vormgeving: [ Studio Evers Haarlem BV ]

Redactie: Peter Klosse

Illustraties: [ Studio Evers Haarlem BV ]

Druk: $\quad$ Febodruk B.V. - Enschede

Dit boek is gepubliceerd door

Academie voor Gastronomie

Amersfoortseweg 90

NL-7346 AA Hoog Soeren

www.academiegastronomie.nl

(c) Peter Klosse, 2004

ISBN 90-9017 885-6

NUR $882,440,447$

Niets uit deze uitgave mag worden verveelvoudigd en/of openbaar gemaakt door middel van c fotokopie. microfilm of op welke andere wijze en/of door welk ander medium ook, zonder voorafga schriftelijke toestemming van de uitgever. 


\section{Proefschrift}

ter verkrijging van de graad van doctor aan de Universiteit Maastricht, op gezag van de Rector Magnificus, Prof.mr. G.P.M.F. Mols, volgens het besluit van het College van Decanen, in het openbaar te verdedigen op woensdag 24 maart 2004 om 16.00 uur.

door:

Peter Ronald Klosse

geboren te Apeldoorn op 3 februari 1956 
Promotors:

Prof.dr. W.H.M. Saris

Prof.dr. H.C. Hemker

Beoordelingscommissie:

Prof.dr.ir. R.P. Mensink (voorzitter)

Prof.dr. H.F.P. Hillen

Prof.dr. P.B. Soeters

Dr. H. This (Collège de France, Parijs)

Prof.dr. van Trijp (Universiteit Wageningen) 


\section{Contents}

1. Introduction: The Classification of Flavors _ 8

$\begin{array}{lll}1.1 & \text { The elusive taste ___ } & 8\end{array}$

1.2 Defining taste, flavor and related concepts___ 9

$\begin{array}{lll}1.3 \text { Sensory Science____ } & 11\end{array}$

$\begin{array}{ll}1.4 \quad \text { Palatability and liking _ } 15 & 15\end{array}$

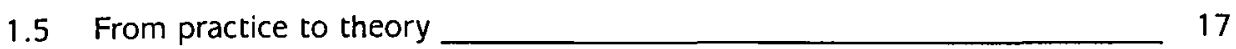

$\begin{array}{ll}1.6 \text { Developing a flavor classification } 17 & 17\end{array}$

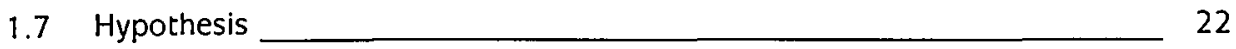

References _ـ 23

2. The act of tasting: the physiology of flavor registration. A review. __ 26

2.1 Introduction 26

2.1.1 Tasting: an intricate process _ـ 26

$\begin{array}{ll}2.1 .2 \text { Tasting: the oral process _ـ_ } 27 & 27\end{array}$

$\begin{array}{ll}2.1 .3 \text { Flavor registration through three different systems _ } 28 & 28\end{array}$

2.2 The gustatory system 30

2.2.1 The tongue map: a general misconception___ 30

2.2.2 Papillae, taste buds and taste cells __ 31

2.2.3 Non-tasters, tasters and super-tasters _ 33

$\begin{array}{ll}2.2 .4 \text { Basic flavors? } & 35\end{array}$

2.3 The olfactory system __ 36

2.3.1 Orthonasal and retronasal smell__ 36

$\begin{array}{ll}2.3 .2 & \text { The olfactory process ___ } 37\end{array}$

$\begin{array}{lll}2.3 .3 \text { Odor composition and preferences_______ } & 39\end{array}$

2.3 .4 Olfaction, health and age 40

2.4 The trigeminal system__ 41

2.4.1 No flavor without some kind of mouthfeel __ 41

2.4.2 The neural trigeminal system _ 41

$2.4 .3 \mathrm{CO}_{2}$, astringency, and trigeminal sensitivity _ 44

2.4.4 Underestimated role of thermo- and mechanoreceptors?___ 45

2.5 Ascending the neural pathway __ 46

2.5.1 Neural information and flavor _ 46

$\begin{array}{ll}2.5 .2 \text { Further into the brain } & 47\end{array}$

2.5 .3 Biological need or hedonic value?

2.5 .4 Liking and wanting _ـ 50

2.5.5 Flavor as the result of imprints of neural activities ___ 51

2.6 Sensory interaction ___ 53 
2.6.1 Synesthesia __ 53

2.6.2 Flavor enhancement by umami _ 57

2.6.3 Adaptation and (de)sensitization $\quad 59$

2.6.4 Carry-over effects _ 60

2.7 Conclusion 62

$\begin{array}{ll}\text { References } & 62\end{array}$

3. An empirical test of a new flavor classification model:

the Flavor Styles Cube (FSC)

Abstract 70

$\begin{array}{ll}3.1 & \text { Introduction } \\ 3.2 & 71\end{array}$



3.2.1 Description of the empirical flavor style model __ 73

3.2.2 Selection of products and target structure ____ 76

$\begin{array}{ll}3.2 .3 \text { Testing the empirical model _ } & 79\end{array}$

3.3 Results_ 80

3.3.1 Subject characteristics 80

3.3.2 The hypothesized eight factorial structure of the FSC

3.3.3 Restructuring the three dimensional FSC structure ___ 82

3.3.4 Confirming the three factor structure of the FSC __ 83

3.3.5 Evaluation of product positions in the Flavor Styles Cube _ 84

3.4 Conclusion $\quad 86$

$\begin{array}{lr}\text { References } & 89\end{array}$

4. The formulation and evaluation of Culinary Success Factors (CSFs) that determine the palatability of food $\quad 92$

$\begin{array}{lr}\text { Abstract } & 92\end{array}$

4.1 Introduction 93

4.2 Materials and methods __ 94

$\begin{array}{lll}4.2 .1 \text { Study } 1 \ldots 94 & 94\end{array}$

4.2.2 Study $2 \ldots 95$

4.3 Results_ 96

4.3.1 Results study 1: Culinary Success Factors_ 96

4.3.2 Results study 2: Evaluation of CSF concept _ 97

4.4 Discussion 100

4.4.1 Palatability objectified __ 105

References 106

Appendix 1: Questionnaire Chefs__ 108

Appendix 2: Tasting forms 109

5. Umami in wine 110

Abstract_r 110 
5.1 Umami and flavor 110

5.2 Umami sources in wine

5.2.1 Grape variety and maturity

5.2.2 Alcoholic fermentation, influence of yeast

5.2.3 Malolactic fermentation

5.2.4 Special types of fermentation: sweet wines and méthode traditionnelle _ 115

5.2.5 Other sources: ageing, 'sur lie and batonnage' ___ 116

5.3 Future ventures 116

References 117

6. Analysis of glutamic acid in wine in relation to flavor: the link to umami_ 120

$\begin{array}{ll}\text { Abstract } & 120\end{array}$

6.1 introduction 121

6.2 Materials and methods __ 122

6.2.1 Wine samples 122

6.2.2 Chemical analysis__ 124

6.2.3 Statistical procedures _ 124

6.3 Results 124

6.4 Discussion _ 128

References 131

Appendix: table 6-3 _ 134

7. Discussion and general conclusions 136

7.1 Only 'gustation' is a sense; flavor registration is a sublimation of senses _ 136

7.2 Formulating the physics of flavor perception _ 138

7.3 Liking: product and human perspective _ 139

7.3.1 Product values and liking _ 139

7.3.2 Human values and liking __ 142

7.4 Behavioral process of food choice

7.5 The function of flavor classification in the process of food choice __ 145

7.5.1 Flavor classification and product identification _ 145

7.5.2 Flavor classification and product development $\quad 147$

7.5.3 Flavor classification and cross-cultural differences___ 148

7.5.4 Flavor classification and combination of flavors__ 149

7.6 Conclusions 150

7.7 Craftsmen of flavor and Sensory scientists _ 151

Appendix: the Flavor Identification System (F.I.S.) _ 152

References 153

Summary _ 156

Acknowledgements _ 159

Curriculum Vitae _ 160 


\section{Chapter 1 \\ Introduction: \\ The Classification of Flavors}

\subsection{The elusive taste}

Eating and drinking are closely related to the quality of life. People tend to find it important to select the 'right' foods and beverages, because they provide an important source of pleasure in daily life. As i.e. reported by Birch (1999) who concluded that the only activities of daily life rated higher than 'a fine meal' were (a) spending time with family, (b) holidays, and (c) sex. Of these activities, eating and drinking have a high daily frequency and a strong biological drive, being essential to keep the human biological system going. Although the intake of food or beverage is a biological necessity, the flavor of these 'intakes' provides the extra dimension: it gives meaning and pleasure to it (Drewnowski, 1997). The rate of pleasure may differ from i.e. person to person, situation to situation and culture to culture, but the function of flavor in relation to food is the same: it is the discriminating factor, the basis of food choice, preference, and intake. Consequently, everybody has experience with flavor and tasting, personal likes and dislikes, and preferences for certain foods and drinks in specific situations. People do not eat or drink just to survive and it may safely be assumed that tasting plays a predominant role in everybody's daily life.

The human sense of taste mediates the flavor of edible products to the brain. All kinds of different aspects of taste are well-known. Nevertheless, in comparison with the other senses, taste might even be poorly understood (i.e. DeCastro. 2000; Ackerman, 1990). This situation may well be explained by the fact that the perception of flavor requires an active involvement of the other senses. Smell and taste are considered to be the chemical senses. They are closely related, in more than one way. Firstly, smell is an inseparable part of taste: a lot of what is tasted is in fact registered through the olfactory system. Secondly, people tend to undervalue both senses. In ranking the importance of their senses people put sight and hearing above smell and taste (Vroon, et al., 1994). Illustratively: the words 'anosmic' (total or partial loss of the sense of smell) and 'aguesic' (no perception of taste) do not belong to the everyday vocabulary. like 'blind' or 'deaf'. It can even be argued that people with poor tasting or smelling abilities might not be aware of their problem. According to Finkelstein and Schiffman (1999), there is a great need for methods to treat such chemosensory losses.

The chemical senses share yet another characteristic: they are hard to classify. Colors and sounds can be denominated by their objective physical qualities, like wavelength or vibration per second (millimicrons, Herz), and intensity (like lux or decibel). The 
recognition and subsequent definition of these physical properties makes it possible and even logical to distinguish between the objective and the subjective sides of sounds and colors. Up to now the objective base of taste (and smell) has not been defined. Subsequently, in discussing flavor the objective and subjective side are often mixed. Many flavor classification attempts in history took the so-called primary or basic tastes (sweet, salty, sour and bitter) as a base (Bartoshuk, 1978). Yet - as will be shown - these flavor components are only a part of flavor as a whole. Therefore, they can not serve as a basis for classification as other important factors need to be taken into account as well.

\subsection{Defining taste, flavor and related concepts}

In books and articles on taste not all concepts are exactly defined and treated in the same way. Taste and flavor are for instance often treated as synonymous, which can be confusing, and flavor itself is often interpreted as the combination of taste and smell, which is incomplete. In some languages, e.g. Dutch and German, there is even only one word for both concepts. In this thesis the following definitions are used.

Taste: (the noun) is a very general word that can best be used in a sensorial context. In this work the sense of taste is regarded as an integrative sensorial experience, in which all senses participate. To prevent misunderstanding, the part that registers tastants (like sweet, sour, salty, and bitter) through papiliae on the tongue can best be referred to as 'gustation'. In reference to products the word 'flavor' is used.

Flavor: is the complex combination of the olfactory. gustatory and trigeminal sensations perceived during tasting. Flavor may be influenced by tactile, thermal, painful and/or kinaesthesic effects (ISO 5492:1992 Glossary of Terms Relating to Sensory Analysis). The concept of flavor is used in relation to all food products (solid and fluid), in regard to what is being tasted. Flavor is technically based on product characteristics. Coffee and tea, apples and bananas, fish and meat are technically different, and these differences are universally assessed in a similar way. At the same time flavor may have an emotional side, which leads to preferences and appreciation. To mention one example: in some cultures insects are a delicacy, in others people wouldn't dream of eating them.

Flavor registration or tasting (the verb): is used in the sensorial context, the act of tasting and the registration of what is being tasted. These words are used for the objective, technical side of flavor.

Palatability: is a product related concept that refers to a successful combination of product characteristics. Palatability and liking are easily confounded but are indeed quite different concepts. 
Appreciation or liking: is how the one who tastes, evaluates the flavor. Flavo registration and flavor appreciation can be quite different. An emotional association witl a certain flavor may be so strong that it influences its registration. This phenomenon $i$ for instance known with strong brands or previous experiences.

Figure $1-1$ visualizes the specific relation between these concepts.

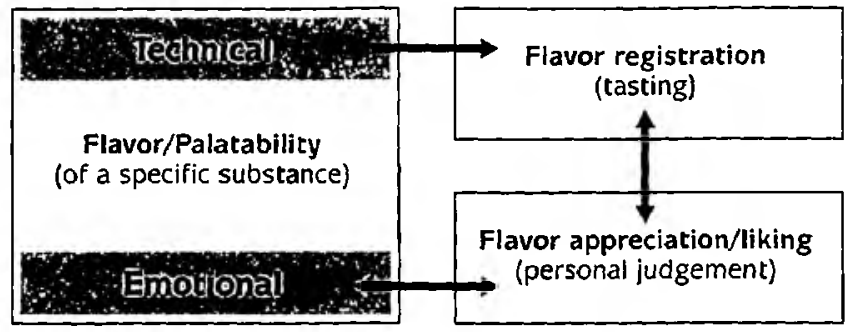

Figure 1-1: The interrelation between flovor, flavar registration and flavor appreciation
The arrows in figure 1 indicate the interrelationshi between flavor, registratic and appreciation. The flave of a substance can techr cally, and thus objectively $t$ registered by product sp cialists and sensory pane' Statistical techniques (i. Bech. Hansen \& Wienber 1997) and technical instr ments, like the electric

nose' and 'electrical tongue', instruments to measure the rheology, and the gaschr matograph are getting more and more sophisticated and can also be used objectively analyze product characteristics (Li Rong, Wang Ping, Hu Wenlei, $20 \mathrm{C}$ Göpel et al. 1998). However, the consumer assessment of a particular flavor may $r$ be the same. Consumers are not neutral observers. Their taste registration influenced by i.e. mood, experience, physical condition. and other substances $t$ are registered at the same time. There is not a direct relationship between prod quality as such and consumer appreciation. It is conceivable that although prod quality may be high based on product characteristics, the consumer does not ass this quality in the same way. In other words: a product is not good, unless it is for to be good. This concept is known in marketing as the difference between product approach and the consumer approach and applies to many other proc categories as well (Kotler, 1976).

To better understand the human appreciation of flavor it is essential to $\mathrm{kr}$ more about the relations between flavor itself, how it is registered, and apprecia The arrow at the emotional level between flavor and flavor appreciation goes in $t$ directions to implicate that a strong appreciation of a well known brand is likel influence its flavor registration. This explains how even elements that are viewe undesirable from a technical point of view can be accepted or even be liked fror 
ir. Flavo

ition witl

menon $\mathrm{i}$

figure 1-

Iationshi

sgistratic

The flave

in techr

sctivelyt

duct sp

ry pane

ques (i.

Wienber

cal instr

'electriı

e gaschı

e used

nlei, 201

or may 1

istration

rances $t$

en prod

gh prod

i not ass

$s$ it is for

etween

ver proc

ial to $\mathrm{kr}$

apprecia

goes in $t$

$\exists$ is likel,

e viewe;

ked fror 1

emotional point of view (Guinard. Uotani, Schilch, 2001). To get a better understanding of such and other influences there is a need for further development and basic research (Beauchamp, 1996).

\subsection{Sensory Science}

The human senses register modalities from the physical environment which are 'translated' in electrical signais, which is the medium of communication of the brain. Different kinds of inputs are registered by different senses. Sensory Science includes all senses, not only tasting, although it may seem that tasting in the broadest significance has annexed the field (Martens, 1999). Sensory science is truly a multidisciplinary science that involves many aspects. Tasting is arguably the most intriguing and certainly the most complex of the senses. The fact that the functioning of tasting involves the other senses as well adds to its predominant position in the field (Winquist, et al., 1999). By its nature there is always an interaction between a physical input and the human registration as is illustrated in figure 1-2.

The complex interaction between products on the one side and individuals on the other implies that many different types of researches can be found in literature, fed by many different disciplines in the field of sensory science.

To start with the product side, the definition of flavor holds that foods and drinks are complex mixtures of different components. The

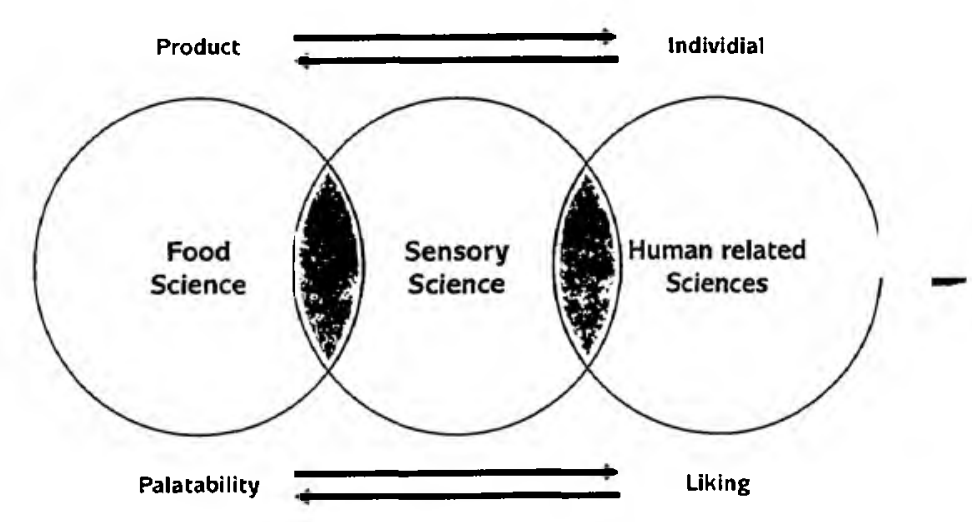

Figure 1-2: the product and human side of sensory science sense of taste relies on a simultaneous registration of:

gustatory components, or tastants, basically registered through various kinds of papillae in the oral cavity;

olfactory components, or odorants, which are registered through receptors in the nose, and coming both from outside (orthonasal) and from within the oral cavity (retronasal); 
mouthfeel components, registered by the receptors of the neural trigeminal system both in the nose and in the mouth. Mouthfeel components can be both non-volatile and volatile.

Flavor is always a composition of these three elements; not one can be missed. The olfactory and gustatory neural systems are so interwoven that they are generally conceived as one. If, for instance, the nasal system is blocked because of a cold, many products are hardly identified (figure 1-3) (Vroon, 1994). The same can be said from any other impairment in one of the sensory systems involved in tasting.

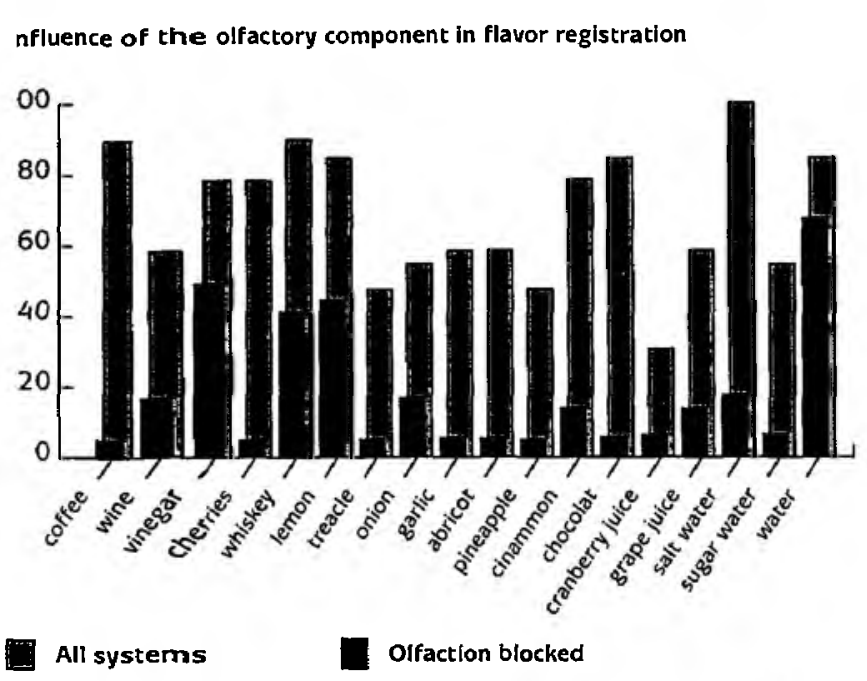

Figure 1-3: influence of the olfactory system on flavor registration (Vroon, 1994)
Flavor is influenced by tactile, thermal, painful and/ or kinesthetic effects (ISO 5492: 1992 Glossary of Terms Relating to Sensory Analysis). All trigeminal influences gather within the concept of mouthfeel. Both the importance and versatility of mouthfeel is illustrated by many everyday examples: from the fizzy tingle of $\mathrm{CO}_{2}$ in soda, beer or Champagne, to the burn from hot peppers, black pepper, and other spices such as ginger, and from the tenderness of a steak, to the right creaminess or thickness of a sauce or soup, and from the crispy dryness of toast or the crust of fresh bread, to the soft juiciness of a ripe pear, melon or peach. Temperature also contributes to mouthfeel. In each of these examples flavor appreciation is closely related to the expected mouthfeel: melted ice cream or beer without fizz have lost much of their appeal.

Sound is reported to influence the perception of crisp, crunchy and crackly structures. If a crisp product does not produce the corresponding sound, it is considered to be stale and of poor quality (Duizer, 2001).

The gustatory, olfactory and trigeminal components (smell and touch) can be considered as the primary or intrinsic constituents of flavor and flavor registration (figure 1-4). 
In a 'blind tasting experiment' attention is focused on these three elements. It is an acceptable method to assess product qualities.

In addition to the primary or intrinsic components of flavor, there are extrinsic components that are basically registered by the other senses, vision and hearing. They are not a part of the physical product, but yet - strongly - related to it. They serve as an introduction, and help in selecting the right food products. At

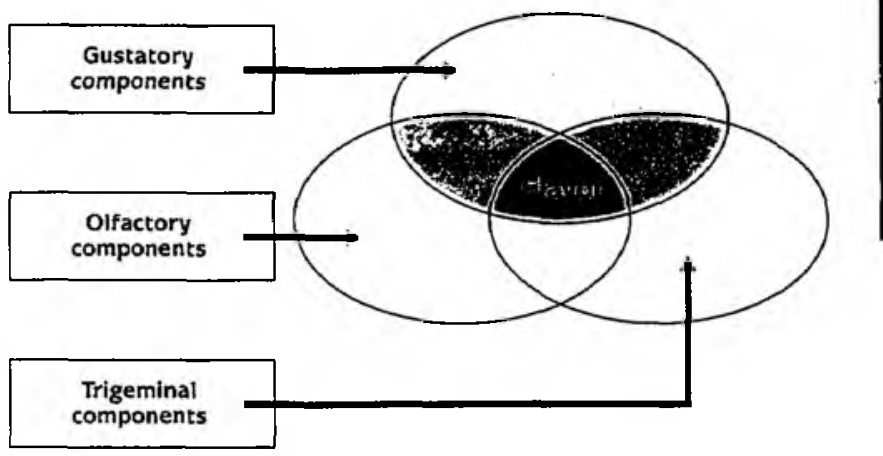

Figure 1-4: the intrinsic components of flavor the same time seeing and hearing can be potent drivers of liking and disliking. As such these senses have a supportive function in regard to taste, which involves flavor appreciation. Packaging, brand names, health claims and product image are examples of extrinsic factors that are known to influence flavor registration. Both the role and the importance of these extrinsic factors should not be underestimated. More and more, researchers are interested in the effects of these factors and how they interact with the perception of intrinsic product characteristics (Lange, Rousseau, Issanchou, 1999). Color for instance, influences taste thresholds, sweetness perception, pleasantness and acceptability (Clydesdale, 1993). In a French study a white wine was artificially colored red, and subsequently wine experts olfactory described it as a red wine (Morrot, Brochet, Dubourdieu, 2001). Visual or auditory heaith claims, like 'fat-free', 'low-fat', 'diet', or 'sugar-free' are also known to be powerful in certain consumer segments. When tested blindly, subjects may like such a product less than the regular version, but when they know the difference, they may prefer it anyway (Guinard, et. al, 1996). Price is another factor that can influence purchase behavior. Low prices are likely to be associated with inferior quality and contrariwise, a high price may induce consumers to prefer a less liked product (Lange, Issanchou, Combris, 2000). Because of the influence of such extrinsic factors the results of an 'as branded' flavor research are likely to deviate from a blind tasting (Guinard et al., 2001). In all these types of studies real products are at the focus of interest. How does its flavor relate to appreciation, preference, quality, circumstances and well being? Flavor registration is hardly an issue; psychosomatic, cognitive and marketing aspects are looked at. Another 
type of sensory food research studies the chemical and physical properties of foor products and their relation to preference and palatability (i.e. Richardson-Harman et al 2000; Lawlor, et al., 2002; Safari et al. 2001). The way the chemical elements of fooc ingredients or nutrients react and interact is also an interesting field of study. Irritatior is an example of a chemical reaction, as are suppression and the interaction of chemicals between them (i.e. Breslin, 1996; Prescott, 1999). Aspects like these are likely tc influence flavor appreciation. The above mentioned examples of sensory research are basically product oriented and involve the left side of figure 1-2.

The right side of this figure 1-2, considers the human side of sensory science Human related sensory science is also diverse. One type of taste research focuse: specifically on flavor registration: the reaction and registration of chemical component: is measured. Research focuses on the neuro transmission of taste through taste bud? and chemical reactions. Important contributions are to be found in neurophysics chemistry, (micro)biology, and physiology in regard to this orientation. Animais are often used in these fields of research. Consequently: real products and product characteristics are not included, the focus is on the reaction of basic elements that are thought to be registered on the tongue, i.e. sweet, sour, salty, bitter, and umami Studies and experiments in this field have produced a great understanding of the functioning of the human taste system, and the similarities between people. Tast $\epsilon$ thresholds of the basic tastes have been established and universally compared. Despite differences between people there is a general agreement about the way and intensity taste is registered (i.e. Lindemann, 1999).

Human studies in sensory science also involve i.e. food choice and behavior. Drewnowski (1997) reports that demographic, economic and socio-cultural variables play a major role in determining food choices at any age. Whereas taste preferences for sugar and fat may well be innate, group consumption of sugars and fats is determined by economic factors, including income. Economic growth has been associated with an improvement in and a progressive globalization of the human diet. Sociological studies focus on the effects of group behavior. People tend to eat more when other people are present, and more specifically, females tend to eat significantly more when eating with a male than when eating with another female, whereas males eat the same amount regardless of the sex of their companion. Meals ingested with spouse, family, or friend are significantly larger $(22 \%, 23 \%$, and $14 \%$ respectively) than meals ingested with others but without family or friends present, whereas meals ingested with coworkers are significantly smaller (16\%). In general, morning, midday and evening meals are conceptionally different; expectations are not the same (DeCastro, 2000). In psychology and sociology there are contributions that are related to both flavor registration and flavor appreciation as far as it involves the human perspective. Aspects of the mind are

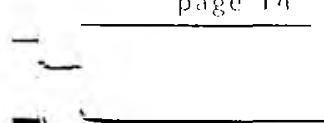


studied and especially the role our mind plays in assessing flavor. Cognition, memories, associations, stress, fatigue, mood and disturbances of food intake (such as anorexia nervosa and bulimia) are areas of study, to mention a few. Again, product characteristics are mostly not taken into account, as the focus is on the human psyche.

The conclusion may be drawn that sensory studies are versatile, and that in basically all fields of science valuable contributions are found that explain different aspects of tasting. But despite the many articles that have been written and the research that has been conducted, there is still much about taste and tasting to be left to explain. Evidently neither the human, nor the product orientation in sensory science has led to a full understanding. The challenge for sensory science is to consider taste as a whole and see how the individual parts fit in. That implies the establishment of a liaison between the hard sciences (i.e. chemistry, biochemistry, physics, and neurology) and soft sciences (i.e. psychology, sociology, anthropology and marketing) that are involved in taste, flavor, tasting and flavor appreciation (Martens, 1999) (figure 15). It also means that the subjective, erratic, everchanging consumer, who is generally rationed away as a scientific nuisance, has to be included (DeCastro, 2000). This truly interdisciplinary approach will characterize

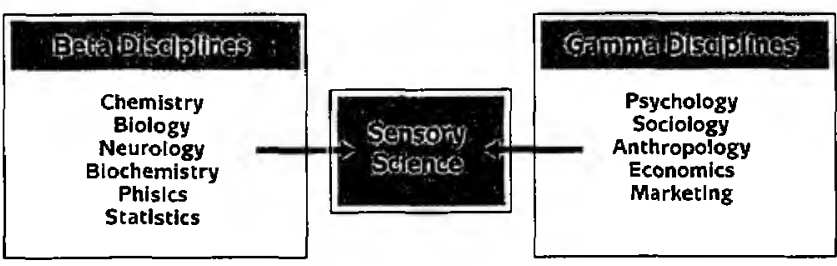

Figure 1-5: Sensory Science, the liaison of sciences this thesis.

\subsection{Palatability and liking}

Figure 1-2 shows that the concept of palatability is used in regard to products. Liking, on the other hand is defined as the positive human response. Even palatable products need not necessarily be liked. Internal and external forces influence flavor appreciation. Appetice is probably the most conspicuous internal influence, as is illustrated by the saying 'hunger makes the best spice'. Neuropeptides in the human brain may continuously be monitoring the need for energy and certain nutrients and directing food choices. Children with 'pica' crave and consume soil containing a particular mineral they are lacking in their bodies. The peculiar food habits some women experience during their pregnancy may also be explained on this basis (Poothullil, 1995). In the human brain different regions are involved in 'liking' and 'wanting', each with their own 
systems and neuroregulators (Berridge, 1996: Levine \& Billington, 1997). To underst liking the decision to eat or drink has to be taken as starting point. The actual acl tasting is a consequence of a choice that has more or less consciously been made.

This is not a new concept. In 1904 Pavlov was awarded the Nobel Prize for showing 1 not the actual food, but the thinking about it, triggered by the sound of a bell, induced physiological reflex of salivation. In his honor it is referred to as the Pavlov-effect psychology it is also called 'classical conditioning'. There are many everyday examples. $M$ of what is liked and disliked is a result of conditioning or learning. Coffee, alcohol, tobac and some vegetables are well known examples of products that eventually are learnt to appreciated. Often there are underlying needs. Smoking a cigarette is often related to strt many people drink alcohol as a part of social customs, while coffee is supposed to incre the level of activity and often related to sleeping difficulties. Some of these popular bel: may not be true or even unhealthy, but that is irrelevant because they act as stimuli. In synergetic view it is essential to link these kinds of stimuli to taste. Their causal relations is the starting point of the taste process. As Spector (2000) has pointed out, it is import to note that this use of the terms 'stimulus' and 'response' is non-conventional. definition of the stimulus and/or the response determines the level of the analysis. $\ln$. perspective the consumer is put centrally, s/he is the stimulus in deciding if and what to he the chosen product is the logical response, like in the following illustration (figure 1-6). T line of reasoning diverges from the classical sensorial conception where the producl considered to be the stimulus and flavor registration, or rather liking as a desirable respon The brain is not a passive stimulus-drive device. The processing of stimuli is controlled top-down influences that constantly create predictions about forthcoming sensory eve and shape their registration (Engel, Fries \& Singer, 2001).

\section{Product orientation:}

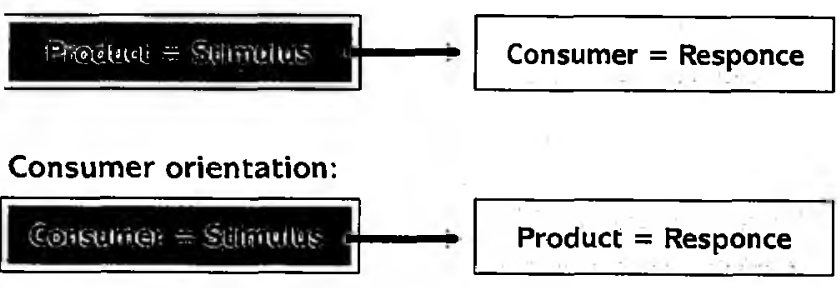

Figure 1-6: The stimulus - response turnaround
The significance of $t$ turnaround is that the $\mathrm{Cc}$ sumer's personal circu stances and expectatic become implicit, which $\mathrm{cc}$ sequently reduces the co plexity of understandi flavor appreciation. The $\mathrm{i}$ plication is that the cons mer needs to be able recognize the flavor

products in such a way that $5 /$ he is able to make the right choices. These 'right choic will almost certainly be appreciated as they fit the individual beliefs and circumstanc 
To be able to make such choices requires that flavor has to be made tangible, recognizable and/or comprehensible. It will be shown that this can be achieved by the use of flavor styles, the classification of flavor based on product characteristics.

\subsection{From practice to theory}

The basis of this work lies in daily practice. It started out as a study on the flavor of wine in 1989. The results of many tasting experiences were never systemized and hardly documented. Yet they provided new insights that at first have proven to be useful in understanding the flavor of wine. Mouthfeel and flavor richness were identified. It took some time before it dawned that these were concepts that described flavor in general and could easily be applied to food products other than wine. This initiated the understanding of wine and food pairing and resulted in courses and consumer books on this subject.

After years of continued study and refining, the desire for systemization and scientific substructure grew. In the course of this mission enthusiasm has further developed as strong indications were found in support of this new view. The concept must now be evaluated in a systematic and scientific way in order to be refereed by the scientific community. This thesis is the result of this desire and asks for arguments in support, or against the concept.

\subsection{Developing a flavor classification}

It is assumed that humans generally have a tendency to like sweet and salty and to dislike acidity and especially bitter (Berridge, 1996; Birch, 1999). Nevertheless, many of the universally liked products with high consumption volumes, like beer, chocolate, wine, tea and coffee contain considerable amounts of bitter tasting elements that apparently do not hinder the general appreciation of these products. Rather, bitter contributes to the complexity and enjoyment of beverages and foods (Drewnowski, 2001). According to Erickson (2000) the real 'root' issues in taste may not have been identified. He states that the lack of systemization has cost the field of the chemical senses dearly and calls upon an evolution of broad theories in the chemical senses as "these are eventually inevitable, and after 100 years of research, they would not be premature now".

Classification implies a systematic division into classes or groups (Bowker \& Star, 1999). To be able to do this, distinguishable parameters with well-defined 
dimensions are needed. For a classification to be widely used, these paramet dimensions must be easy to recognize, understand and apply. For any classification to be effective it evidently needs to have an objective basis. $T$ general use this basis also needs to be universally applicable. Flavor, registration and flavor appreciation were distinguished as three different co Of these, the last two involve individuals, and are therefore by definition sub The basis of a classification can therefore be found neither in flavor registrati in flavor appreciation. However, as stated before, the flavor of foods objectively assessed. If a classification can be found, it has to be found in the of flavor itself.

Previous attempts to classify flavor were inspired by the four gu: components that are registered on the tongue: sweet, salt, sour and bitter. Eve Aristotle these so-called 'basic' flavors or 'primary' flavors were the center of it (Bartoshuk, 1978). But unlike the primary colors, it is impossible to create all by using just these primary or basic flavors (Schiffman, 2000). There is a reason why the concept of basic flavors is not likely to provide fundamental at on flavor itself: trigeminal aspects are not taken into account. In considering ji basic flavors there is no difference made in hard or soft, crispy or stale, solid o warm or cold, etc. Clearly such elements do play an important part in appreciation. As soon as these textural elements are taken into account, dil answers emerge.

The above mentioned trigeminal elements of flavor are of prepon importance. The general term for these elements is 'mouthfeel' (Gi Mazzucchelli, 1996; Wilkinson, Dijksterhuis, Minekus, 2001). Humans are - sl right at birth - extremely sensitive in regard to mouthfeel. For infants the textu temperature of breast milk is of importance, and later they react strongly texture of the first solid foods. Indeed, most animals are better in smellit seeing, but for humans it is the 'touch' of flavor that guides appreciation. people are highly sensitive in regard to mouthfeel and flavor appreciation. is no flavor without mouthfeel. Toasted bread that has lost its crispness has als much of its appeal. At the same time the dog will gladly eat anything that has on the floor even if it is covered with sand. If only from the start mouthfeel have been put at the center of interest in thinking about taste and flavor, it i have been recognized in an early stage that there is more to flavor than the flavors. The general term 'mouthfeel' can be defined as: the human percepti the texture of food or beverage in the mouth. It covers all trigeminal experit including texture, thermal effects and chemical influences of acids, salts, min metals, and irritants. 
In mouthfeel two main dimensions can be differentiated: contracting and coating. Contracting. The rinsing or cleansing effect of acidity in the mouth is well known. Acidity as a whole plays an important part in the composition of many foods. Physiologically 'sour' reacts chemically, just like salt, through ion channels (Smith \& Margolskee, 2001). At the same time they give tactile, 'tingling' or 'stinging' impressions. Such as the freshness of a green saiad, citric fruit, apples, and pickles. Cold, like in ice cream also gives a fresh and tingling sensation. These elements have a rinsing, refreshing and contracting influence in the mouth. More extreme trigeminal reactions, like from $\mathrm{CO}_{2}$, menthol, raw onion, mustard, ginger, horseradish, and several peppers are similar to these reactions, although they are very different from a chemical and physiological point of view. The common denominator is that there is always a prickling or stinging feeling. Next to these effects, the mouth can also feel dry. Substances that easily take up saliva can cause this. Examples are the dryness of biscuits, the crispness of a fresh crust of bread, potato chips, or roasted meat and the crunchy characteristics of nuts. The drying (roughing, puckering) effect in the mouth caused by tannins (red wine) and other bitter tasting elements (like in coffee, tea or plain chocolate) belong to this characteristic as well.

Coating. The mouth-coating characteristics of creamy, fatty substances and of dissolved sugars, coat the mouth, leaving a layer of i.e. fat or sugar behind. These substances also influence saliva by making it thicker. In beverages alcohol and sugars influence viscosity. The coating layer that such elements leave behind is likely to influence the flavor perception of the next food ingested.

\footnotetext{
Many practical, daily examples demonstrate that coating and contracting products are used to balance each other. Oil (coating) and vinegar (contracting) are mixed together to get a well balanced vinaigrette. The two elements neutralize each other just like a dry slice of toast (contracting) will neutralize a slice of smoked salmon (coating). At the same time the fatness of smoked salmon may also be neutralized with contracting elements like lemon, raw onion of horseradish. In a two dimensional representation these influences can be illustrated as in figure 1-7.
}



Figure 1-7: two dimensions of mouthfeel, 4 quadrants 


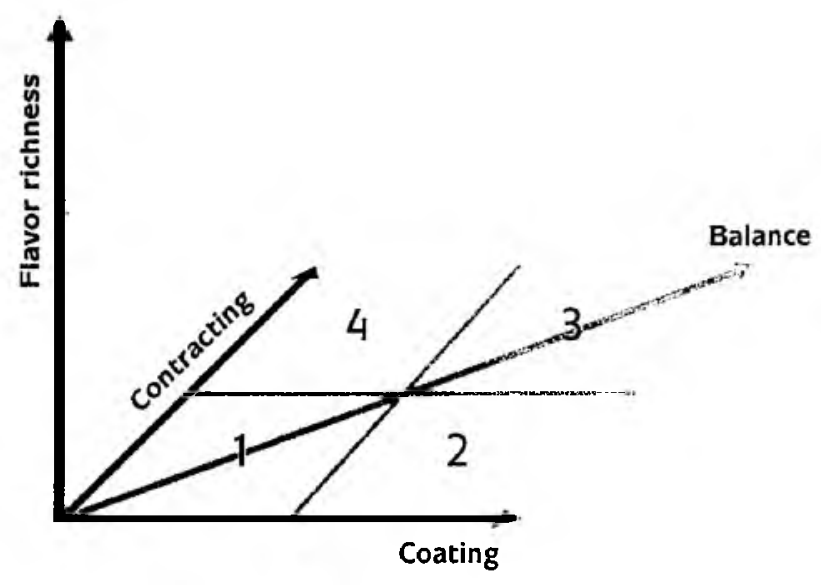

Figure 1-8: the third dimension of flavor: flavor richness

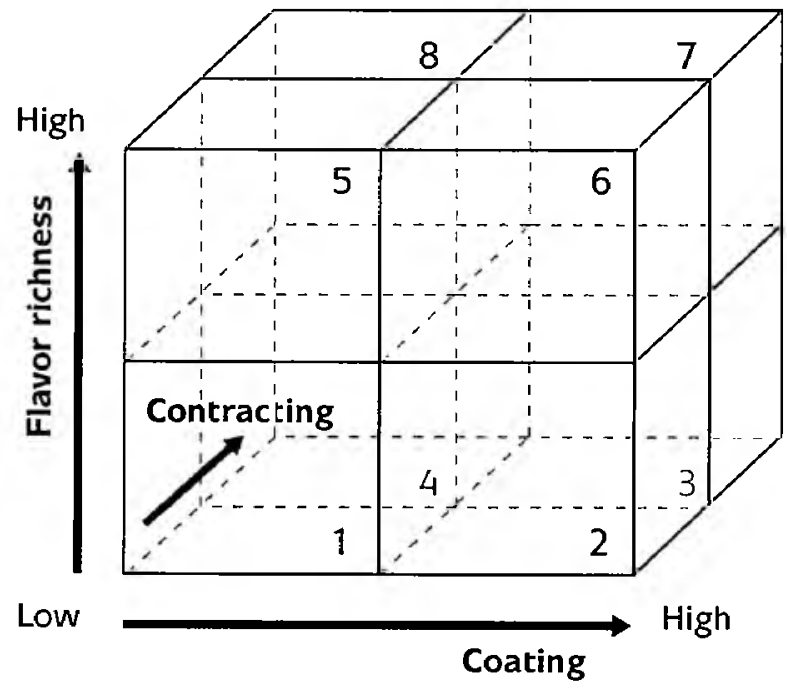

Figure 1-9: The Flovor Styles Cube
If only mouthfeel considered, the presenta of flavor is two-dimensic The third dimension is ' $\mathrm{fl}$; richness'. Flavor richnes: comparable to decibel sound, and to lumen in 1 and can be differentiated $F$ 'low' to 'high'. It can be defi as the relative intensity on level of flavor. The dimens of mouthfeel form the $b$ from which higher intens of flavor can be identified: shown in figure 1-8.

This basic structure be extrapolated into a th dimensional model: the $\mathrm{Fl}$ : Styles Cube (figure 1-9) our experience mouthfeel flavor richness, can be cognized quite easily in kinds of different foods beverages. The dimensions each factor should not be s as 'either, or'; intermed positions are very well possi However, flavors that can identified close to one of corners can be considered to an 'icon' of flavor.

From this illustration following characteristics (t: 1-1) and examples (table 1 can be deduced: 


\begin{tabular}{|l|l|l|l|}
\hline \multirow{2}{*}{$\begin{array}{l}\text { Table 1-1 } \\
\text { FLAVOR STYLE }\end{array}$} & \multicolumn{3}{l|}{ PRIMARY FLAVOR FACTORS } \\
\cline { 2 - 4 } & COATING & CONTRACTING & FLAVOR RICHNESS \\
\hline 1. (NEUTRAL) & LOW & Low & Low \\
\hline 2. (ROUND) & High & LOW & Low \\
\hline 3. (BALANCE LOW) & High & High & Low \\
\hline 4. (FRESH) & LOW & High & Low \\
\hline 5. (ROBUST) & Low & Low & High \\
\hline 6. (RICH) & High & Low & High \\
\hline 7. (BALANCE HIGH) & High & High & High \\
\hline 8. (PUNGENT) & Low & High & High \\
\hline
\end{tabular}

Table 1-1: Characterization of flavor styles

\begin{tabular}{|c|c|c|}
\hline Table 1-2 & TYPICAL EXAMPLES & \\
\hline FLAVOR STYLE & FOOD & BEVERAGES \\
\hline 1. NEUTRAL & $\begin{array}{l}\text { Rice, white bread, zucchini } \\
\text { poached/steamed fish, boiled egg }\end{array}$ & Water \\
\hline 2. ROUND & $\begin{array}{l}\text { Spaghetti, milk chocolate, banana, } \\
\text { melon, avocado, young Gouda } \\
\text { cheese, butcer, plain oil }\end{array}$ & $\begin{array}{l}\text { milk, wines with } \\
\text { a touch of sweet }\end{array}$ \\
\hline 3. BALANCE LOW & Vinaigrette, creamy tomato sauce & $\begin{array}{l}\text { yogurt, balanced daily } \\
\text { wines }\end{array}$ \\
\hline 4. FRESH & $\begin{array}{l}\text { apple, orange, lemon, green salad, } \\
\text { pickles, oysters, tomato, fresh goat } \\
\text { cheese, vinegar }\end{array}$ & $\begin{array}{l}\text { orange juice, acidic } \\
\text { white wines, like } \\
\text { Sancerre. Muscadet, } \\
\text { Riesling }\end{array}$ \\
\hline 5. ROBUST & $\begin{array}{l}\text { biscuits, toast, chips, nuts, pure } \\
\text { chocolate, French fries, grilled meat }\end{array}$ & $\begin{array}{l}\text { coffee, strong tannic } \\
\text { red wines with wood } \\
\text { character }\end{array}$ \\
\hline $\begin{array}{l}\text { 6.RICH } \\
\text { 7. BALANCE HIGH }\end{array}$ & $\begin{array}{l}\text { vanilla, caramel, whipped cream, } \\
\text { virgen olive oil, peanut butter } \\
\text { braised meat, mushrooms, Umami }\end{array}$ & $\begin{array}{l}\text { Sweet, concentrated } \\
\text { wines, fortified wines } \\
\text { Rich, full-bodied not } \\
\text { sweet wines }\end{array}$ \\
\hline 8. PUNGENT & $\begin{array}{l}\text { Peppermint, onion (raw), mustard, } \\
\text { horseradish, red pepper, ginger, } \\
\text { spicy dishes }\end{array}$ & Champagne \\
\hline
\end{tabular}

Table 1-2: Examples of products in flavor styles 


\subsection{Hypothesis}

The proposed Flavor Styles Cube is rooted in practice and it is challenging t1 a solid scientific base. The mission of this thesis is to formulate the theory anc scientific support for it. Literature search and specific research experiments conducted using questionnaires, interviews, advanced statistical techniques chemical analysis. No recent propositions to classify flavor were found. Howev. many aspects of taste, information is abundant. The findings from different sc were put together, combined, and placed in the perspective of the hypothesis Internet is a rich source of scientific information, although the quality is not a guaranteed. The use and functioning of search-engines proved particularly inspira as they have no impediments in regarding certain fields in searching for the words. Hence, they sometimes come up with unexpected results and points of that would otherwise possibly been missed and were helpful in understanding and flavor from a synergetic point of view: there is more to taste and flavor tha sum of all the parts.

The world of flavor is systemized if mouthfeel and flavor richness are us parameters. These factors are proposed as the primary flavor factors whicl objectively be understood and assessed. This leads to the formulation of the follc hypothesis.

\section{Hypothesis}

\section{FLAVOR CAN BE CLASSIFIED BY USING MOUTHFEEL AND FLAVOR RICHNESS AS PARAMETERS}

For this hypothesis to be accepted it is paramount that both parameter indeed registered in tasting, which means the human registration must be equipp register mouthfeel and flavor richness. The sensorial aspects of tasting are revien chapter 2. Three separate systems of registration are distinguished: the gust: olfactory and trigeminal system; individual circumstances may lead to diff perceptions and there are sensory interactions. Next, consumers should be at characterize well-known food products in this way. By the use of factor analysi above structure should be found, as well as the three-dimensional structure. This subject of chapter 3 . where the classification of flavor and the Flavor Styles Cut 
introduced. Chapter 4 presents a study on palatability. This study shows that professional chefs can use the concepts of mouthfeel and flavor richness, which makes comparison of different dishes possible. The proposed classification of flavor initiates this comparison which led to the formulation of Culinary Success Factors that determine palatability. Chapter 5 elaborates on a specific factor related to flavor richness: umami. Deductively, the conclusion was drawn from the Flavor Style Cube that wines must have umami. To assess this, a specific study on the role of amino acids in the flavor of wine was conducted, the results of which are presented in chapter 6. General discussions on the described studies, as well as the final conclusions are formulated in chapter 7 .

\section{References}

Ackerman, D. (1990). A natural history of the senses. New York, Random House Inc. Bartoshuk, L.M. (1978). History of taste research. In Carterette, E.C. \& Friedman. M.P. Handbook of perception, volume VIA, Tasting and Smelling (pp. 3-18). New York, Academic press

Beauchamp, G.K. (1996). Basic flavor research and the food industry. Trends in Food Science \& Technology, 7, 457-458

Bech, A.C., Hansen, M., \& Wienberg, L. (1997). Application of House of Quality in translation of consumer needs into sensory attributes measurable by descriptive sensory analysis. Food Quality and Preference, 8, 329-348

Berridge, K.C. (1996). Food reward: brain substrates of wanting and liking. Neuroscience and Biobehavioral Reviews, 20, 1-25

Brillat-Savarin, J.A., Physiologie du Goût. Sautelet, Paris (1826). American edition: M.F.K. Fisher's transiation of Brillat Savarin's. The Physiology of Taste (1949), Knopf, New York

Birch, L.L. (1999). Development of food preferences. Ann. Rev. Nutrition, 19, 41-62

Bowker, G.C. \& Star, L.S. (1999) Sorting things out: Classification and its consequences MIT press, Boston

Breslin, P.A.S. (1996). Interactions between salty, sour and bitter compounds. Trends in Food Science \& Technology, 7, 390-399

Clydesdale, F.M. (1993). Color as a factor in food choice. Critical reviews in Food Science and Nutrition, 33, 83-101

DeCastro, J.M. (2000). Eating Behavior: lessons from the real world of humans. Nutrition. 16, 800-813

Drewnowski, A. (1997). Taste preferences and food intake. Ann. Rev. Nutrition. 17. 237-253 
Drewnowski, A. (2001). The science and complexity of bitter taste. Nut Reviews. 59, 163-169

Duizer, L. (2001). A review of acoustic research for studying the ser perception of crisp, crunchy and crackly textures. Trends in Food Science \& Techno 12. 17-24

Erickson, R.P. (2000). The evolution of neural coding ideas in the chemical se Physiology \& Behavior, 69, 3-13

Finkelstein, J.A., \& Schiffman, S.S. (1999). Workshop on Taste and Smell ir Elderly: an Overview. Physiology \& Behavior, 66, 173-176

Göpel, W., Ziegler, Ch., Breer, H., Schild, D., Apfelbach, R., Joerges, J. \& Malak (1998). Bioelectronic Noses: a status report, Part I. Biosensors \& Bioelectronics 479-493

Guinard, J.-X., et. al. (1996). Acceptability of fat-modified foods in a populatic older adults: contrast between sensory preference and purchase intent. Food $O \iota$ and Preference, $7,21-28$

Guinard, J-X., Mazzucchelli, R. (1996). The sensory perception of texture mourhfeel. Trends in Food Science \& Technology. 213-219

Guinard, J.-X., Uotani, B, Schlich, P. (2001). Internal and external mappin preferences for commercial lager beers: comparison of hedonic ratings by consur blind versus with knowledge of brand and price. Food Quality and Preference 243-255

Kotier, P. (1976) Marketing Management, Analysis, Planning and Control. Pre Hall, 3rd edition

Lange, C., Rousseau, F., Issanchou, S. (1999). Expectation, linking and purc behaviour under economical constraint. Food Quality and Preference, 10, 31-39

Lange, C., Issanchou, S., Combris, P. (2000). Expected versus experienced qu. trade-off with price. Food Quality and Preference, 11, 289-297

Lawlor, J.B., Delahunty, C.M., Wilkinson, M.G., Sheehan, J. (2002) Relation! between the gross, non-volatlle and volatile compositions and the sensory attrit of eight hard type cheeses. International Dairy Journal, 12, 493-509

Levine, A.S., \& Billington, C.J. (1997). Why do we eat? A neural systems apprc Ann. Rev. Nutr., 17, 597-619

Lévy, C.M., \& Köster, E.P. (1999). The relevance of initial hedonic judgements it prediction of subtle food choices. Food Quality and Preference, 10, 185-200

Li Rong. Wang Ping. Hu Wenlei, (2000). A novel method for wine analysis b on sensor fusion technique. Sensors and Actuators B 66, 246-250

Lindemann, B. (1999). Six common errors: Criticism of the human tongue mar seen in some textbooks. www.med-rz.uni-sb.de/med-fak/physiol2/LDM/chemotopic_1 
Martens, M. (1999) A philosophy for sensory science. Food Quality and Preference, 10, 233-244

McGee, H. On Food and Cooking. The science and lore of the kitchen (1984). Dutch translation: Over eten en koken. (1992) Bert Bakker, Amsterdam

Morrot, G., Brochet, F., Dubourdieu, D. (2001). The color of odors. Brain and Language, 79, 309-320

Poothullil, J.M. (1995). Regulation of nutrient intake in humans: a theory based on taste and smell. Neuroscience and Biobehavioral Reviews, 19, 407-412

Prescott, J. (1999). The generalizability of capsaicin sensitization and desensitization. Physiology \& Behavior, 66, 741-749

Richardson-Harman, N.J., Stevens, R., Walker, S., Gamble, J., Miller, M., Wong, M., McPherson, A. (2000). Mapping consumer perceptions of creaminess and liking for liquid dairy products. Food Quality and Preference, 11, 239-246

Safari, E., Fogarty, N.M., Ferrier, G.R., Hopkins, L.D., Gilmour, A. (2001). Diverse lamb genotypes 3. Eating quality and the relationship between its objective measurement and sensory assessment. Meat Science, 57, 153-159

Schiffman, S.S. (2000). Taste quality and neural coding: Implications from psychophysics and neurophysiology. Physiology \& Behavior, 69, 147-159

Scott, T.R., Giza, B.K. (2000). Issues of neural coding: Where they stand today. Physiology \& Behavior 69, 65-76

Smith, D.V. \& Margolskee, R.F. (2001). Making Sense of Taste. Scientific American, Vol. 288, 26-33

Spector, A.C. (2000) Linking gustatory neurobiology to behavior in vertebrates Neuroscience and behavioral reviews, 24, 391-416

Vroon, P., van Amerongen, A., de Vries, H. (1994). Verborgen verleider, Psychologie van de reuk. Baarn, the Netherlands, Ambo. (in Dutch)

Wilkinson, C., Dijksterhuis, G.B., Minekus, M. (2001). From food structure to texture. Trends in Food Science and Technology, 1-9

Winquist, F., Wide, P., Eklov, T., Hjort, C., Lundstrom, 1. (1999). Crispbread quality evaluation based on fusion of information from the sensor analogies to the human olfactory, auditory and tactile senses. J. of Food Process Engineering, 22, 337-358 


\section{Chopter 2 \\ The Act of Tasting: The physiola of flavor registration. A review.}

\subsection{Introduction}

This chapter covers a review of the literature on the physiology of tasting an neural processes that are involved. Its basic function is to evaluate the hi capability to register mouthfeel and flavor richness, not to discuss in full detail aspect involved.

\subsubsection{Tasting: an intricate process}

Nutrients do not have taste, they have flavor. Humans have taste, it is the s that they use to register flavor. According to Prescott (1999) the use of the 'taste' is generally regarded by sensory scientists as simply imprecise use of lang based on ignorance of the underlying sensory mechanisms. The ISO definition of $f$ states that it is the complex combination of the olfactory, gustatory and triget sensations perceived during tasting. Flavor may be influenced by tactile, the painful and/or kinaesthesic effects (ISO 5492:1992 Glossary of Terms Relatir Sensory Analysis). In dictionaries (i.e. Webster's new world dictionary) as well many scientific articles, flavor is often considered to be only the combination of and smell. The 'trigeminal' components of flavor are in that case left ou consideration. Nevertheless, these are very important.

The ISO definition implies that at least three neural systems are involved in ta and that there are many specific effects that influence flavor registration. This $m$ flavor registration very different compared to other senses. Basically, the ser systems gustation, vision, olfaction, and audition share many common feature vision and olfaction a general type of stimulus (photons or small volatile molecult in its own sensory system transduced by one basic mechanism. The taste syste neurologically, structurally, and chemically divers and this necessitates mul transduction mechanisms, within the same system (Gilbertson, Damak \& Margol: 2000).

The fact that flavor registration relies on a multiple registration of diffe systems essentially implicates that 'flavor' cannot be understood with a sole $f$ on one of the specific systems. Human beings do not and in most cases even car differentiate all the distinct flavor elements in the different systems that add $u$ 'the flavor'. Tasting must be considered as an integrative experience, a sublim: 
of the human senses. This complexity explains, at least partly, why the sense of taste is still not fully understood. To be successful in comprehending flavor registration, a broad view is demanded (Birch, 1999), which aptly conveys our ambition in this chapter.

In tasting, foods and drinks trigger sensory nerve cells that send electrical signals to the brain. This is called 'transduction' which is defined as the process by which events of the physical environment become represented as electrical activity in a sensory nerve cell. lonic concentrations between the inside and outside of body cells are different giving them an electrical potential, which forms the basis of the process of transduction (Bell, 1996; Beidler, 1978). Traditionally, this aspect of taste has received intensive scientific attention; many reports are available, most of which are based on detailed studies often involving all sorts of animal species. It is therefore tempting to elaborate on all of the aspects involved, yet it is clear that it is inconceivable to fully describe the complete transduction of flavor in one chapter. The focus will therefore be on the aspects of flavor registration that help to understand the concept of flavor styles, as the basis of a classification of flavor.

\subsubsection{Tasting: the oral process}

When food is introduced into the mouth the tongue positions and presses it against the palate. This gives textural information. The food is moistened by saliva and a process of chewing and swallowing begins. This is the process of mastication. during which the food is fractured and deformed by a complex combination of compressing, shearing and tensing. The tongue, cheeks and lips play a major role by directing the food and making it ready to swallow. This process coincides with the release of flavor and the assessment of all kinds of textural properties of the food. People have different chewing behaviors and it is not unlikely that these differences lead to different perceptions of what is tasted. Lack of visualization of what goes on poses a major problem (Lucas et al., 2002). Guinard \& Mazzuccheli (1996) reported that individuals with shorter chewing times tended to concentrate more on the initial properties of the food. Also they tended to perceive soft foods texturally as firmer and harder foods as less firm than individuals with prolonged chewing periods.

Saliva plays an important role in this process. Secretion takes place in response to chewing and to certain flavor properties, like its $\mathrm{pH}$. Saliva mixes with the food and acts as a lubricant. It also facilitates flavor perception. Furthermore, saliva contains alpha-amylase (to digest starch), lingual lipase (to digest lipids), and lysozyme (an anti-bacterial enzyme), while the buffer capacity of saliva prevents attack by acid produced by resident micro-organisms. Between humans there is a large variation in flow rate and composition of saliva (Wilkinson, Dijksterhuis \& Minekus, 2001). 


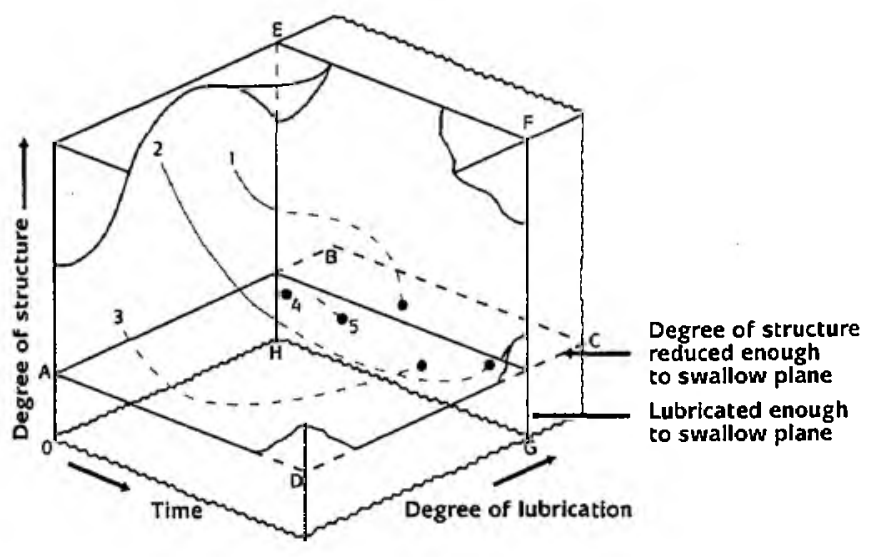

Figure 2-7: The' mouth process model', developed by Hutchings and Lillford (1998).

1. tender, juicy steak; 2. tough dry meat; 3. dry sponge cake; 4. oyster; 5. liquids. Before a food may be swallowed, its 'degree of structure' must have been reduced to the level of plane $A B C D$, and its 'degree of lubrication' must have crossed plane EFGH.
However important the of saliva in tasting is, a ger lack of knowledge of the of saliva on perceptior reported (conference re) 'Food texture: perception measurement', 2002).

To illustrate and desc the breakdown path of $f$ in the mouth Hutchings Lillford (1998) develope three- dimensional mo based on the dimens 'degree of structure', 'de; of Iubrication', and ' $t$ i (figure 2-1). It is clear that oral process is highly dyna with changing food struct and changing perceptior time (Guinard, 1996). In

process multiple systems work closely together in gathering information whic transmitted to our brain where the final result is registered: flavor.

\subsubsection{Flavor registration through three different systems}

In the process of eating or drinking a wide variety of chemical stimuli released, that can stimulate sensory receptors, some of these chemicals molecules) are volatile, others are not. The volatile ones can be odorants or irrit and are transported from the mouth to the nasal cavity. The non-volatiles car tastants, irritants or textural components, some of these are hydrophilic and easily with saliva, others are hydrophobic and do not and may leave a coating I behind. These chemicals and molecules are registered by flavor receptive and irrit sensitive areas in the oral cavity. Tastants and a part of the trigeminal compon are principally registered orally, odorants nasally, while irritants can be registere both passages.

As such, flavor perception involves integration of the separate sensation: olfaction, gustation and trigeminal components, and is influenced by their interac (Laing \& Jinks, 1996; Noble, 1996). Flavor is the outcome of a true synthesis of $t$ neural systems. During registration the boundaries between the systems bec 
blurred, making it practically impossible for a human being to identify which system was responsible for what part of the registration. This is especially true for gustatory and olfactory registration. Nose and mouth function closely together, and do so with amazing speed and seemingly little cognitive effort. The olfactory component of a flavor becomes a part of a new percept; its separate identity is lost (Prescott, 1999) (figure 2-2).

This integrative approach implies that in the flavor of a product specific substances may have a bad/unpleasant flavor of their own. These can even be a valuable part of the product's flavor. In fact, research shows that humans have a tendency to prefer sweet and salty tastes and to dislike sour and especially bitter. Yet many of the truly internationally liked products, like beer, wine, coffee, and chocolate contain considerable amounts of bitter, and analytically the acidity in Coca Cola is extremely high. This shows that unpleasant components may well be an essential component of a popular flavor, just as unpleasant odors may be an essential part of a successful perfume, as they often are. The tendency to 'breed out' bitter from some vegetables to supposedly make them more likable, may eventually prove to be unwise.

Information from ail sources is to be synthesized into a unitary experience with a single hedonic response, appetitive or aversive; liking or disliking. People taste food and decide immediately whether it is something to like or to reject. Not ail tastants and odorants that are chemically present are also registered; their concentration needs to be above the detection threshold. Flavor components that are registered are called suprathreshold. Components that are chemically present, but not detected are called subthreshold. Distortion of the capacity to register flavor is called dysgeusia.

The gustatory, olfactory and trigeminal components can be regarded as the intrinsic components of flavor. In tasting. sensory inputs are not limited to these components. Foods are also appreciated for their appearance, visual texture and color, name, image and recommendations. In other words there are visual and auditory influences as well. These influences are not a physical part of the product, but are strongly related to it and can be regarded as the extrinsic components of flavor (Lange, Rousseau, Issanchou, 1999). However important they are, in this 
chapter attention in principally focused on the intrinsic factors. The following di neural systems are reviewed:

- the gustatory system (chemical registration/'basic tastes')

- the olfactory system (smell)

- the trigeminal system (temperature, texture and irritants)

The next sections will first address each system at the receptor level $(2.2,2$. 2.4). In 2.5 atrention is focused on the neural aspects of flavor registration. questions related to sensory interaction are addressed.

\subsection{The gustatory system}

\subsubsection{The tongue map: a general misconception}

People are acquainted with the basic flavors, sweet, sour, salty, and bitt. that the registration of these elements takes place on the tongue. It is assumed that there are specific areas on the tongue that register one of thest flavors. Many text books feature the so-called tongue-map and the 'whe we-taste-what-indication'. However, this so-called tongue map is based on interpretation of the work of the German Hänig in 1901 (Smith \& Margolskee, Lindemann, 1999). He reported about a study on the sensitive areas on the 1 in regard to the basic tastes, but never suggested that there would be exclusivi on the tongue that register specific tastes or specific taste buds or papillae । registration of these elements.

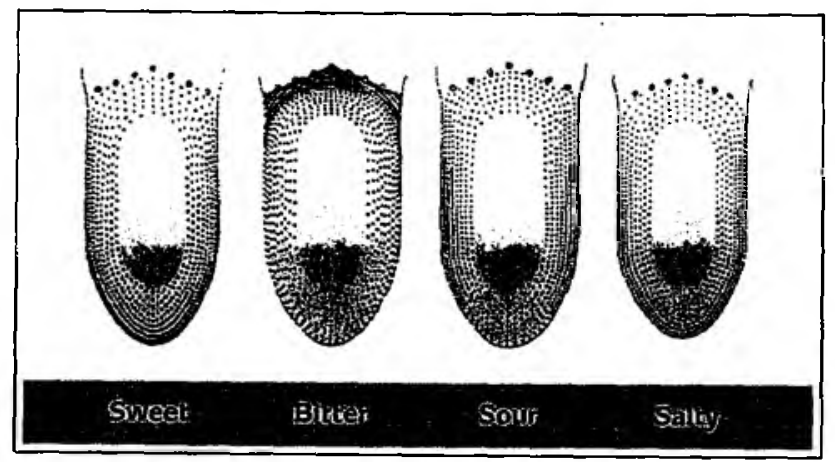

Figure 2-3: the original tongue map by D.P. Hänig (1901) (Lindemann, 1999)
Since Hänig publish concept of the tast running around the rim rongue and along the papillae, it is known tr belt responds to all ( 4 il cases) taste qualities (Lindemann, 1999) (figu This implies that all qua gustation can be elicite all the regions of the that contain taste buds and Margolskee (2001) 
that at present there is no evidence of any kind of spatial segregation of sensitivities that contributes to the neural representation of taste quality. Yet there are some slight differences in sensitivity across the tongue and palate, especially in rodents.

\subsubsection{Papillae, taste buds and taste cells}

Gustation and smell are considered to be the chemical senses, and the basic function of the gustatory and the olfactory system is therefore the registration of chemical components. In gustation registration is done by taste receptor cells (TRC). which lie within specialized structures called taste buds that are predominantly situated on the tongue and soft palate. Most taste buds on the tongue are located within papillae, the visible small lumps that give the tongue its specific appearance. There are four different kinds of papillae:

- fungiform (mushroom like) papillae

- circumvallate (wall like) papillae

- foliate (leaf like) papillae

- filiform (thread like) papillae

Of these, the first three have taste buds. Filiform papillae coat the dorsal surface of the tongue and do not contain taste buds. Instead, they are responsible for keeping the food in place on the tongue and are involved in tactile registration (Guinard \& Mazzuccheli (1996). The sensitive fungiform (mushroom like) papillae are situated on the front part of the tongue. Generally humans have about 200 of these papillae. They can be made visible after taking a drink of milk or placing a drop of food coloring on the tip of the tongue. Fungiform papillae contain about 3 taste buds. The circumvallate papillae are larger and situated at the back of the tongue in the shape of an inverted $\mathrm{V}$. There are roughly only 12 of these bud-containing papillae. Nevertheless they each contain about 250 taste buds, representing about $50 \%$ of all taste buds on the tongue. Taste buds are also located in the foliate papillae, small trenches on the sides of the rear of the tongue. These papillae harbor about 600 taste buds on each side. In total humans have about 6000 taste buds, each with between 50 - 100 taste cells, totaling $300.000-600.000$ cells. Besides in lingual papillae, taste buds are also found in the soft palate, uvula, epiglottis, pharynx, larynx and esophagus (Miller 1986; Miller \& Reedy 1990; Gilbertson, Damak \& Margolskee, 2000; Scott, 2001) (figure 2-4).

Taste buds are onion-shaped structures housing between 50 and 100 taste cells, each of which has fingerlike projections called microvilli that poke through an opening at the top of the taste bud called the taste pore. Chemicals from food, tastants, dissolve in saliva and contact the taste cells through this taste pore. Taste bud cells are 
continuously renewed; new sensory cells develop from basal cells. The turnover of these cells is high ( $\sim$ every 10 days) since they are constantly getting damag the process of tasting (Spector 2000: Beidler, 1978) (figure 2-5).

The gustatory system essentially registers chemical qualities. There are at three nerves involved in flavor transduction: the glossopharyngeal nerve, the ch tympani branch of the facial nerve and the lingual branch of the trigeminal nerve last one is associated to the sense of touch and will be discussed in section 2.4 chorda tympani nerve innervates the taste buds, especially the fungiform, and is $r$ sensitive to chemical stimuli, but responds also to trigeminal elements like coolin. warming of the tongue. Essentially this means that this nerve is also involv trigeminal registration; nevertheless the chemical transduction has received more scientific attention than its thermal role (Lehman. Bartochuk, Catalan Kveton \& Lowlicht, 1995). The glossopharyngeal nerve principally innervate: circumvallate papillae on the back side of the tongue. All gustatory nerves synaf the Nucleus of the solitary tract, where information is assembled and transm further into the brain (see section 2.5).


Figure 2-4: circumvallate papillae represent $50 \%$ of the flavor system despite their small number (In general humans have about 6000 taste buds on the tongue with in total between $300.000-600.000$ taste cells. The: numbers are different from person to person) 


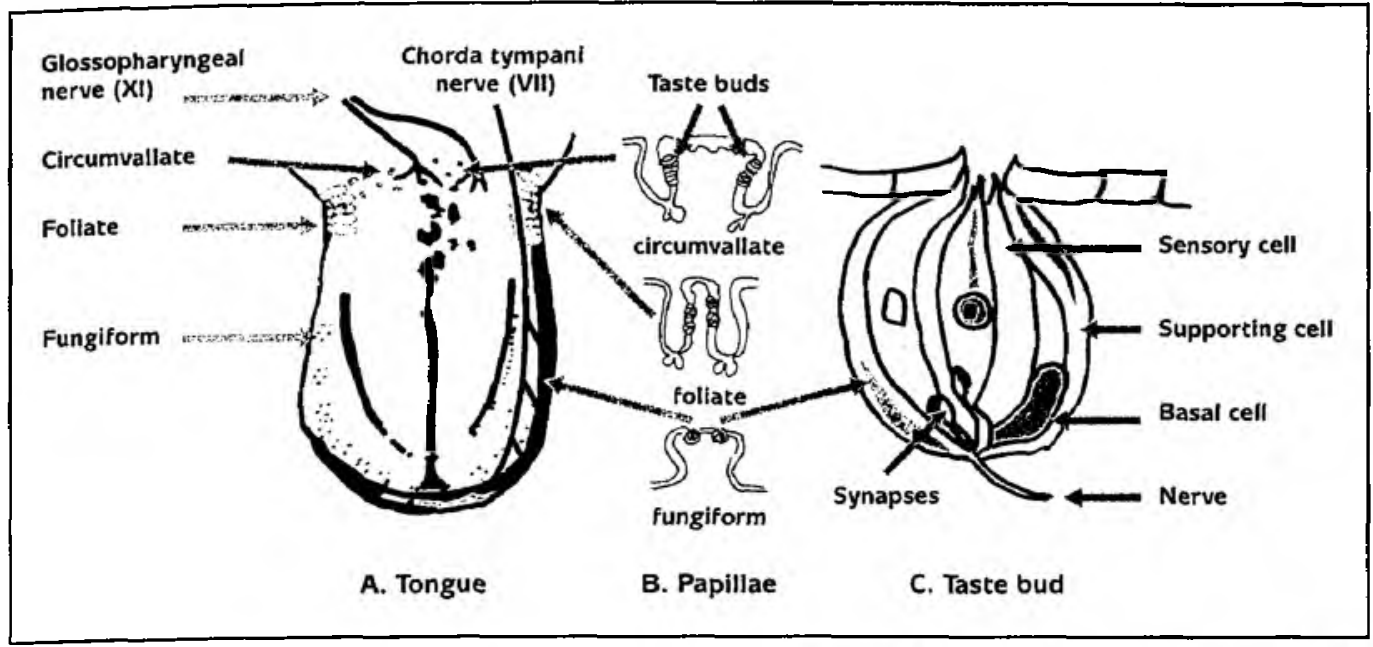

Figure 2-5: Gustatory 'instruments' (Jacob,2000)

\subsubsection{Non-tasters, tasters and super-tasters}

The number of papillae and subsequent taste buds differs between humans. In one study (Miller, 1986) the average taste bud (tb) density on the tongue tip was reported as $116 \mathrm{tb} / \mathrm{cm}^{2}$ with a range from 3.6 to 514 among subjects. The number of gustatory papillae on the tip averaged 24.5 papillae $/ \mathrm{cm}^{2}$ with a range from 2.4 to 80. Taste bud density in the midregion averaged $25.2 \mathrm{tb} / \mathrm{cm}^{2}$ (range: $0-85.9$ ). Subjects with the highest taste bud densities on the tip also had the highest densities in the midregion and the highest number of taste buds per papilla. Taste bud density was 4.6 times higher on the tip than the midregion, which probably accounts for some of the regional difference in gustatory sensitivity. Other reports confirm large intersubject differences in the number of papillae and subsequent taste bud cells.

The fungiform-rich anterior region of the tongue attains adult size by $8-10$ years of age. The posterior region with the foliate and circumvallate papillae continues to grow until 15-16 years. Densities and taste buds of fungiform papillae are reported to be significantly higher in 8-9 old children compared to adults. Furthermore children's papillae are rounder and more homogeneous in shape (Temple, et al., 2002)

As can be expected, these differences lead to variation in human gustatory sensitivity. This issue has received much scientific attention. See for an overview Prutkin et al. 2000. To illustrate: Miller (1990) observed in a study that a group of people with a higher density of taste buds gave significantly higher average intensity 
ratings for sucrose (196\%), $\mathrm{NaCl}(135 \%)$ and PROP (6-n-propylthiouracil) (1L but not for citric acid $(118 \%)$ and quinine $\mathrm{HCl}(110 \%)$ than the lower density $\mathrm{g}$ The number of fungiform papillae seems specifically related to the ability to bitter tasting chemical compounds PTC (phenylthiocarbamide) and PROP. : individuals do not taste its bitterness at all and are referred to as 'non-tas others do, but not as intensely as the group 'super-tasters' that have the fungiform papillae (Tepper, Christensen \& Cao, 2001; Delwiche, Buletic \& Br 2001). In the general population approximately $30 \%$ of individuals are 'non-ta and $70 \%$ are 'tasters' (Birch, 1999). Semantically, one may object to these term called 'non-tasters' do taste very well; however, they do not register the subst PROP or PTC and may experience other substances differently. Result sometimes contradictory but seem to agree on 'super-tasters' having a higher I sensitivity, which supports the observation that fungiform papillae are also in in trigeminal registration (Yackinous \& Guinard, 2001, 2002).

In their study Prutkin et al. (2000) reported that hormones in female: contribute to variation in flavor registration. There is evidence that the ability to (particularly bitter) cycles with the hormone concentration in women of childb، age, rises to a maximum early in pregnancy and declines after menopause. Prut al. elaborate on the consequences of these differences. Early studies suggeste females were more likely to be 'tasters'. This conclusion has been supported by studies since. Early studies also noted that the frequency of tasting varied witr this is supported by many subsequent studies as well. Given the magnitu sensory differences, it is not surprising that food preferences vary with $g$ variation in flavor registration. The studies fall into two groups: those dealin! the disliking of bitter/irritating foods and those dealing with liking/disliki sweet/fat foods. Alcoholism and smoking have been reported more freq among 'non-tasters' than 'tasters' in some studies. 'Super-tasters' tended to less liking for high sweet foods just as they did for bitter foods. Similarly, ' tasters' tended to show less liking for high fat foods. (See also 2.4.3). A Americans show a tendency to prefer higher levels of sweetness in compari: European-Americans (Schiffman, Graham, Sattely-Miller \& Petreson-Dancy, 201 these conclusions Drewnowski and Rock (1995) add that strategies air influencing food preferences and dietary habits in individuals or groups consider the role of these 'genetic taste markers'.

Zinc appears to be an important element in keeping receptor cells in functi maintaining tasting abilities. In several reports (Chou, Chien, Huang \& Lu, Tabuchi \& Ohara, 1997) zinc deficiency is reported to lead to flavor regis disturbances, caused by a decrease of taste buds per papilla. As zinc is known I 
to albumin, nutrition with an optimal level of protein has a key role in maintaining normal zinc status in the body and a keen sense of flavor registration. According to Prasad (2001) zinc deficiency may be more widespread than thought. In the Detroit area one third of well-to-do elderly subjects may have mild zinc deficiency. Poor appetite and decreased caloric and animal-protein intakes are mentioned as possible factors responsible for this deficiency. The loss of capacity to register flavor may explain the reduced appetite.

\subsubsection{Basic flavors?}

In flavor registration it has become common to refer to salty, sweet, sour and bitter as basic or primary flavors. This suggests that these flavors underlie all others and as such form the basic structure of flavor. This idea should be questioned seriously.

Yet, flavor physiology has been dominated over the years by issues of how human taste qualities, i.e. salty, sour, sweet, and bitter, are coded and how the elements react on each other (Smith \& St. John, 1999). Schiffman (2000b) has recently reviewed the usefulness of this concept. First, the coding theory of 'labeled-lines' was proposed to support a relationship between a set of gustatory neurons and a so-called basic taste; i.e. one group of neurons signals 'salty', another separate group signals 'sweet', another separate group signals 'sour', and a final group signals 'bitter'. An overview of psychophysical and neurophysiological experiments, however, suggests that flavor quality is more complex and extensive than the limited range of four flavors; furthermore, four labeled lines do not achieve taste coding. Later the across fiber pattern' was proposed but a full explanation of taste coding was not achieved. That is, the quadripartite hypothesis of four basic flavors is not adequate to organize flavor data. Not only there are more flavor qualities than the so-called basic four, but the socalled 'basic' flavors are not even perceived as singular. More researchers challenge the concept of basic flavors and wonder how the notion of the four basic flavors that was introduced more than a century ago could survive ever since (Erickson, 2000; Delwiche, 1996).

Neurologically and chemically there is a poor relation between the basic flavors. They are not registered in the same way and substances that are chemically different may have a similar flavor. In research, only some specific chemical components are often used, like quinine, $\mathrm{NaCl}, \mathrm{HCl}$, and sucrose. Besides these, there are nevertheless many other substances that have a similar flavor but a completely different chemical structure. Interesting examples are to be found in sweet, where i.e. aspartame, saccharine, and chloroform are perceived as being sweet although they have chemically nothing in common with sucrose (Walters, 1996). Furthermore, temperature and $\mathrm{CO}_{2}$ have been reported to influence our perception of sweet (Cowart, 1998; Schiffman et al., 2000). 
Bitter tasting components have vastly different chemical origins as well. The la common chemical structures suggests that there may be several different rece and/or transduction processes (Cubero-Castillo \& Noble, 2001). In general swee bitter flavors react on the outside of gustatory receptor cells, while salty or sour $\mathrm{fl}$ enter these cells directly through ion-channels (Smith \& Margolskee, 2001). differences in transduction are further discussed in 2.5 .

As research methods get more and more sophisticated new 'basic flavors' en Japanese scientists have identified Umami. glutamic acid, as a new, fifth, 'basic' (Gilbertson, 2000; Bellisle, 1999; see also 2.6.2). Glutamic acid is one of the 20 ; acids that make up the proteins in meat, fish, and some vegetables. It is also abund aged cheese, and other fermented products. Synthetic glutamate is used extensiv the food industry where it is used as a flavor enhancer in the form of the ac monosodium glutamate (MSG) (Tepper \& Nurse, 1998). One should not be surpri this finding will cascade in the recognition of many other 'basic' flavors whic ultimately undermine this concept as a whole. For instance, it is suggested that tf an additional flavor for fatty acids, with their own neural system. Neurons respond oral texture of fat, sensed by the somatosensory (trigeminal) system (Bray, 2000; Critchley, Browning. Hernadi \& Lenard, 1999).

Boucher et. al (2003) report that there is growing evidence that gustator trigeminal pathways may interact. Gustatory fibers also respond to therma mechanical stimuli. The traditional basic flavors like salty, sweet and sour are not gustatory, they are felt as well. We would therefore hypothesize that the conc 'mouthfeel', comprising all trigeminal effects, should be considered as a basic flave will be discussed in further detail in section 2.4 .

In summary, tasting is much more than just receptors for the four (or five) trad basic flavors and the biochemical interactions they induce in gustatory cells gustatory system is just one of three systems in registering flavor. Attention I system alone, without taking the olfactory system and the trigeminal system into at can not explain the full picture. The concept of basic flavors is therefore inadequat should not be used to explain the sensory system that registers flavor. To $p$ misconceptions, another name like 'gustatory flavors' could be considered.

\subsection{The olfactory system}

\subsubsection{Orthonasal and retronasal smell}

The fact that smell is an extremely important part of flavor registration is accepted. This is very likely due to the fact that many have personally exper 
how a severe head cold can impair our ability to taste. In everyday tasting, smell and gustation are one unified perception that can hardly be distinguished from one another: they are intertwined and perceived as a unity. Olfaction can be differentiated in two aspects: the orthonasal and the retronasal smell. The first is the smell which is basically coming from the outside and registered through the nose; the other is registered from within the oral cavity. These two aspects can be seen as two functionally distinct senses. The orthonasal perception functions for identifying objects at a distance. It gives information about the potential palatability, both in positive (attractive smell) and negative (bad smell) situations. The retronasal perception (also referred to as 'inner nose') contributes to flavor and hence food identification in the mouth (Rozin, 1982). Both 'smells' are important for assessing the characteristics, richness and complexity of a certain flavor. As such, apart from respiration, the nose has not only an appetitive or warning function, but also a 'flavor' function.

\subsubsection{The olfactory process}

In contrast to the relatively limited number of tastants that historically have been considered in gustation, there are many volatile chemicals stimulating smell. Sensations as diverse as the smells of citrus, cut grass, mint, various flowers, woods, fruits, herbs, spices, burnt aromas, sulfuric aromas, ethereal, fatty and sweet (like vanilla) smells are all well known. Thus the qualitative range of olfaction seems quite wide compared to gustation. It is therefore widely agreed that smells provide the majority of diversity in our flavor experiences (Prescott, 1999).

Odorants are small molecules with a molecular mass of less than $1 \mathrm{kDa}$. It is light enough to be breathed into the nose but heavy and complex enough to be recognized (Bell, 1996). As was shown in figure 2-2, odorants may stimulate both the olfactory nerve and the trigeminal nerve. Trigeminal sensations such as burning, stinging, sharpness, and coolness can be produced by chemical activation of trigeminal fibers within the olfactory system. Free nerve endings of cranial nerve $V$ are largely located in mucosal tissue within the nose and sinuses, oral cavity, and eyelids. As soon as these endings are stimulated, brain regions other than those involved in olfaction are activated (Brand, Millot \& Henquell, 2001). Hydrophobic odorants are transported to olfactory receptors by odorant-binding proteins (OBPs). Such odorants are commonly described as 'green' or 'floral' (Bell, 1996).

In general, women tend to have higher scores on tests of odor identification than men and retain their olfactory capabilities longer (Brand, 2001; Doty, 2001).

A certain 'smell' usually consists of a complex mixture of many odorants. These are recognized by olfactory receptor proteins, which trigger a change in a G-protein 
and cascade in a series of chemical activity, ultimately leading to a depolarizati the cell membrane and causing a spike discharge (nerve impulse). Such spikes 1 down into the olfactory bulb (Bell, 1996; Doty 2001). The intensity of the stir is related to the number of activated receptors and their location in the nose col the nature of the scent. That is, each scent is expressed by a spatial patte receptor activity, which in turn is transmitted to the bulb (Freeman, 1991) olfactory bulb can be compared to the nucleus of the solitary tract in the gust system (figure 2-6).

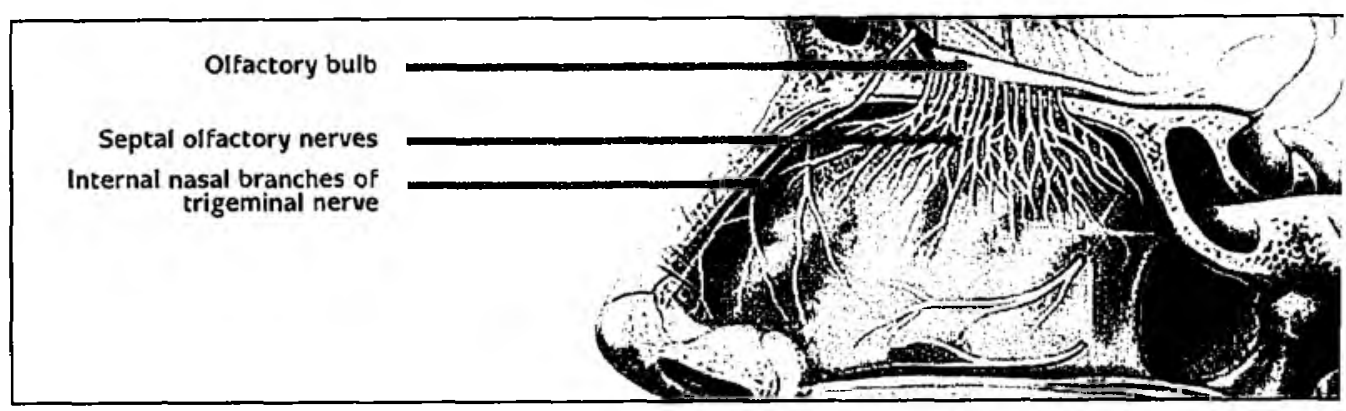

Figure 2-6: The olfactory receptors (Internet site Yale University)

Just as in the gustatory system, there are three major cell types involved in the process of odorant registration: olfactory receptor cells, supporting (or sustencular) cells, and basal cells (Gold, 1999; Brand, 2001). The function of the olfactory receptor cells is to transduce odorants into membrane depolarization. They are bipolar neurons: a single dendrite and a single axon. The dendrite extends to

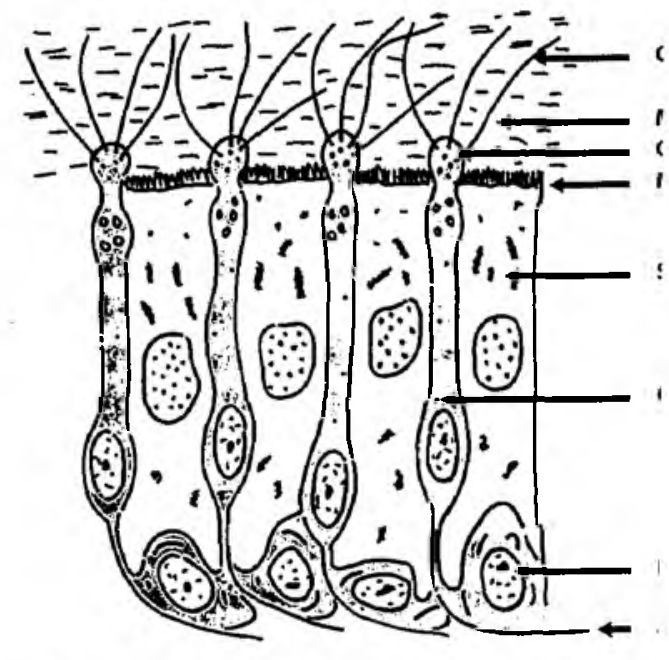

Figure 2-7: Different cell types of the olfactory syster 
the surface and has a number of cilia at the tip. These cilia are embedded in a mucus layer. Electrical current is generated here, at the site of odorant binding. Humans have - six million olfactory receptor cells (about ten times the number of gustatory celis), that, in aggregate, comprise cranial nerve l. Of the sensory systems, the number of cells is only exceeded by vision (Doty, 2001). The supporting cells have two functions. In the first place they insulate the receptor cells from one another and may help regulate the composition of the mucus. Secondly, the supportive cells contain a high concentration of cytochrome $\mathrm{P} 450$-like enzymes. These enzymes are thought to oxidize volatile odorants, making them less membrane permeable. The basal cells are involved in the regeneration of dead olfactory cells, just as in the gustatory system (Gold, 1999) (figure 2-7).

\subsubsection{Odor composition and preferences}

Ideally the flavor follows the smell. The smell gives a first impression and a certain expectation. Therefore, the flavor should match the expectation that is raised by the smell. Context and cognition often play an important role. A bad smelling oyster is not fit for consumption, while a strong smelling cheese may be considered to be just perfect. Responses to odors can vary enormously. One person may find a certain odor unpleasant or even irritating or noxious while another may not notice it or even find it pleasing. However, only few references can be found about this aspect of smell, most probably due to the fact that research on this subject is complex because of personal, cognitive and contextual interpretations (Monell Chemical Senses Center, 2001).

At the same time, some fragrances seem to be rather universally liked and are known to be appetizing, like the odors of vanilla, roasting and baking. The universal liking for these odors may even be innate, but little is known. Birch (1999) suggests that responses to the basic flavors may have an unlearned component that is tuned to detection of ingredients (sugars are sweet, $\mathrm{NaCl}$ is salty, and many poisons are bitter). Olfaction is organized to identify foods more holistically, rather than to identify nutrients, and to be readily influenced by learning and experience. But, as she states, "unfortunately we know even less about the development of the olfactory preferences than we know about flavor preferences."

A natural fragrance that a subject can quickly identify with a single sniff is usually composed of several hundred odorants. If fragrances are produced synthetically only the most important components (mostly ranging from 10 to 20) are used. The hundreds of other odorants that are present in the natural original add to the complexity of the real fragrance. Instruments of analytical chemistry such as gas chromatography are increasingly sophisticated and good at qualifying both the 
presence and the quantity of fragrance components. Yet they are poor when it comes to identifying the key or dominant odorants of a certain mixture. The human brain has the capacity to identify differences in a smell at a much more detailed level. In fact, millions of olfactory receptors are available to encode the components of a mixture. The brain transforms this information into a unified sensory experience, which is immediately associated to places and feelings and also compared to those previous experiences (Bell, 1996).

While humans are very good in detecting odors, they generally have problems identifying and naming them. A possible explanation may be that the registration of odorants principally involves the right hemisphere of the human brain, while linguistic processing is predominantly under control of the left hemisphere. As mentioned before, as soon as trigeminal elements are part of it, other - bilateral brain areas are stimulated as well. It can be expected that such odors can be named more easily (Brand, 2001; Vroon, van Amerongen \& de Vries, 1994).

\subsubsection{Olfaction, health and age}

As human beings get older, progressive decline in olfactory ability has been reported. Subjects over 60 years of age smell less than younger ones (Brand, 2001; Vroon, 1994; Kaneda, 2000). In normal ageing there is a moderate loss of neurons and nerve fibers in the olfactory receptor cells. - bulb, and - tract (Murphy, Nordin \& Jinich, 1999). Between age 65 and 80 about half of the olfactory function is lost. Over 80 years of age people usually have lost three quarters of their ability (Doty, 2001).

As olfaction is an important part of flavor registration, olfactory dysfunction is associated with decreased enjoyment of food. In the preparation of dishes for older people this aspect could be taken into account. However, the change in perceptional abilities coincides with changes in food preferences and beliefs about food (often in relation to health) as people get older. Therefore, the causal relation between the two developments is hard to establish (Rolls, 1999).

As soon medication becomes a part of the daily routine dramatic changes may occur. Over 250 drugs have been reported to affect flavor registration (Finkelstein \& Schiffman, 1999). There are many medical conditions or disorders associated with olfactory dysfunctions. Examples are alcoholism and drug abuse, head trauma, HIV, anorexia nervosa (severe stage), and schizophrenia (Doty, 2001). Patients with very early symptoms of Alzheimer's disease experience a severe decline of olfactory abilities. Murphy et al. (1999) suggest therefore that memory-based olfactory tests may contribute to early diagnosis of Alzheimer's disease. Doty (2001) puts this in a broader perspective: "olfactory loss is likely the first clinical sign of some neurodegenerative diseases". 


\subsection{The trigeminal system}

\subsubsection{No flavor without some kind of mouthfeel}

Next to gustation and olfaction, flavor registration in influenced by the trigeminal neural system. The trigeminal system is diverse and associated to the sense of touch. In flavor registration trigeminal effects gather in the concept of mouthfeel, however different the origin of the effect may be. There is no flavor without some kind of mouthfeel. Apparently, our ancestors knew this very well. Etymologically the word 'taste' stems from the medieval English word 'tasten', which originates from the old French 'taster', meaning 'to handle, touch, taste'. It is probably derived from the Latin 'tangere', which means to touch (Webster's dictionary; Ackerman, 1990). In contemporary Dutch the word 'tasten' still means to touch. Indeed, there is no flavor without touch: hard, soft, crispy, crunchy, effervescent, spicy, dry, viscous, fatty, puckering, warm, and cold are all sensations that are felt in the oral cavity. Nevertheless, this essential part of flavor has not received much attention. According to Guinard (1996), texture has been referred to as the 'forgotten attribute' because for many years it commanded little attention. As stated before, trigeminal components are an integral part of flavor registration, and are included in the definition of flavor.

There are many everyday examples that show both the importance and versatility of mouthfeel. Such as the fizzy tingle of $\mathrm{CO}_{2}$ in soda, beer or Champagne, the hot burn from the different kinds of peppers, the tingling sting of ginger and some spices, the tenderness of a steak, the coolness of menthol, the pungency of mustard or horseradish, the bite from raw onions and garlic, the right creaminess or thickness of a sauce, the crispy dryness of toast or the crust of fresh bread, the soft juiciness of a ripe pear, melon or peach and the refreshing crispness of a ripe apple. In addition, temperature also contributes to mouthfeel.

Note that the origin and chemical characteristics of these mouthfeel effects are very different. Nevertheless, in each of these examples human quality judgment is closely related to the expected mouthfeel.

\subsubsection{The neural trigeminal system}

The trigeminal nerve system is responsible for mediating the sensations that influence mouthfeel. Three major physiological classes of nerve fibers can be discriminated in the lingual branch of the trigeminal nerve:

- mechanoreceptors, for the sensations of touch

- thermoreceptors, for discriminating temperatures

- nociceptors, involved in the registration of pain and irritation 


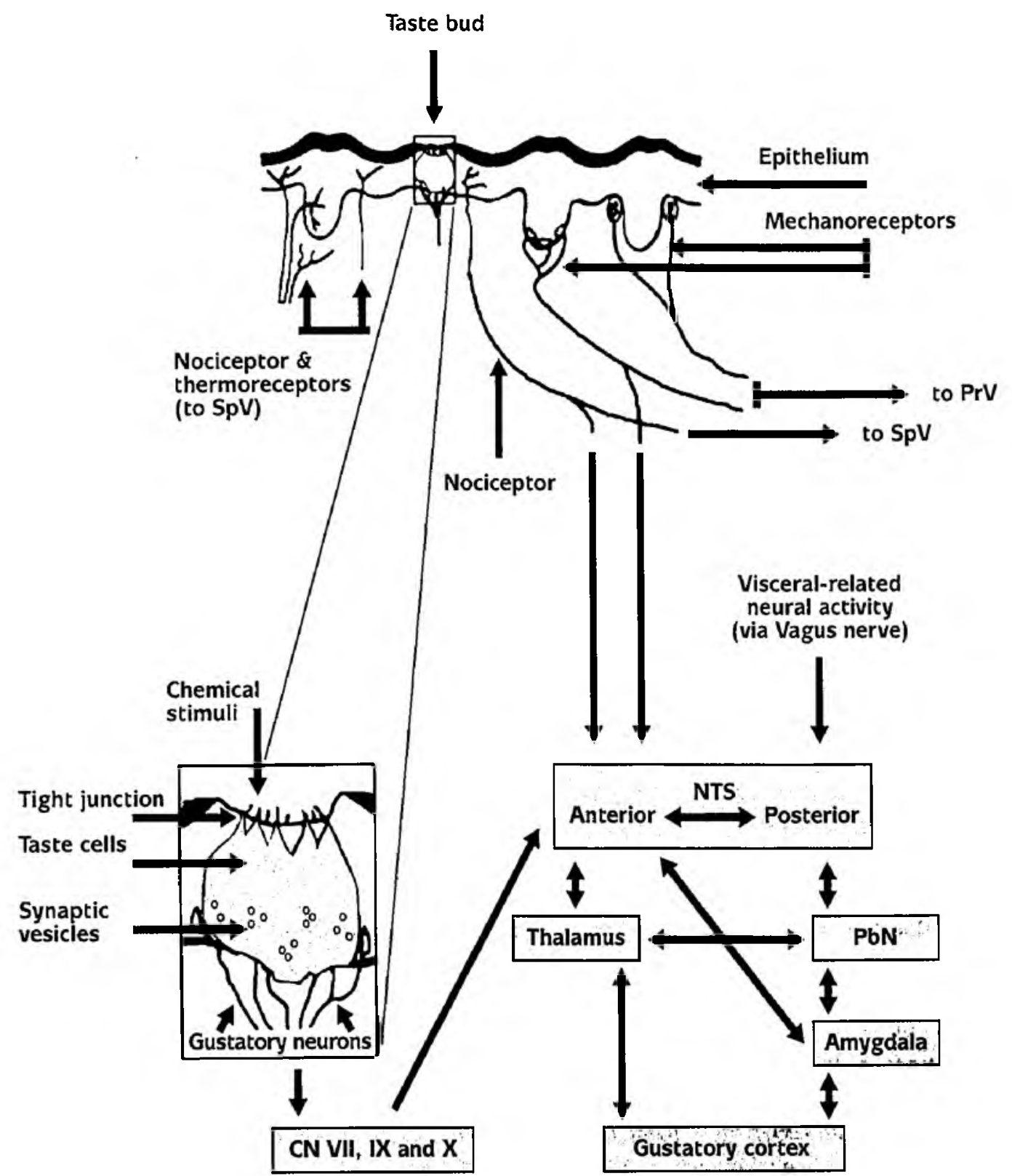

Figure 2-8: The trigeminal connections in the mouth: PrV: principal trigeminal nucleus; SpV: spinal trigeminal nucleus; PbN: pontine parabrachial nucleus; NTS: nucleus of the solitary tract: $C N$ VII, IX, X: cranial nerves. (Katz, Nicolelis, Simon, 2000) 
Just as in the case of the olfactory and gustatory systems, the trigeminal system is closely related and easily integrated into the other systems involved in flavor registration, which makes it hard for any individual to differentiate between systems. Pepper is generally considered to be a taste and menthol a smell, even though they are actually examples of oral and nasal chemical irritations, transmitted principally by nociceptors. Trigeminal neurons are reported to respond non-selectively to the variety of these chemicals. This makes it difficult to make qualitative distinctions among different irritant sensations (Carstens, Carstens, Dessirier. O'Mahony, Sudo \& Sudo, 2002). The term 'mouthfeel' is the general term for all the effects, elicited by the trigeminal system registered orally and/or nasally.

Anatomically, the importance of mouthfeel can also not be ignored. The large numbers of trigeminal fibers, relative to the other sense organs are impressive. Prutkin et al. (2000) report that $75 \%$ of the innervation of the fungiform papillae comes from the trigeminal neurons that surround them. Even the taste bud itself seems organized to provide trigeminal access to the oral milieu. Trigeminal fibers ascend around the taste bud itself, forming a cup-shaped structure. The trigeminal endings seem to use the specialized structure of the taste bud to find a channel to the external environment. This suggestion is consistent with the observation of high responsiveness to pepper chemicals in areas such as the tip of the tongue that are rich in fungiform papillae (Lawless, 1996). It also fits the observation mentioned earlier that especially 'super-tasters' perceive trigeminal elements (fat, bitter, sweet, irritating substances) differently (Yackinous \& Guinard, 2001, 2002) (figure 2-8).

There are several distinct compounds that are known to irritate but they may give different kinds of sensation (Lawless, 1996; Green, 1996):

- Hot compounds: peperine (black pepper), capsaicin (red pepper), histamine, nicotine

- Cool compounds: menthol, and neomenthol

- Stinaina comoounds: allyl isothiocyanate, and hydroxy benzyl isothiocyanate (mustard, radish, onion, garlic), zingerone (ginger), citric acid (i.e. lemon)

- Burnina compounds: ethanol. cinnamic aldehyde (cinnamon), curcumin (curry)

- Astringent/drvina compounds: hydrolyzable tannin, and condensed tannin (wines)

Differences were found in lag time (short vs. long), burning vs. tingling and longitudinal extent between capsaicin, piperine, cinnamic aldehyde, eugenol, ginger oleoresin, cuminaldehyde and ethanol (Cliff \& Heymann, 1992). 
The human response to oral and nasal irritants, like piperine, capsaicin, menthol, and $\mathrm{CO}_{2}$ has several properties that are different from gustation and olfaction. In the first place irritants take longer to develop and tend to linger longer. Secondly, some irritants are known to desensitize during prolonged exposure (Dessirier, 2001; Green, 1996). Thirdly, the responsiveness to irritation from capsaicin is significantly higher in the throat and the roof of the mouth than at either the front or back of the tongue.

\subsection{3 $\mathrm{CO}_{2}$, astringency, and trigeminal sensitivity}

From the sheer number and popularity of carbonated drinks it can be concluded that they apparently elicit a sensation that is highly sought after. Yet the underlying neural mechanisms are poorly defined. Dessirier et al. (2001) hypothesized that $\mathrm{CO}_{2}$ is converted via carbonic anhydrase into carbonic acid, which excites lingual nociceptors that project to the trigeminal nuclei. The oral sensation of carbonation is reduced by capsaicin and by blockers of carbonic anhydrase. The influence of capsaicin on $\mathrm{CO}_{2}$ is an example of what is called desensitization.

The flavor of wines, especially young red ones, can be characterized by proanthocyanidins (tannins). Their specific flavor characteristic is described as 'astringent'. Astringency is a trigeminal sensation which has a drying influence in the mouth (Vidal, et al., 2003). This effect is ascribed to the binding of salivary proteins and mucopolysaccharides (the slippery components of saliva), causing them to aggregate or precipitate, thus taking away the ability of saliva to coat and lubricate oral tissues. One feels this result as a rough and dry sensation on oral tissues, even when there is fluid in the mouth. The term astringent is derived from the Latin for 'binding' (Guinard, 1996; Gabel et al., 2001). Acidic polysaccharides in wine reduce the coarse, dry and puckery perception of astringency. Perception is also influenced by ethanol content (Vidal, et al., 2003). Note that 'roughness' and 'dryness' are difficult to perceive unless a person moves the tongue against other oral tissues (which we do ali the time when eating). An active perceiver is required for this astringent perception. Therefore, the study of astringency must practically be done with human subjects, and is less well-suited for scientific studies using animals or electrophysiological simulators (Lawless, 1996).

In 2.2.3 it was shown that the number of fungiform papillae varies from person to person and leads to different perceptions. As these papillae are also linked to the trigeminal system, it is not surprising that 'super-tasters' experience oral irritants and other mouthfeel related aspects more intensely than those with fewer fungiform papillae do (Prutkin et al., 2000; Bartoshuk, 2000). Interestingly, other mouthfeel related experiences as viscous substances like dairy fats, salad dressing, guar gum, 
Ja oil also produce the most intense sensations to 'super-tasters'. A study of Tepper and Nurse (1998) confirms this. 'Tasters' and 'super-tasters' could discriminate differences in fat content (10 or $40 \% \mathrm{fat}$ ) of salad dressings that the 'non-tasters' could not. Although medium and 'super-tasters' showed no preference for either dressing, the 'non-tasters' preferred the $40 \%$ fat sample. This implies that fat perception and preference can be linked to genetic and anatomical variation between individuals.

This is not as easy to explain as the result with irritants, because less is known about the innervation of fungiform papillae by the touch afferents in the trigeminal nerve. However, Prutkin included a study of two-point thresholds, and found that the average two-point threshold corresponded to approximately the average distance between fungiform papillae. That is, subjects felt both points when each was touching a different fungiform papilla. This suggests that the fungiform papillae may act as an array of sensors for detecting oral rouch sensations (Prutkin et al., 2000; Bartoshuk, 2000).

\subsubsection{Underestimated role of thermo- and mechanoreceptors?}

In our review of the trigeminal system much attention was focused on the role of nociceptors and thus of oral and nasal irritants. This is consistent with the data found. Apparently, aspects of pain are considered to be the more interesting part of trigeminal effects. However, painful irritation is just one of the elements of mouthfeel. The role of thermo- and mechanoreceptors must not be underestimated. The texture and the temperature of food play an important part in the appreciation of it and is only partly explained by irritants. The effects of temperature on flavor are well known. Many drinks and foods require a certain temperature to be fully appreciated. Texture is defined as the sensory and functional manifestation of the structural, mechanical and surface properties of foods (and drinks) detected through the senses of vision, hearing, touch and kinaesthetics (Szczesniak, 2002). An apple is expected to be hard and crisp, and a pear, melon or peach is best appreciated when they are soft and juicy. Sauces and soups need to have the 'right' thickness or creaminess, and the palatability of many vegetables and carbohydrate-rich foods (pasta, potatoes) is also strongly related to texture. Furthermore, it is widely accepted that fat jtself is an important sensory element. There is evidence that groups of neurons respond unimodally to the texture of fat, while others respond to gustatory and olfactory inputs (Rolls et ai., 1999). The mechanoreceptors of the trigeminal neural system supposedly are the ones to register this part of flavor. In view of their important role in palatability and flavor appreciation, they must be included to explain the concept of mouthfeel (Prescott, 1999). 


\subsection{Ascending the neural pathway}

\subsubsection{Neural information and flavor}

The receptor neurons in each sensory system may have different functions and operate differently, but they ail do the same job: converting a stimulus from the environment into an electrochemical nerve impulse, which is the common language of the brain. Basically, sensory systems like vision, audition, olfaction and gustation share many common features (Beidler, 1978). From the review on the three neural systems that are involved in the registration of flavor, one can draw the conclusion that there is sophisticated knowledge about the way how components of flavor are registered both orally and nasally, although not all aspects have been uncovered as of yet. Nevertheless the receptors are only the first level of registration. To quote Spector (2000): "with so much recent focus on the transduction in the gustatory system, it is easy to be seduced into thinking that the solutions to the neural basis of gustatory function are to be found at the level of the receptor cell. But this level represents only the first stage of signal processing, albeit an absolutely essential one".

Following the neural pathways that ultimately lead to the recognition, interpretation and evaluation of flavor is a very complex matter. As can be expected, each of the three systems has its own transduction specialists. From the literature in this field we gather that their knowledge has hardly been synthesized in a comprehensive theory on flavor transduction. Clearly. this complexity drives it well beyond the scope of this review. Also, neural functioning as such bears little relevance to our objective to classify flavor. However, to complete the picture of flavor registration we will shortly mention interesting aspects and focus on the question: "what happens with the peripheral information of the three systems involved in registering the intrinsic components of flavor when it enters the brain?"

In transduction a tastant interacts either with proteins on the surfaces of cells or directly with porelike proteins called 'ion channels'. These interactions cause electrical changes in the receptor cells that trigger them to chemical signals that ultimately result in brain impulses (Smith, 2001). Different chemicals use differen channels. In the gustatory system, chemicals that produce salty and sour flavors acl directly through ion channels, just as pain-like sensations registered chrougt nociceptors of the trigeminal system. Sweet and most bitter flavors, umami, man! odorants, and fat are registered on the outside of cells. They trigger changes withit the cell by binding to receptors on a gustatory cell's surface that are coupled i cytoplasmatic molecules called G-proteins. These generate intracellular compound called 'second messengers' (the taste stimulus is the first messenger). Secon 
nessengers alter electrical properties of the gustatory cell and modulate the release If neurotransmitters. The G-protein of the gustatory system was called 'gustducin' because of its simiiarity to transducin, the protein in retinal cells that transduces the signal of light into the electrical impulse that constitutes vision (Smith \& St. John, 1999).

Flavor registration pathways may thus be classified in two kinds: the ion-channel group (IC), and the G-protein-coupled receptors (GPCR). Within each group different kinds of gustatory receptor cells have been identified, with specific qualities. Research in this field is rapidly progressing. The gustducin-linked receptors have now been identified as a family of $\sim 25$ GPCRs. Some are more present in fungiform papillae, others in foliate or circumvallate papillae (Gilbertson et al., 2000).

Essentially this implies that some cells in one taste bud may respond to one stimulus, while other cells in the same taste bud may respond to other stimuli. $\mathrm{Na}^{+}$ ions of a $\mathrm{NaCl}$ stimulus are able to enter taste cells directly, resulting in the depolarization of the cell, without the interference of second messengers. When another stimulus activates gustducin, a sequence of intracellular reactions is triggered: activation of adenylyl cyclase, leading to the formation of cyclic adenosine monophosphate (CAMP), and the closing of $\mathrm{K}^{+}$channels that leads to depolarization of the cell. It is generally thought that next to this CAMP sequence, there is a second and separate chain of transduction events where the G-protein activates a different effector protein, inositol triphosphate $\left(\mathrm{IP}_{3}\right)$, causing a release from the cytoplasmic matrix of intracellular calcium that modulates ion channel gating. Both are examples of second messengers. It is suggested that for instance sucrose makes use of both these transduction mechanisms (Fujiyama, 1998; Gilbertson et al., 2000).

The oifactory systems works only with GPCRs. The role of CAMP has been established; there are doubts about the role of $\mathrm{IP}_{3}$ (Doty, 2001; Brand, 2001). In the trigeminal systems both $I C$ and GPCR receptors are reported. Especially chemical irritation is gated through ion channels (McCleskey \& Gold, 1999; Katz, et al., 2000).

\subsubsection{Further into the brain}

From the first reception areas in the brain, like the nucleus of the solitary tract (gustatory system), the olfactory bulb (olfactory system), and the thalamus VPL (trigeminal system). electrical currents are received by the primary cortexes of each system. The principal function of this stage in registration is a first identification of the tastant, odorant or mouthfeel. But as these primary cortexes are still a part of their own neural pathway. it is not flavor that is being identified. For a full identification of flavor the systems have to converge. The diagram developed by Rolls (figure 2-9) shows the individual pathways and the sites of convergence. There are 
actually two neural centers for flavor registration: one that is biologically driven (the lateral hypothalamus and amygdala) and another one that is involved in the pleasure and reward values of flavor (the orbitofrontal cortex) (Rolls, 1999; Rolls, 2000a; Rolls, 2000b; Rolls, 2001). We will elaborate on this subject, because this observation has far reaching consequences and helps to understand flavor registration as a whole.

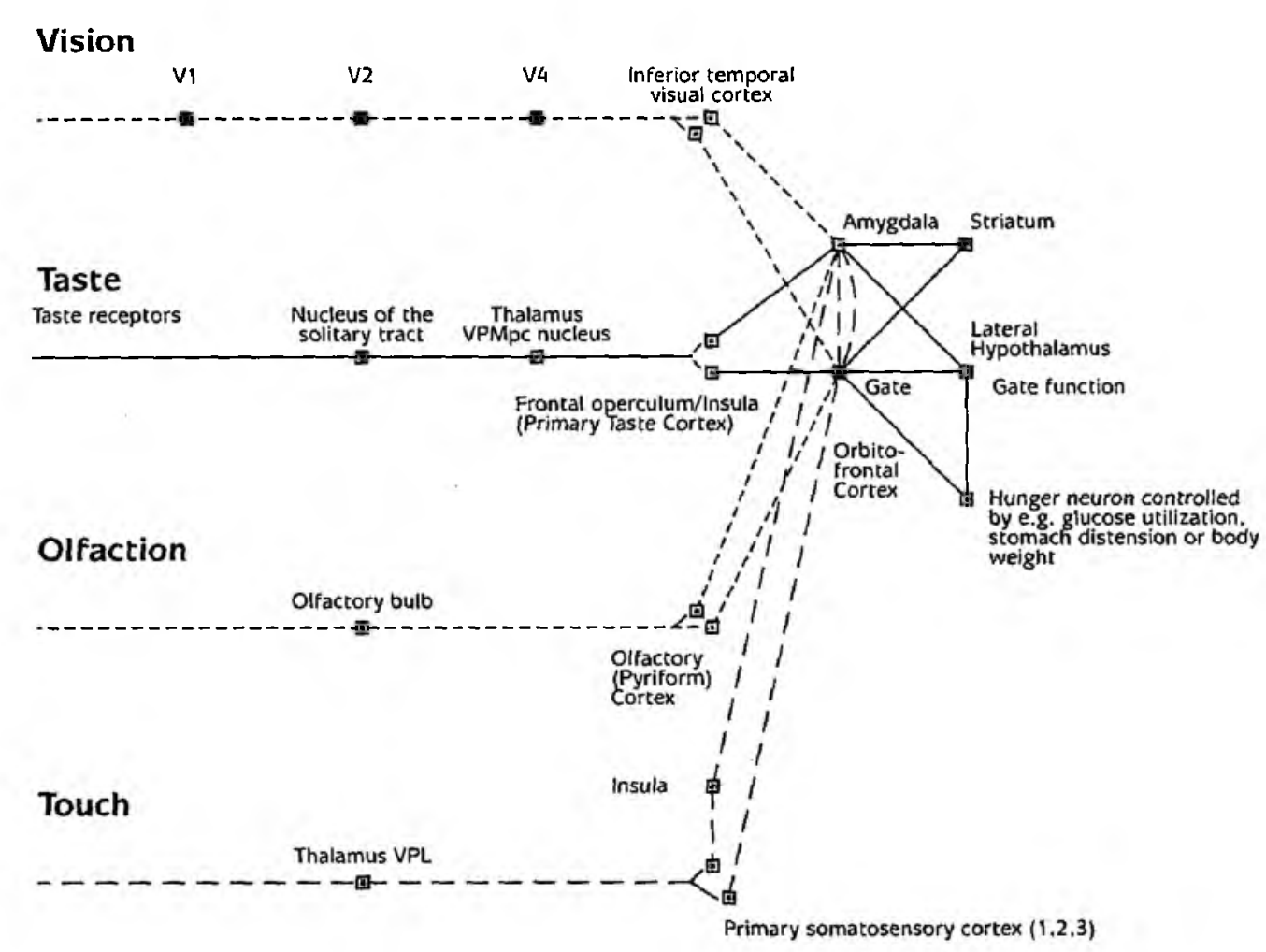

Figure 2-9: Schematic diagram showing some of the gustatory, offactory, trigeminal, and visual pathways to the amygdala and the orbitofrontal cortex. (Rolls, 1999, 20006)

\subsubsection{Biological need or hedonic value?}

It cannot be considered as a coincidence that in many languages we find saying like 'hunger makes the best spice'. The French equivalent would be 'à qui a faim, tol est pain' (if you are hungry, you enjoy everything like bread). Likewise in Spanish the say 'a buen hambre no hay pan duro' (if you are hungry there is no old bread). I 
Dutch it would be 'honger maakt rauwe bonen zoet' (hunger makes raw beans taste sweet). Apparently, hunger (and thirst) has a powerful influence on our perception of flavor. In a state of deprivation individuals do not worry about hedonic aspects such as palatability, because the functioning of the biological system is threatened. Palatability quickly becomes an issue in a situation of good health, and as abundance and prosperity increase.

The explanation for this phenomenon can be found in the difference of what Levine \& Billington (1997) describe as 'energy deficit-induced feeding' and 'hedonicinduced feeding'. Humans eat for a variety of reasons. In biology, energy needs are put centrally, but time of the day, social setting, stress, boredom, palatability, and food availability at little or no cost may also be initiators of food intake. If 'appetite' is defined as a desire for food, and 'satiety' as the fulfillment of this desire, one is seduced in thinking that both are part of a simple regulative system. In fact, appetite and satiety are very complex mechanisms in eating behavior, with many peptides, hormones and other elements involved (for a review read Bray, 2000,). Only some elements that are involved in the process will be mentioned.

In arousing appetite, the neurotransmitter neuropeptide $Y$ (NPY) plays an important role. Orexin-A, orexin-B, $\beta$-endorphin, and galanin are examples of other peptides that are reported to stimulate food intake. NPY is reported to be the most potent peptide stimulator of feeding that has been described to date. It is present in many parts of the brain and strongly induces the motivation to eat. It overrides all counterregulatory systems of satiety and body weight regulation. Such systems include peptides like leptine, corticotrophin-releasing hormone (CRH), cholecystokinin (CCK), enterostatin, and bombesin; most of them are produced in peripheral tissues and reported to decrease food intake. Of these leptine is often mentioned as an important peptide. When overeating leads to the growth of white fat cells (adipocytes), leptine is synthesized and secreted in the blood stream. In the brain it binds to the leptine receptor, which reduces the production of NPY, thus decreasing the biological motivation to eat (Shiraishi, Oomura, Sasaki \& Wayner, 2000; Bray, 2000; Wahlsten, 1999; Bray, 2000b).

The role of peptides such as NPY and leptine is very much related to energy needs and thus involved in energy-deficit induced feeding. The system suggests that as soon as the energy deficits are resolved, the eating should stop as a stage of satiety is reached. [deally the above system regulates food intake and energy balance. But in our modern society inexpensive and good tasting foods are readily available and many people eat too much. Other neuroregulators than NPY that stimulate food intake bring this about. They often belong to a family of endogenous opioid peptides that are related to the so-called 'reward-value' of palatable food, which implies that 
these peptides are involved in hedonic-induced feeding, registered in the orbitofrontal cortex. This system has its own satiety, which is different compared to the 'biological one', and more related to specific food that is eaten (or beverage that is drunk). Therefore it is called 'sensory specific satiety', and defined as 'the pleasantness of the sight and the flavor of a food eaten to satiety decreases while other foods not eaten to satiety remain relatively pleasant' (Rolls \& Rolls, 1997). The difference between the two satiety's is clear: satiety itself is based on internal signals while sensory specific satiety is - at least partly - based on external signals. It has been shown that sensory specific satiety is strongly dependent on sensory aspects of food, such as its flavor and mouthfeel. As both kinds of satiety take time to develop, it can be assumed that slow eating may tend to reduce meal size and thus food intake. On the other hand, quick eating and variety in a meal will enhance intake (Rolls \& Rolls, 1997, Westerterp-Plantenga et al., 1990).

Quite another influence on eating may be related to the sympathetic nervous system (SNS), which modulates changes i.e. in heartbeat and blood pressure. It is hypothesized that the SNS also plays an important role in food intake. A lon sympathetic activity, which is observed in fasting and in low temperatures, is associated with a low threshold for eating and, when food is available, more food is eaten (Bray, 2000b).

Stress in general has also been associated with food intake. Of particular interes is corticotropin releasing hormone $(\mathrm{CRH})$, which generally acts on a reduction of foo intake (Levine \& Billington, 1997). The role of nicotine is also of interest. It is ar alkaloid that acts on nicotinic receptors, which also decrease food intake. Othe reports state that both positive and negative moods have a positive influence on thr amount of food eaten, just as the presence of other people, the day of the week, anc if alcohol is consumed (Patel \& Schlundt, 2001). Although no direct references wer, found of neuroregulatory explanations, it is likely that they will be discovered.

\subsubsection{Liking and wanting}

From the above, the conclusion may be drawn that specific neurologici processes influence the human motivation to eat and the consequent food choict and that these processes can have a biological or a hedonic origin. Poothullil (1995 suggests the possibility that the human body may continuously be monitoring th need for certain nutrients. Peculiar cravings some women experience during the pregnancy may be explained on this basis. He reports many examples that show the humans apparently have a remarkable ability to balance intake and expenditure und varying circumstances, in spite of the fact that the foods ingested differ in ener content, sensory qualities and nutrient composition. It may well be that there at 
many physiological processes going on without ever being actively and consciously noticed. This implies that subconscious physiological pathways may drive food choices and that eating and drinking as a motivational state may co-exist with physiological mechanisms. It also underscores the importance of proper food identification and recognition by consumers, as they possibly may - subconsciously want specific nutrients to replenish physiological needs. A classification of flavor based on objective parameters could prove to be very useful in that respect.

Does the above imply that humans automatically like what they want? Berridge (1996) reports that it seems axiomatic that we want the rewards we like and like the rewards we want. Yet, while this is usually the case, recent evidence indicates that wanting and liking do not always go together. In relation to flavor, 'liking' corresponds more closely to palatability, while 'wanting' is associated with appetite. It is the distinction between the disposition to eat and the actual pleasure of eating, or - in orher words - the difference between motivation and affect. Both are part of the reward value of food and - thus - under control of the orbitofrontal cortex. Liking and wanting are separate systems. As stated before, opioid and benzodiazepine/ GABA neurotransmitter systems appear to be most directly related to liking. On the other hand, dopamine neurotransmitter systems and the central nucleus of the amygdala appear to participate more directly in wanting than in liking. Research has shown that dopamine-depleted rats still 'like' rewards and also still know the rewards they 'like', but they fail to 'want' the rewards they 'like' (Berridge, 1996; Berridge \& Robinson, 1998).

The neural aspects of 'wanting' and 'liking' touch the concept of flavor appreciation and palatability. It would be interesting to know more about the specificity of wanting in relation to liking, however no literature was found. It could be a very interesting prospect for future research to elucidate if 'wanting' is specifically related to a certain element of a food or a drink.

\subsubsection{Flavor as the result of imprints of neural activities}

As early as 1750, in a book called A physical essay of the senses (Le Cat) there are reports that people without a tongue are able to taste (Bartoshuk, 1978). In his famous 'Physiologie du Goût' (1826), Brillat-Savarin also mentions this phenomenon. In fact there are many examples of individuals with extensive nerve damage to the tongue whose flavor registration remains more or less intact. For example, the chorda tympani nerve can easily get damaged, i.e. during ear surgery, as this nerve crosses the medial surface of the eardrum. When this happened, in some cases individuals did not experience a decrease in tasting abilities, although the taste function did not return to the area that was serviced by the damaged nerve (van den Akker, 2000). 
Apparently the human nervous system has the capacity to bypass barriers by activating other routes and thus keeping flavor registration more or less intact. Flavor perception appears to result from a system with a great deal of redundancy such that even relatively extensive losses often go unnoticed (Lehman et al., 1995).

An important and ever returning debate in the scientific sensory community questions whether sensory qualities are coded in 'labeled lines' or rather 'across fibers'. The across-fiber pattern (AFP) theory, postulates that taste quality is represented by the pattern of activity across the afferent population. Stimuli with similar flavors produce similar patterns of activity. The other view is that activity in a few distinct neuron types codes taste quality in a 'labeled-line' fashion. Neurons responding best to sucrose, for example, would represent 'sweetness', and those responding best to $\mathrm{NaCl}$ would code 'saltiness'. The general view seems to be that gustatory cells are what is called 'broadly tuned'. Different combinations of cells result in different perceptions. Gustatory receptors themselves are not specific, but instead are generalized and differential, similar to the sensors used with smell (Lavigne \& Anslyn, 2001).

To illustrate: recently the functioning of the gustatory receptor that responds to amino acids, or umami was identified. With this discovery scientists have now explained gustatory receptors for three 'basic tastes': sweet, bitter, and Umami. Apparently those receptors belong to the same family of proteins, called T1R. Different T1R genes can be expressed in cells in different combinations to yield cells that respond to a specific flavor. For example T1R2 and T1R3 combine to function as a sweet receptor, designated as $T 1 R 2+3$. The newly found receptor for amino acids is a combination of $T 1 R 1$ and $T 1 R 3$, designated as $T 1 R 1+3$ (Zuker, 2002). This fundamentally means that there is no separate 'sweet' or 'bitter' receptor. 'Sweetness' and 'bitterness' are perceptions resulting from the properties of the network of intercellular gustatory connections in the brain. The relatively broad tuning of these neurons makes it unlikely that they are capable of unambiguously coding information about taste quality. Rather, these neuron types play a critical role in establishing unique AFP's that distinguish among flavor stimuli. The relative activity across these cell types represents taste quality, much like the patterns of activity across broadly tuned photoreceptors code information about stimulus wavelength (Smith \& St. John, 1999). Hopefully the correct identification of all receptors will eventually yield the understanding of how flavor is encoded.

However important the issue of transduction of flavor stimuli may be, it is doubtful that the ultimate answers on the functioning of the human registration of flavor are to be found there. Historically sensory perception (of all senses) has beer studied as isolated modalities. Recent developments in research using moderr 
function imaging methods (FMRI) question if perception in general must be seen as separate modular functions, where the different senses operate independently of each other. Many daily events are registered simultaneously by several senses at the same time, for example by both the eyes and the ears; in flavor registration by eyes, ears, tongue, nose and touch, as illustrated in figure 2-9. A study on quality evaluation of crispbread showed that subjects needed olfactory, tactile and auditory information to recognize samples (Winquist et al., 1999). Such cross-modal interactions between the senses may be the rule and not the exception in perception. Cortical pathways that previously were thought to be sensory-specific are modulated by signals from other systems. Although the study of cross-modal processing is still in its infancy, a consistent pattern of results is beginning to emerge. The neural pathways responsible for the first detection of sensorial signals are, to a large extent, anatomically distinct, but in the brain these signals trigger different networks of brain regions. In one study for instance, it was shown that seeing a talking face, in the absence of sound activated the primary auditory cortex. Such findings suggest that cross-modal interactions may be mediated at a relatively early level of processing in the brain, leading to a new integrated percept. This concept challenges the common belief that modality-specific cortices function in isolation from other modalities (King \& Calvert, 2001; Calvert, Campbell, \& Brammer, 2000; Shimojo \& Shams. 2001; Hadjikhani \& Roland, 1998).

\subsection{Sensory interaction}

\subsubsection{Synesthesia}

Cross-modal interaction of the senses in regard to flavor is worth further elaboration. Foods and beverages are complex mixtures with principally gustatory, olfactory and trigeminal components (figure 2-2). Scientifically it would be helpful if humans were neutral registrars of these components, but clearly this is not the case. Humans are not organized as a sensory laboratory. In fact there are many factors that influence human registration. In the process of flavor registration, qualities in one sensory system can evoke effects in another system. This general phenomenon is called synesthesia. It is defined as an involuntary conscious sensation that is induced by a stimulus in another modality. As the flavor system is very complex with an active involvement of different senses, synesthesia-like, cross-modal effects are abundant. Components interact with each other. Sensory interactions occur each time we eat or drink. In some combinations the flavor of individual components is suppressed, in others the opposite may occur: enhancement of flavors. Sweetness or sourness wil] 
for instance enhance the fruity flavor of beverages or fruit. Salt and MSG are know to enhance the flavor of all kinds of dishes and broths (Noble, 1996). There are mar more examples of sensory interactions, and not all of these interactions are positivi

Examples of interactions are mentioned below. These should be seen as commc tendencies that are to be found in literature and that are believed to have a gener applicability.

\section{Vision - flavor.}

Changing the color of a wine that somebody knows well by adding a neutral foc coloring can fool any connoisseur. If a white wine is changed to red it is subsequent described as a red wine (Morrot, Brochet, Dubourdieu, 2001). Different senso signais are converged in the orbitofrontal cortex which provides a mechanism for tl sight of a food to influence its flavor (Rolls, 2001). There are many examples th show that flavor registration is influenced by vision. Of the various appearance ch racteristics of foods, color is probably the most important, especially if quality related to the color, for example the ripening of fruit or the association of col change with deterioration and spoilage (Clydesdale, 1993). Foods need to have $t$ ) right color, and colors themselves lead to certain expectancies. Colors are al reported to influence the perception of 'refreshing', and of sweetness. Red color yogurt will be judged as being fruitier or sweeter than uncolored yogurt, even thou, the level of sweetness is the same (Zellner \& Durlach, 2002). Good-looking food $n$ induce eating $i t$, just as seeing people enjoy a certain food will do so. Just plain seei and having foods on hand leads to an increased intake (Painter, Wansink \& Hieggell 2002). In a study involving candy it was shown that consumption is lower if can wraps are left in view (Higgs, 2002). Visual advertisements in general are design to enhance taste qualities. Strong brand names are known to have a positive impi on flavor registration. These differences can be assessed in consumer tests like blind vs. as-branded flavor research.

\section{Smell - flavor.}

Gustatory and olfactory interactions occur each time we eat or drink and I importance of smell to flavor can hardly be underestimated. In general, the smell food can have a great influence on appreciation and palatability. The pleasing aro of freshly baked bread, just as that of baking cookies and cakes, roasting meat, cofi beans or almonds must be contributed to the Maillard reaction. A complex chemi reaction that - besides smell - influences the color, flavor, texture, and nutritional va of foods. Of these, especially the flavor component is sought after for it is known be generally liked and appetizing (Martins, Jongen \& Van Boeckel, 2001). 
Smells certainly add to the attraction of foods. They also influence - at least partly - satiety, which is called olfactory sensory-specific satiety. Just smelling food as long as it would normally take to eat during a meal, leads to partial sensoryspecific satiety (Rolls \& Rolls, 1997).

A number of studies have shown that certain odors, when added to flavors can modify the perceived intensity of that flavor. A mixture of food odors like strawberry. pineapple, raspberry or caramel and sucrose is judged sweeter than sucrose alone (Prescott, 1999). Some odors are known to enhance sweerness and at the same time to suppress the sourness of citric acid (i.e. caramel and lychee) (Frank, Van der Klaauw \& Schifferstein, 1993; Stevenson, Prescott \& Boakes, 1999). Gustatory and odor stimuli interact most strongly when the associations are congruent and logical. In the case of both orange- and lemon-flavored systems, increasing the acid and/or sugar concentration increased the fruitiness intensity and 'flavor impact' (Noble, 1996).

Smells that match the 'right' color are perceived as being more intense than in combination with another color. Good examples are lemon-yellow, strawberry-red, caramel-brown. Specific brain areas showed higher activity if odors were smelt with the right colors, implying that i.e. caramel is smelt stronger when seeing the color brown than when seeing other colors. Similarly, the auditory cortex is more active if a subject hears and sees somebody talking (Shimojo \& Shams, 2001; Calvert, Campbell \& Brammer, 2000). Such strong relations have important implications for food design and packaging.

\section{Sound - flavor.}

Just as vision, hearing can also alter our flavor registration. Approving or disapproving remarks will certainly influence the individual registration.

There are a number of textural components that have an auditory element. Think of crispness, crunchiness and crackliness. The difference in perception between crunchy and crackly products and crispy ones can be explained by sound: crunchy and crackling sounds are lower than crispy ones. If a crisp product does not produce the expected sound, it is considered to be stale and of poor quality. (Duizer, 2001). These words should therefore be used with care as expectancy is involved. It would be a mistake to call a crunchy product 'crispy'.

\section{Gustation - flavor.}

When two different flavor components are mixed at moderate or strong concentrations, the mixture will often yield a flavor sensation that is less intense than the simple sum of the component flavors. This is called suppression. As it was thought for a long time that all flavors were compositions of 'basic flavors', there are 
many studies available on reactions. Breslin (1996) reviewed extensively the research on the interaction of ail kinds of sweet, sour or bitter tasting substances. Sweetness and sodium salts are known to suppress bitter flavors. Sugar in coffee decreases the bitter flavor of caffeine (Calvino, Garcia-Medina, Cometto-Munez, Rodriguez, 1993). Just as the removal of sugar and fat from many foods unmasks underlying bitter attributes (Walters, 1996). As sugar and fat both involve mouthfeel it would be interesting for a study to be conducted on the effects of the coating of papillae on the bitter perception.

Chlorhexidine, a bitter tasting antiseptic, severely impairs the identification of salty ( $\mathrm{NaCl}, \mathrm{KCl}$ ), and bitter tasting substances (such as quinine. $\mathrm{HCl}$ ) (Gent, Frank. Hettinger, 2002).

Gymnemic acid (a mixture of bitter acidic glycosides) blocks the sweet flavor of all sweet stimuli (Gent, Frank. Hettinger, 2002). The same effect is observed with 'lactisole' (Walters, 1996).

How salts and acids affect each other depends on concentration: they enhance each other at moderate concentrations but suppress each other at higher concentrations. In sensory flavor research in general, mixture interactions will be dependent on:

- the specific chemicals in question,

- the magnitude of their perceived intensity.

- the particular concentrations examined,

- whether they are subthreshold (present, but not perceived) or suprathreshold (present and perceived),

- and the particular method that is used (Breslin, 1996).

Essentially this implies that a certain care is appropriate in extrapolating research results to real foods and drinks.

\section{Touch - flavor.}

Fat is an important constituent of food that affects its palatability and nutritional value. Palatability is enhanced in two ways: in mouthfeel and flavor. Both are relevant to appetite and the pleasantness of food. Therefore, foods that are high in fat are often over-consumed and many individuals find it difficult to reduce their fat intake. Consequently, there is a growing demand for fat replacements in foods. A prerequisite in the development of these is understanding how fats are detected. Clearly, tactile aspects like moistness, creaminess and viscosity are important, but possibly fatty acids can also modulate ion channels of gustatory receptor cells. This would not be surprising, considering that other acid-likes (glutamic and tannic acid) 
are also a combination of tactile and gustatory registration. It appears that viscosity alone cannot explain creaminess, as fat replacers that match viscosity do not capture the full sensory appeal of fat (Rolls et al., 1999; Monell, 1999).

Next to these aspects, fat has been shown to reduce the oral burn of i.e. capsaicin and the (earlier mentioned) bitterness of i.e. caffeine. Examples are of the use of cream in coffee, milk in tea or the general flavor profile of pure chocolate as opposed to milk chocolate, where the latter may be preferred by the general public, but certainly not by chocolate-lovers.

$\mathrm{CO}_{2}$ stimulates not only trigeminal fibers, but also gustatory ones, altering especially the perception of sweet, salty and sour flavors. Adding $\mathrm{CO}_{2}$ to a sucrose mixture reduced the perception of sweetness, while sourness increased. Likewise, when added to a salty mixture, saltiness decreased while the perception of sourness again increased. However, when carbonation was added to citric acid its sourness decreased, while bitterness increased. On the bitterness of quinine, $\mathrm{CO}_{2}$ had little effect (Cowart, 1998). Not only is the perception of tastants influenced by $\mathrm{CO}_{2}$; the substance is also reported to block aroma (Lawless, 1996).

The human flavor registration is blurred through the different systems. This blurring is for instance illustrated by the trigeminal sensations of astringency. Principally, tannins in foods must be considered as chemical stimuli (tannic acid), and yet the astringent sensations they produce seem largely tactile. The mouth feels rough and dry, lips and cheeks seem to contract. Although scientific analysis would categorize astringency as a group of chemically-induced oral tactile sensations, most wine tasters would say that astringency is an important component of wine 'flavor'. This highlights, once again, the integrative nature of flavor in combining inputs from multiple modalities (Lawless, 1996).

\subsubsection{Flavor enhancement by umami}

In relation to flavor enhancement special attention needs to be focused on the 'fifth' basic flavor, umami. Umami has been defined as a distinct flavor, elicited by glutamates. Glutamic acid is one of the amino acids, found in ail protein-containing foods, being one of the most abundant and important components of proteins. Glutamate occurs naturally in meats, fish (salmon), cheeses (Parmesan), milk, eggs, and vegetables (mushrooms, green peas, corn, tomatoes, spinach, carrots, and peppers). Glutamate is an important neurotransmitter, a chemical which allows neurons in the brain to communicate between each other. It is produced by the human body and is vital for growth, nerve metabolism and brain function.

Monosodium glutamate (MSG) is the sodium salt of glutamic acid. The use of MSG as an additive in food goes back to the Asian cooks of antiquity, who used 
seaweed called Sea Tangle to make a starch. Ikeda discovered in 1908 the link between dried seaweed (Laminaria japonica, traditionally used for flavor improvement), and glutamate (first isolated in 1866). After its discovery, the Japanese began commercial production of glutamate almost immediately. 30 Years thereafter it was produced in North America, derived from corn and wheat gluten. Today, MSG is produced in the United States from sugar beet molasses, in a fermentation process similar to that used in making yeast and sauerkraut. As an additive, MSG is widely used in the food industry. Umami is often only associated

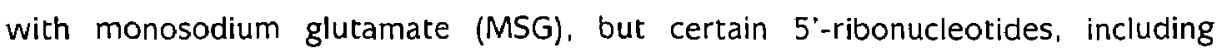
inosine-5'-monophosphate (IMP), guanosine-5'-monophosphate (GMP) and adenosine-5'-monophosphate (AMP) also elicit the specific umami flavor (Bellisle, 1999; Chaudhari, Yang, Lamp, Delay, Cartford \& Than, 1996; Shiffman, 2000d).

The role of these compounds in flavor is very interesting as they have the characteristic to enhance ratings of overall flavor and preference. In other words: they make food taste better. The flavor of umami is often not specifically identified in a food; the pure flavor of MSG is even considered not to be pleasant. It was described as 'soapy-metallic', and also bitter. So it is not the flavor of umami that is interesting, but rather the effect that it has. Terms as 'thickness', 'complexity', ol 'body' are often used by sensory panelists when asked to describe the flavor of umami (Fuke \& Ueda, 1996). The word umami means 'delicious' in Japanese (Bellisle 1999). These words indicate that the addition of MSG to food, either synthetically or in the form of natural ingredients containing it, is broadly associated to the palatability of food, as if more flavor-registers are pulled open. The flavor enhancing effect occurs even at levels of concentration too low to be discriminated, and work: best in combination with salt. In research experiments, dishes with MSG wert universally liked better than dishes without it. MSG harmonizes well with salty anc sour flavors, but does little for sweet foods such as cakes, pastries or candies. Th. amount of sait in dishes can effectively be reduced in combination with MSG. It i estimated that the potential reduction of $\mathrm{Na}+$ in soups is $40 \%$ (Fuke \& Ueda, 1996) Elderly who - in general - suffer from a loss in flavor registration capacit significantly enjoy foods more when (a mixture of) MSG is added (Schiffmar 2000d).

Glutamates are likely to be transduced by mGluR4, a G-coupled protei glutamate receptor, which is found in gustatory taste buds of circumvallate an foliate papillae and innervating the chorda tympani (cranial nerve VII) (Zuker, 2002 Gilbertson et al., 2000; Chaudhari et al., 1996). There is a difference in naturi glutamates and synthetic MSG. In the natural form glutamic acid is linked $t$ 'peptide' or 'bound' linkages that are broken apart slowly in the digestive process. 
MSG, the glutamate is not bound in a protein molecule (Lindemann, 1999). The amino acids glutamic acid and glutamine are converted to glutamate in the body. Some people are known to be sensitive to these amino acids. Blushing, rash, headache, increased heart rate and pressure on the head and neck are symptoms. MSG is often associated with the so-called 'Chinese restaurant syndrome' as MSG is extensively used in these kitchens in the form of Ve-tsin, and Soy sauce. Many toxicological studies have been conducted, but they failed to show specific toxic effects. A 1992 report from the Council on Scientific Affairs of the American Medical Association stated that glutamate in any form has not been shown to be a 'significant health hazard.' Also, the 1987 Joint Expert Committee on Food Additives of the United Nations Food and Agriculture Organization and the World Health Organization have given MSG the GRAS status.

\subsubsection{Adaptation and (de)sensitization}

Adaptation is a well-known phenomenon in sensory science. In sound, touch. vision and smell humans have a tendency to adapt to a certain stimulus. It is a functional capacity enabling the organism to respond to changes in stimulation (Dalton, 2000). Adaptive processes are well-known to affect the human registration of flavor as well. Sensitivity to tastants and odorants decreases as a result of a prolonged exposure to that stimulus. As stated before, this phenomenon is called 'sensory-specific satiety'. Offering a greater variety of different foods will increase the total intake. Brillat-Savarin (1826) formulated it as his 8th aphorism: "it is heresy to insist that we must not mix wines: a man's palate can grow numb and react dully to even the best bottle after the third glass from it".

Irritant chemicals in food spices, as well as carbonation activate trigeminal pain pathways. There seem to be two distinct temporal patterns: sensitization and desensitization. In sensitization the intensity of irritation progresses when repeatedly applicated. It is observed with capsaicin, piperine, citric acid and concentrated $\mathrm{NaCl}$. The contrary pattern, desensitization, where the perceived intensity declines, is seen with nicotine, menthol, mustard oil, cinnamaldehyde, zingerone and ethanol. Occurrence of such patterns is dependent on interval frequency and degree of excitation (quantity). Humans adapt to these pain-like irritations. Individuals that are accustomed to spicy food develop a higher threshold for capsaicin or zingerone. This might reflect a chronic state of desensitization. Similarly, frequent consumers of spirits adapt to the oral burn of ethanol. They can call a spirit 'soft' or 'smooth'. Infrequent consumers of the same drink will experience it quite differently. Habituation will lead to individual assessments of sensory characteristics in these cases. As such this kind of desensitization has a strong cognitive influence. 
Nevertheless, all research reports indicate a large inter- individual variability in sensitivity (Carstens et al. 2002; Prescott, 1999b, 2000).

Adaptation is also well known in chemical flavors like salt and sweetness. People grow accustomed to certain levels. In case of a sudden change in dietary habits (sugar of sodium free) flavor is judged as less palatable. After the flavor system is 'reorganized' appreciation increases. This adaptation generally takes about a week. It is possible that the regeneration of taste cells plays a role in this process.

\subsubsection{Carry-over effects}

Besides synesthesia attention needs to be focused at 'carry-over effects', defined as: the response to a stimulus is influenced by a previous sample (Cubero-Castillo \& Noble, 2001). In a laboratory it is variable to take into account, as carry-over effects may invalidate the results. Sequential sensitization needs to be minimized. In everyday life carry-over effects are inevitable, and will also have a large effect. During the course of a meal or a tasting, previously tasted foods or drinks are likely to influence the perception of the next. There are several factors that are responsible for such interactions.

The first phenomenon is called 'successive contrast' and refers to the influence of flavor intensity. After having tasted something with a high flavor intensity, the intensity of the following is perceived to be less intense than when it is preceded by something with a low flavor intensity (Schifferstein \& Oudejans, 1996). A variant of 'successive contrast' is 'hedonic contrast', which can be best described by the Italian proverb 'il meglio e l'inimico del bene', which is translated as 'the best is the enemy of the good'. This implies that stimuli are rated less good when compared very good, similar stimuli, than when compared alone, or with less good similar stimuli (Zellner, Kern \& Parker, 2002b).

Another phenomenon is called 'cross-adaptation'. It is defined as a reduction of sensation of one stimulus, following a prolonged stimulus by another. It is hypothesized that it is caused by shared receptor processes (Stevens, 1996).

Bitter flavors are considered to linger in the mouth implying that perceived bitterness increases with successive intakes. This sensitization is compound-specific. In one study caffeine is reported to be the least affected by other bitter-tasting compounds tested, while - at the same time - it exerted the largest sensitization effect on the other compounds. This result is explained by the different ways bitter elements may be transduced. Caffeine penetrates cell membranes to activate calcium channels directly. Such compounds may take longer to leave the gustatory cell than compounds that are registered otherwise (Cubero-Castillo \& Noble, 2001; Watters. 1996). 
The use of alcohol together with food is another example of how the flavor of one compound may change the perception of the flavor of other ones. Moderate use of ethanol is reported to alter the registration of sensory properties of items consumed at the same time. Most reports mention a marked reduction of bitter flavors, and slightly diminished ratings for sourness and saltiness, while sweet flavors are often slightly enhanced in combination with ethanol (Matthes \& DiMeglio, 2001).

Fat and dissolved sugars (like in honey) have the capacity to coat the mouth with a film that will also influence the registration of succeeding sips or bites. We propose to call these kinds of influences 'residual flavors'. Practically the effect can easily be demonstrated by tasting successively honey and fresh orange juice and vice versa. After the honey the orange juice will appear to be much more acidic. Likewise, the flavor of acidic wines can be negatively influenced by viscous residues of cream sauces. Literature on this subject is scarce. The results of a study on the influence fat residues on the registration of other flavors are shown in table 2-1 (Valentova \& Pokorný, 1998).

\begin{tabular}{|l|l|l|l|l|}
\hline $\begin{array}{l}\text { Table 2-1: } \\
\text { FLAVOR }\end{array}$ & $\begin{array}{l}\text { ACCEPTABILITY } \\
\text { BEFORE OIL }\end{array}$ & $\begin{array}{l}\text { INTENSITY } \\
\text { BEFORE OIL }\end{array}$ & $\begin{array}{l}\text { ACCEPTABILITY } \\
\text { AFTER OIL }\end{array}$ & $\begin{array}{l}\text { INTENSITY } \\
\text { BEFORE OIL }\end{array}$ \\
\hline Sweet & 34 & 47 & 40 & 10 \\
\hline Salty & 77 & 69 & 78 & 77 \\
\hline Acidic & 28 & 47 & 45 & 55 \\
\hline Bitter & 26 & 68 & 23 & 43 \\
\hline Astringent & 35 & 77 & 22 & 44 \\
\hline
\end{tabular}

Table 2-1: Effect of oil on the intensity of flavors (\% of the scale) (Valentova \& Pokorny, 1998)

The perceived intensity of sweet, bitter and astringent decreased considerably, while the perceived intensity of salty and acidic increased. Differences in the chemical structure of these flavors may explain such effects, and especially their hydrophobicity (Valentova \& Pokorný, 1998).

The influences mentioned above shed a particular light on the relevance of laboratory experiments in relation to real life situations. Flavor adaptation is frequently observed in research settings. However, during normal eating the results are quite different (Theunissen, Polet, Kroeze, Schifferstein, 2000). Real life situations are almost by definition uncontrolled in which both accidents and serendipities are rather the rule then the exception. 


\subsection{Conclusion}

Flavor can be studied from a human and a product angle. In this chapter the human angle is reviewed: flavor registration. Flavor registration is not a single sense but rather a sublimation of the human senses. Literature was reviewed on the three sensorial systems that register the intrinsic flavor components, the gustatory. olfactory and trigeminal system. Each of these systems seems to work independently in conveying information to brain areas where it is integrated and assembled to the percept of flavor. Differences between humans and cross modal sensorial interferences influence registration and tasting. If the physiology underlying the transduction of single sensory modalities is already complex, the physiology underlying a multi-sensorial experience of tasting, is at least three times as complex.

The 'four basic flavor hypothesis' has dominated the field and research methods. This implies that attention has been focused on the gustatory part of flavor registration. Consequently, answers on flavor registration as a whole are not to be expected; gustation is just one part of flavor perception. Furthermore it is influenced by trigeminal and olfactory elements. Next, brain areas and more specifically motivational systems of liking and wanting may have a top-down influence on perception. Also, other sensory systems such as sight and sound are liable to influence flavor. This implies that real foods, studied in naturalistic settings are likely to give better answers on flavor registration in general.

In wanting to know more about color, it is quite logical to study the physical aspects of color and not the human perception of light. Likewise, potential answers on flavor are likely to be found at the physical product level and hardly at the sensorial level of flavor registration.

\section{References}

Ackerman, D. (1990). A natural history of the senses. New York (Random House Inc.) Akker, E.H. van den. Een kwestie van goede smaak, Chorda Tympani en middenoorchirurgie. Referaat 25 mei 2000, Kliniek Keel-, Neus- en Oorheelkunde, Universitair Medisch Centrum, Utrecht. (in Dutch)

Bartoshuk, L.M. (1978). History of research on taste. In Carterette, E.C. \& Friedman. M.P. Handbook of perception, volume VIA, Tasting and Smelling (pp. 3-16). New York, Academic press

Bartoshuk, L.M. (2000). Comparing sensory experiences across individuals: recent psychophysical advances illuminate genetic variation in taste perception. Chemical Senses, 25, 447-460 
Beidler, L.M. (1978). Biophysics and chemistry of taste. In Carterette, E.C. \& Friedman. M.P. Handbook of perception, volume VIA, Tasting and Smelling (pp. 2149). New York, Academic press

Bell, G.A. (1996). Molecular mechanisms of olfactory perception: their potential for future technologies. Trends in Food Science \& Technology, 7, 425-431

Bellisle, Fr. (1999). Glutamate and the UMAMI taste: sensory, metabolic, nutritional and behavioral considerations. A review of the literature published in the last 10 years. Neuroscience and Biobehavioral Reviews, 23, 423-438

Berridge, K.C. (1996). Food reward: brain substrates of wanting and liking. Neuroscience and Biobehavioral Reviews, 20, 1-25

Berridge, K.C., Robinson, T.E. (1998). What is the role of dopamine in reward: hedonic impact, reward learning, or incentive salience? Brain Research Reviews, 28, 309-369

Birch, L.L. (1999). Development of food preferences, Ann. Rev. Nutrition 19, 41-62

Boucher, Y., Simons, C.T., Faurion. A., Azérad, J., Carstens, E. (2003). Trigeminal modulation of gustatory neurons in the nucleus of the solitary tract. Brain Research. 973, 265-274

Bray, G.A. (2000). Afferent signais regulating food intake. Proceedings of the Nutrition Society, 59, 373-384

Bray, G.A. (2000b). Reciprocal relation of food intake and sympathetic activity: experimental observations and clinical implications. Int. Journal of Obesity, 24, suppl. 2. S8-S17

Brand, G., Millot, J.-L., Henquell, D. (2001). Complexity of olfactory lateralization processes revealed by functional imaging: a review. Neuroscience and Biobehavioral Reviews, 25, 159 - 166

Breslin, P.A.S. (1996). Interactions between salty, sour and bitter compounds. Trends in Food Science \& Technology, 7, 390-399

Brillat-Savarin, J.A. Physiologie du Goût. Sautelet, Paris (1826). American edition: M.F.K. Fisher's translation of Brillat Savarin's, The Physioiogy of Taste (1949), Knopf, New York

Calvert, G.A., Campbell, R. \& Brammer, M.J. (2000). Evidence from functional magnetic resonance imaging of crossmodal binding in the human heteromodal cortex. Current Biology, 10, 649-657

Calvino, A.M., Garcia-Medina, M.R., Cometto-Muniz, J.E., Rodriguez, M.B. (1993). Perception of sweetness and bitterness in different vehicles. Perception and Psychophysics, 54, 751-758

Carstens, E., Carstens, M.I., Dessirier, J.-M.. O'Mahony, M., Simons, C.T., Sudo, M., Sudo, S. (2002). It hurts so good: oral irritation by spices and carbonated drinks and the underlying neural mechanisms. Food Quality and Preference, 13, 431-443 
Chaudhari, N., Yang, H., Lamp. C., Delay, E., Cartford, C., Than, T. (1996). The Taste of monosodium glutamate: membrane receptors in taste buds. Journal of Neuroscience, 16, 3817-3826

Chou, H.-C., Chien, C.-L., Huang, H.-L, Lu, K.-S. (2001). Effects of zinc deficiency on the vallate papillae and taste buds in rats. J. of the Formosan Medical Association, 100, 326-335

Cliff, M. \& Heymann, H. (1992). Descriptive analysis of oral pungency. Journal of Sensory Studies, 7, 279-290

Clydesdale, F.M. (1993). Color as a factor in food choice. Critical reviews in Food Science and Nutrition. 33, 83-101

Conference report: Food texture: perception and measurement (2002). Report of an international workshop. Food Quality and Preference, 13, 237-255

Cowart, B.J. (1998). The addition of $\mathrm{CO}_{2}$ to traditional taste solutions alters taste quality. Chemical Senses, 23, 397-402

Cubero-Castillo, E. \& Noble, A.C. (2001). Effect of compound sequence on bitterness enhancement. Chemical Senses, 26 (4), 419-424

Dalton. P. (2000). Psychophysical and behavioral characteristics of olfactory adaptation. Chemical Senses, 25, 487-492

Delwiche, J. (1996). Are there 'basic' tastes? Irends in Food Science \& Technology, 7, 411-415

Delwiche, J.F., Buletic, Z., Breslin, P.A.S. (2001). Relationship of papillae number to bitter intensity of quinine and PROP within and between individuals. Physiology \& Behavior, 74, 329-337

Dessirier, J.-M., Simons, C.T., O'Mahony, M. \& Carstens, E. (2001). The oral sensation of carbonated water: Cross-desensitization by Capsaicin and potentiation by Amiloride. Chemical Senses, 26, 639-643

Doty, R.L., (2001). Olfaction. Ann. Rev. Psychology 52, 423-452

Drewnowski, A., Rock, C.L. (1995). The influence of genetic taste markers on food acceptance. American Journal of Clinical Nutrition, 62, 506-511

Duizer, L. (2001). A review of acoustic research for studying the sensory perception of crisp, crunchy and crackly textures. Trends in Food Science \& Technology, 12, 17-24

Erickson, R.P. (2000). The evolution of neural coding ideas in the chemical senses. Physiology \& Behavior 69, 3-13

Finkeistein, J.A., \& Schiffman, S.S. (1999). Workshop on Taste and Smell in the Elderly: an Overview. Physiology \& Behavior, 66, 173-176

Frank, R.A., van der Klaauw, N.J., Schifferstein, H.N. (1993). Both perceptual and conceptual factors influence taste-odor and taste-taste interactions. Perception and Psychophysics, 54, 343-254 
Freeman. W.J. (1991). The Physiology of Perception. Scientific American. February, vol. 264, 78-85

Fujiyama, R., Miyazaki. T., Miyamoto, T., Okada, Y., Mizuno, A., Inokuchi, T, Sato, T. (1998). Intracellular free calcium concentration in human taste bud cells increases in response to taste stimuli. FEBS letters, 434, 47-50

Fuke, S. \& Ueda, Y. (1996). Interactions between umami and other flavor characteristics. Trends in Food Science \& Technology, 7, 407-411

Gawel, A., Iland, P.G., Francis, I.L. (2001). Characterizing the astringency of red wine: a case study. Food Ouality and Preference, 12, 83-94

Gent, J.F., Frank, M.E., Hettinger, T.P. (2002). Taste confusions following Chlorhexidine treatment. Chemical Senses, 27, 73-80

Gilbertson, T.A., Damak, S., \& Margolskee, R.F. (2000). The molecular physiology of taste transduction. Current Opinion in Neurobiology, 10, 519-527

Green, B.G. (1996). Chemesthesis: Pungency as a component of flavor. Trends in Food Science \& Technology, 7, 415-419

Gold, G.H. (1999). Controversial iss ues in vertebrate olfactory transduction. Ann. Rev. of Physiology, 61, 857-871

Guinard, J-X., Mazzucchelli, R. (1996). The sensory perception of texture and mouthfeel. Trends in Food Science \& Technology, 213-219

Hadjikhani, N. \& Roland, P.E. (1998). Cross-modal transfer of information between the tactile and the visual representations in the human brain: a Positron Emission Tomographic study. The Journal of Neuroscience, 18, 1072-1084

Higgs, S. (2002). Memory for recent eating and its influence on subsequent food intake. Appetite, 39, 159-166

Hutchings, J.B. \& Lillford, P.J. (1998). The perception of food texture - The philosophy of the breakdown path. Journal Textural Studies, 19, $103-115$

Internetsite: http://www.truthinlabeling.org

Internetsite: http://www.fda.gov/opacom/backgrounders/msg.html

Jacob, T.J.C. (2000), internetsite: http://www.cf.ac.uk/biosi/staff/jacob/teaching/ sensory/taste.html\#Transduction

Kaneda, H. (2000). Decline in taste and odor discrimination abilities with age, and relationship between gustation and olfaction. Chemical senses, 25 (3), 331-337

Katz, D.B., Nicolelis, M.A.L. \& Simon, S.A. (2000). Nutrient tasting and signaling mechanisms in the gut IV. There is more to taste than meets the tongue. Am. J. Physiological. 278: G6-G9

King, A.J. \& Calvert, G.A. (2001). Multisensory integration: Perceptual grouping by eye and ear. Current Biology, 11, R322-R325

Laing. D.G. \& Jinks, A. (1996). Flavour perception mechanisms. Trends in Food Science \& Technology, 7, 387-391 
Lange, C., Rousseau, F., Issanchou, S. (1999). Expectation, linking and purchase behaviour under economical constraint. Food Quality and Preference, 10, 31-39

Lavigne, J.J. \& Anslyn, E.V. (2001). Sensing a paradigm shift in the field of molecular recognition: from selective to differential receptors. Angewandte Chemie, International Edition, 40, 3118-3130

Lawless, H.T. (1996). Flavor. In Cognitive Ecology. (Chapter 8, pp. 325-380, New York, Academic Press

Lehman, C.D., Bartoshuk, L.M., Catalanotto, F.C., Kveton, J.F. \& Lowlicht, R.A. (1995). Effect of Anesthesia of the Chorda Tympani Nerve on Taste Perception in Humans. Physiology \& Behavior, 57, 943-951

Levine, A.S., \& Billington, C.J. (1997). Why do we eat? A neural systems approach. Ann. Rev. of Nutrition, 17, 597-619

Lindemann, B. (1999). Six common errors: Criticism of the human tongue maps as seen in some textbooks. www.med-rz.uni-sb.de/med-fak/physiol2/LDM/chemotopic_l.htm

Lucas, P.W., Prinz, J.F., Agrawal, K.R., Bruce, I.C. (2002). Food physics and oral physioiogy. Food Ouality and Preference, 13, 203-213

Martins, S.I.F.S., Jongen, W.M.F. \& Van Boeckel, M.A.J.S. (2001). A review of Maillard reaction in food and implications to kinetic modeling. Trends in Food Science \& Technology, 11, 364-373

Mattes, R.D. \& DiMeglio, D. (2001). Ethanol perception and ingestion. Physiology \& Behavior, 72, 217-229

McCleskey, E.W., Gold, M.S. Ion channnels of nociception. Annual Review on Physiology (1999), vol. 61, pp. 835-856

Miller, IJ. Jr. (1986). Variation in human fungiform taste bud densities among regions and subjects. Anat. Rec. , 216, 474-482

Miller, IJ. Jr, Reedy. F.E. Jr. (1990). Variations in human taste bud density and taste intensity perception. Physiology \& Behavior 47, 1213-1219

Monell Connection, the (1999). Newsletter from the Monell Chemical Senses Center, Fall 1999

Monell Connection, the (2001). Newsletter from the Monell Chemical Senses Center, Spring 2001

Morrot, G., Brochet, F., Dubourdieu, D. (2001). The color of odors. Brain and Language, 79, 309-320

Murphy, C., Nordin, S. \& Jinich, S. (1999). Very early decline in recognition memory for odors in Alzheimer's disease. Ageing. Neuropsychology, and Cognition. 6. 229-240

Noble, A.C. (1996). Taste-aroma interactions. Trends in Food Science \& Technology, 7, 439-444 
Patel, K.A. \& Schlundt, D.G. (2001). Impact of moods and social context on eating behavior. Appetite, 36, 111-118

Painter, J.E., Wansink, B. \& Hieggelke, J.B. (2002). How visibility and convenience influence candy consumption. Appetite, 38, 237-238

Poothultil, J.M. (1995). Regulation of nutrient intake in humans: a theory based on taste and smell. Neuroscience and Brobehavioral Reviews, 19, 407-412

Prasad, A.S. (2001). Discovery of human zinc deficiency: Impact on human health. Nutrition, 17, 685-687

Prescott, J. (1999). Flavour as a psychological construct: implications for perceiving and measuring the sensory qualities of foods. Food Quality and Preference, 10, 349-356

Prescott, J. (19996). The generalizability of capsaicin sensitization and desensitization. Physiology \& Behavior, 66, 741-749

Prescott, J. (2000). Responses to repeated oral irritation by capsaicin, cinnamaldehyde and ethanol in PROP tasters and non-tasters. Chemical Senses, 25, 239-246

Prutkin, J., Duffy, V.B., Etter, L., Fast, K., Gardner, E., Lucchina, L.A., Snyder, D.J., Tie, K., Weiffenbach, J., Bartoshuk, L.M. (2000). Genetic variation and inferences about perceived taste intensity in mice and men. Physiology \& Behavior, 69,161-173

Rolls, B.J. (1999). Do chemosensory changes influence food intake in the elderly? Physiology \& Behavior, 66, 193-197

Rolls, E.T. \& Rolls, J.H. (1997). Olfactory Sensory-Specific satiety in humans. Physiology \& Behavior, 61, 461-473

Rolls, E.T., Critchley, H.D., Browning, A.S., Hernadi, I., Lenard, L. (1999). Responses to the sensory properties of fat of neurons in the primate orbifrontal cortex. Journal of Neuroscience, 19, 1532-1540

Rolls, E.T. (1999). The functions of the Orbitofrontal Cortex. Neurocase, 5, 301-312

Rolls, E.T. (2000a). Memory systems in the brain. Ann. Rev. Psychology, 51, 599-630

Rolls, E.T. (2000b). The Orbitofrontal Cortex and Reward. Cerebral Cortex, 10, 284-294

Rolls, E.T. (2001). The rules of formation of the olfactory representations found in the Orbitifrontal cortex olfactory areas in primates. Chemical Senses, 26, 595-604

Rozin, P. (1982). Taste-smell confusions, and the duality of the olfactory sense. Perception \& Psychophysics, 31, 397-401

Schiffman, S.S., Graham. B.G., Sattely-Miller, E.A., \& Peterson-Dancy, M. (2000). Elevated and sustained desire for sweet taste in African-Americans: a potential factor in the development of obesity. Nutrition, 16, 886-893

Schiffman, S.S. (20006). Taste quality and neural coding: Implications from psychophysics and neurophysiology. Physiology \& Behavior, 69, 147-159 
Schiffman, S.S.. Sattely-Miller E.A., Graham, B.G., Bennett, J.L., Booth, B.J., Desai, N., Bishay, 1. (2000c). Effect of temperature, $\mathrm{pH}$, and ions on sweet taste. Physiology and Behavior, 68, 469-481

Schiffman, S.S. (2000d) Intensification of sensory properties of foods for the elderly. J. of Nutrition, 130, suppl., 927S-930S

Schifferstein, H.N., Oudejans, I.M. (1996). Determinants of cumulative successive contrast in saltiness intensity judgments. Perception and psychophysics, 58 (5), $713-724$

Scott, T.R. (2001). The role of taste in feeding. Appetite, 37, 111-113

Shimojo, S. \& Shams, L. (2001). Sensory modalities are not separate modalities: plasticity and interactions. Current Opinion in Neurobiology, 11, 505-509

Shiraishi, T, \& Oomura, Y., Sasaki, K., Wayner, M.J. (2000). Effects of leptin and orexin-A on food intake and feeding related hypothalamic neurons. Physiology \& Behavior, 71, 251-261

Smith, D.V. \& Margolskee, R.F. (2001). Making Sense of Taste. Scientific American, Vol. 288, 26-33

Smith, D.V., \& St. John, S. (1999). Neural coding of gustatory information. Current Opinion in Neurobiology, 9, 427-435

Spector, A.C. (2000). Linking gustatory neurobiology to behavior in vertebrates. Neuroscience and behavioral reviews, 24, 391-416

Stevens, D.A. (1996). Individual differences in taste perception. Food Chemistry, 56, 303-311

Stevenson, R.J., Prescott, J., Boakes, R.A. (1999). Confusing taste and smells: how odours can influence the perception of sweet and sour tastes. Chemical Senses, 24, 627-635

Szczesniak, A.S. (2002). Texture is a sensory property. Food Quality and Preference, 13, 215-225

Tabuchi, R. \& Ohara, l. (1997). Optimal protein level is required for normalization of taste sensitivity in rats. Nutrition Research, 17, 1749-1760

Temple, E.C., Hutchinson, I., Laing, D.G., Jinks, A.L. (2002). Taste development: differential growth rates of tongue regions in humans. Developmental Brain Research, 135, 65-70

Tepper, B.J., Nurse, R.J. (1998). PROP taster status is related to fat perception and preference. Annals New York Academy of Science, 30; 855: 802-804

Tepper, B.J., Christensen, C.M., Cao, J. (2001). Development of brief methods to classify individuals by PROP taster status. Physiology \& Behavior, 73, 571-577

Theunissen, M.J., Polet, I.A., Kroeze, J.H., Schifferstein, H.N. (2000). Taste adaptation during the eating of sweetened yogurt. Appetite, 34, 21-27 
Valentova, H. \& Pokorný, J. (1998). Effect of edible oils and oil emulsions on the perception of basic tastes. Nahrung. 42, 406-408

Vidal, S., Courcoux, P., Francis, L., Kwiatkowski, M., Gawel, R., Williams, P., Waters, E., Cheynier, V. (2003). Use of an experimental design approach for evaluation of key wine components on mouth-feel perception. Food Quality and Preference, in press

Vroon, P., van Amerongen, A., de Vries, H. (1994). Verborgen verleider, Psychologie van de reuk. Ambo publishers, Baarn, the Netherlands. (in Dutch)

Wahisten, D. (1999). Single-gene influences on brain and behavior. Ann. Rev. on Psychology, 50, 599-624

Walters, D.E. (1996). How are bitter and sweet tastes related? Trends in Food Science \& Technology, 7, 399-403

Westerterp-Plantenga, M.S., Westerterp, K.R., Nicolson, N.A., Mordant, A., Schoffelen, P.F.M., ten Hoor, F. (1991). The shape of the cumulative food intake curve in humans, during basic and manipulated meals. Physiology and Behavior, 47, 569-576

Wilkinson, C., Dijksterhuis, G.B., Minekus, M. (2001). From food structure to texture. Trends in Food Science and Technology, 1-9

Winquist, F., Wide, P., Eklov, T., Hjort, C., Lundstrom, I. (1999). Crispbread quality evaluation based on fusion of information from the sensor analogies to the human olfactory. auditory and tactile senses. Journal of Food Process Engineering, 22, 337-358

Yackinous, C.A. \& Guinard J.-X. (2001). Relation between PROP taster status and fat perception, touch and olfaction. Physiology \& Behavior, 72, 427-437

Yackinous, C.A. \& Guinard, J.-X. (2002). Relationship between PROP (6-n-propylthioracil) taster status, taste anatomy and dietary intake measures for young men and women. Appetite, 38, 201-209.

Zellner, D.A. \& Durlach, P. (2002). What is refreshing? An investigation of the color and other sensory attributes of refreshing foods and beverages. Appetite, 39 , 185-186

Zellner, D.A., Kern, B.B. \& Parker, S. (2002b). Protection of the good: subcategorization reduces hedonic contrast. Appetite, 38, 175-180

Zuker, (2002). Internetsite: http://www.hhmi.org/news/zuker3.html 


\title{
comess \\ An Empirical Test of a new flavor Classification Model: the Flavor Styles Cube (FSC)
}

P.R. Klosse, A.B. Cramwinckel, F. Schevers, W.H.M. Saris, J.C.M. van Trijp, I.A. van der Lans

Kevwords: classification, human taste, flavor, food, mouthfeel, richness of flavor, flavor styles, Flavor Styles Cube, food marketing

Submitted.

\begin{abstract}
Flavor classification is important for food production and food marketing. Current approaches fall short and therefore the concept of flavor styles as alternative classification scheme was developed and tested: the Flavor Styles Cube (FSC). The structure for this classification was found by distinguishing 'contracting', 'coating' and 'richness of flavor'. Contracting and coating are two dimensions of mouthfeel, indicating the importance of mouthfeel in flavor perception. Richness of flavor is the third dimension; depending on the presence of these three dimensions eight flavor styles are defined. Together they constitute the Flavor Styles Cube, a model that is already widely applied in culinary practices for the composition of dishes and their combination with wines (e.g. Klosse, 2003). To validate this empirical model a study was executed to rate 48 well known food products on the different characteristics of the flavor styles by 166 consumers with general interest in taste and flavor. A factor analysis resulted in eight factors representing flavor styles, explaining $70.7 \%$ of the variance. The flavor styles were labeled as: neutral, round, fresh, balance low, dry, pungent, full, and balance high. Furthermore, the three dimensional structure underlying this classification system was analyzed, explaining $45.8 \%$ of the variance. Finally, the factor structure was (procrustes) rotated toward the theoretical target structure. The expected position of the 48 products was compared to their actual position in the Flavor Styles Cube as judged by experts. In this analysis 32 of the 48 products scored as expected. Taken together these results suggest that the Flavor Styles Cube, based on mouthfeel en richness of flavor is a plausible model for flavor classification. This classification model indicates that the complexity of variety of flavor can be reduced to only three dimensions. Therefore it may stimulate effective communication between marketing and product development to position products with desired product properties.
\end{abstract}




\subsection{Introduction}

This study posits and reports the results of an alternative system for the classification of flavor. In general, a system of classification is a practical method in order to get a better understanding of a complex subject (Costa, Dekker, Beumer. Rombouts, Jongen, 2001). it facilitates comparison of products or elements that are essentially different. A classification system calls for generalization and abstraction: the periodic table of elements is a good example, just as the color spectrum. To elaborate on light: undifferentiated there seems to be only intensities of white light; when broken down the colors of the rainbow appear in order of their wavelengths. Understanding the spectrum and colors as reflection of light facilitates the use of colors and communication, based on objective parameters.

As there is currently no practical system to classify flavors, food marketing and production just have the (non) color 'white' to work with, which impedes communication and comprehension of flavor as a whole. Therefore there is an ongoing process in trying to get a better understanding of flavor and finding a basis for classification. Ever since Aristotle (384 - $322 \mathrm{BC})$, attempts have been undertaken to describe basic taste qualities. Linda Bartoshuk (1978) gives a detailed historical overview in the Handbook of Perception. Throughout history the 'four basic flavors' sweet, sour, salty, and bitter are mentioned. Sometimes new elements were added, which were later rejected by others. For instance, Aristotle recognized astringent, pungent, and harsh, besides the 'basic' four. In 1581 Fernel added fatty and insipid (tasteless). In 1825 Horn mentioned alkaline (but not the other tastes). and in 1880 Wundt mentioned metallic. In 1916 Henning constructed the 'taste tetrahedron'. He placed sweet, sour, bitter and saline at the four corners of this figure. According to Henning these were not 'basic' tastes, but rather points of reference to which other tastes could be related. He described a continuum of many tastes along the edges and surfaces of his tetrahedron. Different compositions of the basic elements lead to distinct flavors, just as different colors mix easily to become a new color (Erickson, 2000).

Despite all these efforts, the matter of creating a structure based on basic taste qualities remains unresolved. However, the 'four-basic-taste-assumption' (FBT) has continued to dominate the scientific field, and although it is subject to discussion it has remained largely without systematic appraisal and it did not lead to systematic classification of flavor (Delwiche, 1996: Schiffman, 2000a; Breslin, 2001). Even the 'tongue map', commonly reproduced in textbooks, is wrong (Smith \& Margolskee, 2001). In his review Erickson (2000) concluded that the lack of systemization has cost the field of chemical senses dearly. 
One likely explanation for the failure of finding a structure based on the FBT may be that it focuses only on the 'basic flavors' of the gustatory system, which is just one of the neural systems that is actively involved in flavor registration. Therefore the FBT is not likely to serve as a basis for flavor classification (i.e. Wardle et al., 2001; Erickson, 2000). Contrarily the fundamental ISO definition of flavor does offer a new perspective to classify the world of flavor. It defines flavor as the complex combination of the gustatory, olfactory and trigeminal sensations perceived during tasting. Flavor may be influenced by tactile, thermal, painful and/or kinaesthesic effects (ISO 5492: 1992 Glossary of Terms Relating to Sensory Analysis). This characterization implies that the human experiences with foods are syntheses of many sensations, including gustation, olfaction, texture, temperature, fluidity, chemical irritation, etc. (Prescott, 1999). The concept of 'flavor' should be considered as a holistic, integrative, multi-sensorial perception, in which basically all senses are involved.

The ISO definition essentially makes a distinction in the gustatory and olfactory registration on the one hand and trigeminal components on the other. Apparently these trigeminal effects are found to be important or different enough to emphasize their specific role in a separate sentence. As the neural trigeminal system is basically involved in the sensory registration of 'touch', the term 'mouthfeel' would aptly cover all trigeminal effects in flavor registration. 'Flavor richness' on the other hand could be used as the general term for the result of the other principal neural systems involved in flavor registration, gustation and olfaction. It was hypothesized that a model could be developed by making a distinction within mouthfeel in two major groups: coating and contracting elements. These two dimensions, together with flavor richness as the third dimension, form the basic structure of the Flavor Styles Cube (FSC), in which eight sub cubes can be distinguished: the flavor styles. This model which actually classifies flavor in eight distinct groups based on similarity in characteristics is described below in further detail.

To posit and validate the concept of flavor styles, products were selected and scored on attributes that could describe the various flavor styles. Based on factor analysis the flavor styles were labeled. Further analyses were executed to confirm the three-dimenslonal structure of the model and to compare the found positions of the products with their expected positions. The results are used to assess this system of flavor classification system based on 'mouthfeel' and 'richness of flavor' as independent variables. 


\subsection{Materials and methods}

\subsubsection{Description of the empirical flavor style model}

The FSC and the subsequent flavor styles were developed in daily practice and are already being applied in culinary practice (Klosse, 2003). In flavor, mouthfeel and flavor richness go hand in hand: every flavor is a combination of the two. In mouthfeel, the origin of the two main dimensions contracting and coating can be very different. Contraction in mouthfeel can be caused by i.e. salts, acids, dryness, cold or irritating substances such as capsaicin. Coating elements are i.e. fatty, sweet (sugar) and jelly-like components. In the flavor of foods or drinks both coating and contracting elements are often present, and their mutual proportions determine mouthfeel. A basic example is vinaigrette where the contracting force of vinegar is counterbalanced by the oil (coating). Depending on the proportion of both components, the mouthfeel of the vinaigrette can be characterized as coating or contracting. It can also be characterized as balanced if neither the vinegar, as contracting force, nor the oil as coating force dominates the flavor profile of the vinaigrette. Coating and contracting forces can be rated from low to high and consequently, within mouthfeel, four quadrants can de distinguished. Other elements like the quality of the oil and vinegar used, the addition of i.e. sait, pepper. mustard, honey and herbs will influence flavor richness, which is considered to be the third dimension, as is illustrated in figure 3-1.

\section{As flavor richness can also} be rated from low to high, a set of eight different lowhigh combinations of coating. contracting and flavor richness can be extracted from this basic structure (table 3-1). A flavor style is considered to be characterized by a specific low-high combination of three dimensions of flavor. Figure 3-2 illustrates the location of each flavor style within the FSC.

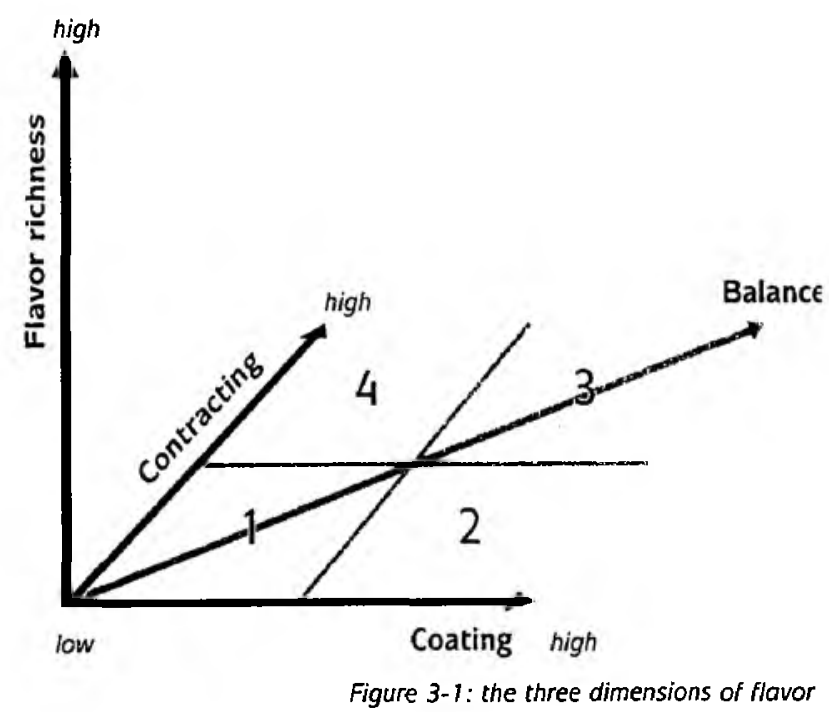




\begin{tabular}{|l|l|l|l|}
\hline \multirow{2}{*}{$\begin{array}{l}\text { Table 3-1 } \\
\text { FLAVOR STYLE }\end{array}$} & \multicolumn{3}{|c|}{ PRIMARY FLAVOR DIMENSIONS } \\
\cline { 2 - 4 } & COATING & CONTRACTING & FLAVOR RICHNESS \\
\hline 1 & Low & Low & Low \\
\hline 2 & High & Low & Low \\
\hline 3 & High & High & Low \\
\hline 4 & Low & High & Low \\
\hline 5 & Low & Low & High \\
\hline 6 & High & Low & High \\
\hline 7 & High & High & High \\
\hline 8 & Low & High & High \\
\hline
\end{tabular}

Table 3-1: The basic characteristics of flavor styles

Foods and drinks are complex mixtures of different components. This implies that individual components influence each other. Changes in mixtures may lead to different profiles. This implicates that the position of real foods or drinks in the FSC is dynamic. The three dimensional structure of

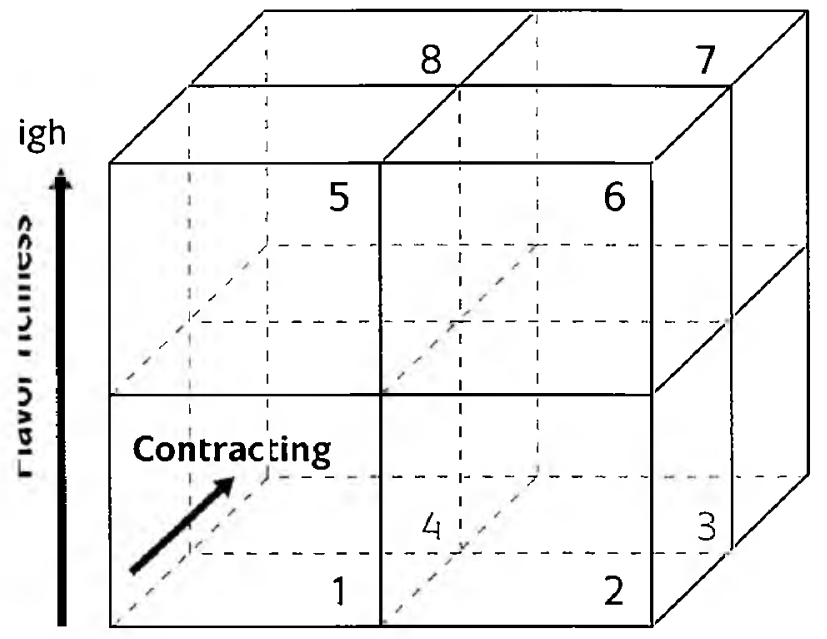

ow

High

\section{Coating}

gure 3-2: the empirical model of the FSC the FSC implies that ail flavors can be positioned within the cube. The cor-ners represent 'clear flavors'. Products that are positioned close to a specific corner can be considered to be 'icons' of that specific flavor style. Flavor styles within the cube that lie above each other are closely associated. These flavors resemble in mouthfeel but differ in flavor richness; their basic characteristics are discussed tentatively below. 


\section{Flavor stvles 7-5. 'neutral' and 'robust'}

Flavor style 1 represents 'flavorless' or very little flavor both in 'mouthfeel' and in 'richness of flavor'. Distilled water can be situated close to this corner. In the history of flavor classification Fernel proposed at one time the term 'insipid' (Bartoshuk, 1978). A term that still exists these days but it has a negative association. We prefer to use value-free terms as indications for the specific flavor styles. 'Neutral' would be an appropriate term to characterize this flavor style. Flavor style 5 is the extension of style 1 and is characterized by 'robust'. In practice robustness can be associated to a certain dryness. Several influences may account for dryness. The first is absorption of saliva as happens with dry solid foods such as toast, biscuits, crackers, and chips. Next, tannins are known to affect saliva making the mouth rough (Kallithraka, Bakker, Clifford, Vallis, 2001). Astringency is the appropriate term for this kind of bitterness; it is a trigeminal sensation rather than a gustatory stimulus. Some young red wines can be 'drying' or 'puckering' (Gawel, lland. Francis, 2001). Likewise some other bitter tasting substances like strong coffee or tea and pure chocolate with a high percentage of cocoa can be astringent, bitter or acrid (Drewnowski \& GomezCarneros. 2000). The flavor qualities 'harsh' and 'astringent', that were originally included in the classification of flavor by Aristotle, would fit here (Bartoshuk, 1978). It may be noted that although the characteristics of products around corner 5 may not always be instantly pleasant to consume. Their role can be functional in relation to other food components.

\section{Flavor stvles 2-6. 'round' and 'full'}

Both styles are characterized by the thin and coating layer that is left behind in the oral cavity by fats and dissolved sugars (Rolls, Critchley, Browning, Hernadi \& Lenard, 1999; Valentová \& Pokorný, 1998). Fatty as a flavor characteristic was also introduced by Fernel (Bartoshuk, 1978), and sweet has always been recognized. However different, both elements share that they are coating in mouthfeel. Physiologically these aspects of flavor are sensed by the mechanoreceptors of the trigeminal system. Their acuity is quite remarkable: differences in viscosity as small as $1 \mathrm{mPa}$ can be sensed and particles as small as $5 \mu \mathrm{m}$ can be detected (Guinard, 1996). The difference between flavor style 2 and 6 is explained by flavor richness.

\section{Flavor stules 3-7. 'balance'. from low to high}

Flavor becomes balanced if coating and contracting forces compensate each other. Furchermore we propose that umami (often referred to as fifth basic flavor) 
is principally active in these flavor styles, and especially as flavor richness increases. Basically umami stands for the taste that is enticed by glutamic acid. It is widely used in the food industry to enhance flavor, palatability and overall preference (Schiffman, 2000b). Statistical analysis of terms that are used to describe umami flavor, showed a correlation with ratings for complexity. mildness, brothy, and meaty (Fuke \& Ueda, 1996). These are descriptions of flavor that would perfectly suit these styles. Furthermore, in perception umami is reported to be transduced by special G-protein-coupled receptors, different from the effect of sweet, fats, acids, and salt, which justifies its separate position, (Gilbertson, Damak, \& Margolskee, 2000).

\section{Flavor Stvles 4-8. 'fresh' and 'Dunaent'}

Flavor styles $4-8$ are basically characterized by contraction in the oral cavity. Acids and salts are weil-known substances that have a contracting influence. Acidity is also reported to increase saliva flow (Guinard, Zoumas-Morse \& Walchak, 1998). Physiologically these substances are reported to enter the ion-channel of taste cells directly (Gilbertson, 2000; Smith \& Margolskee, 2001). Flavor style 8 represents the physiological influences of oral irritants, like capsaicin, gingerone, and $\mathrm{CO}_{2}$, which ail activate trigeminal pain pathways (Carstens et al., 2002). Those reactions are mediated by the nociceptors of the trigeminal system that also enter directly into ion-channels (McCleskey \& Gold, 1999).

\subsubsection{Selection of products and target structure}

In order to test the flavor styles three general and descriptive flavor characteristics were selected per group, twenty-four in total (table 3-2).

\begin{tabular}{|l|l|}
\hline $\begin{array}{l}\text { Table 3-2 } \\
\text { FLAVOR STYLE }\end{array}$ & FLAVOR CHARACTERISTICS/ATTRIBUTES \\
\hline 1 & Light flavored, neutral, light \\
\hline 2 & Smooth, supple, creamy \\
\hline 3 & Can be eaten/drunk continually, simple, stable \\
\hline 4 & Sour, contracting, fresh \\
\hline 5 & Robust, solid, power ful \\
\hline 6 & Full flavor, ripe flavor, filling \\
\hline 7 & Complex, differentiated, subtle \\
\hline 8 & Spicy, hot, explosive \\
\hline
\end{tabular}

Table 3-2: descriptive terms for each flavor style 
Table 3-3 shows the hypothesized structure of factor loadings against the fundamental dimensions of the FSC. This structure will later be used in the procrustes analysis to evaluate the results of the exploratory factor analysis. In this structure low $=0$, and high $=1$. If a flavor style is characterized by more than one dimension, the value is 0,707 ( 2 dimensions) and 0,577 ( 3 dimensions) keeping the sum of the squared loadings at 1.

\begin{tabular}{|c|c|c|c|}
\hline \multirow[t]{2}{*}{ Table 3-3 } & \multicolumn{3}{|c|}{ TARGET MATRIX } \\
\hline & COATING & CONTRACTING & RICHNESS \\
\hline light (1) & 0 & 0 & 0 \\
\hline light flavored (1) & 0 & 0 & 0 \\
\hline neutral (1) & 0 & 0 & 0 \\
\hline supple (2) & 1 & 0 & 0 \\
\hline creamy (2) & 1 & 0 & 0 \\
\hline smooth (2) & 1 & 0 & 0 \\
\hline stable (3) & .707 & .707 & 0 \\
\hline Can be eaten/drunk continually (3) & .707 & .707 & 0 \\
\hline simple (3) & .707 &, 707 & 0 \\
\hline Contracting (4) & 0 & 1 & 0 \\
\hline fresh (4) & 0 & 1 & 0 \\
\hline sour (4) & 0 & 1 & 0 \\
\hline powerful (5) & 0 & 0 & 1 \\
\hline robust (5) & 0 & 0 & 1 \\
\hline solid (5) & 0 & 0 & 1 \\
\hline ripe flavor (6) &, 707 & 0 &, 707 \\
\hline full flavor $(6)$ & .707 & 0 & .707 \\
\hline filling (6) & .707 & 0 &, 707 \\
\hline differentiated (7) & .577 & .577 & .577 \\
\hline subtle (7) & .577 & .577 & .577 \\
\hline complex (7) & .577 &, 577 &, 577 \\
\hline explosive (8) & 0 & .707 & .707 \\
\hline spicy (8) & 0 & .707 & .707 \\
\hline hot $(8)$ & 0 & .707 & .707 \\
\hline
\end{tabular}

Table 3-3: target matrix.

Next, consumers should be able to characterize different kinds of foods using the selected attributes. In the design of the study the products were primarily selected for the characterization of the flavor attributes, and not as representatives of distinct flavor 
styles. In subsequent analysis the results were used to find the respective position of the food products and to compare these positions with their expected flavor styles.

Yet, the selected products had to meet a number of requirements:

- The participants should know the products very well.

- The differences between the various brands of a product should be minimal, because otherwise the participants would be assessing different products. Differences in ratings should not be attributable to differences in brands, but should be based on 'blind' differences in flavor between products.

- The products should be very different and cover a broad range to allow a test on the generic nature of the FSC classification scheme.

- An a priori classification of the products should be available to evaluate the results of repositioning the products in the FSC.

To ensure statistical power the number of items studied in a factor analysis should be twice the number of variables (Moskowitz, 1994; Powers, 1984). Table 3-4 shows the list of products included in this study. Each of these products was classified according to the FSC model by two of the authors who are acquainted with the model (expert judges). In table 3-4 the hypothesized flavor style of each product is given in brackets.

\begin{tabular}{|l|l|l|}
\hline \multicolumn{2}{|l|}{ PRODUCTS } \\
\hline Bable 3-4 & Fresh orange juice (4) & Apple turnover (7) \\
\hline Rusk (biscuit) (5) & Potato chips (1) & Pickle (4) \\
\hline Brie cheese (7) & Cream puffs (2) & Mocha coffee (5) \\
\hline $\begin{array}{l}\text { Carbonated mineral } \\
\text { water (4) }\end{array}$ & $\begin{array}{l}\text { Strawberry yogurt, } \\
\text { low fat (3) }\end{array}$ & $\begin{array}{l}\text { Speculaas, } \\
\text { typical Dutch (5) }\end{array}$ \\
\hline Chocolate custard (2) & Hard boiled egg (1) & Tea (5) \\
\hline Green peas (2) & Frankfurter (3) & Orange soda (4) \\
\hline Salted peanuts (5) & Currant bun (3) & Iceberg lettuce (4) \\
\hline Milk, low fat (2) & Yogurt, high fat (3) & Buttermilk (4) \\
\hline Honey (6) & Treacle wafer (7) & Cucumber (1) \\
\hline Young Gouda cheese (2) & Sweet popcorn (2) & Pickled onions (4) \\
\hline Prawn crackers (5) & Vanilla yogurt (6) & Beer, plain (4) \\
\hline Old Gouda Cheese (5) & Milk/hazelnut chocolate (2) & Pure chocolate (5) \\
\hline Whipped cream (6) & Licorice (3) & Carrot, raw (1) \\
\hline Plain spaghetti, no sauce (2) & Russian salad (7) & White rice (2) \\
\hline Wheat bread (1) & Liver sausage (6) & Cottage cheese (8) \\
\hline Vanilla custard (2) & Breakfast cake (5) & Jce cream (2) \\
\hline
\end{tabular}

Table 3-4: products with their hypothesized flavor style 


\subsubsection{Testing the empirical model}

A questionnaire containing closed format questions was developed, asking participants to score these well-known and popular food products on the flavor characteristics on a scale from $0-10$. The products were randomly numbered 1-48. The design required the participants to rate 48 products on 24 flavor characteristics. To solve the problem of compliance, the participants were randomly subdivided; each group rated 16 products on the 24 characteristics. Every group had to rate a different combination of products, which resulted in the following configuration:

- Group 1 rated products 1 through 16

- Group 2 rated products 17 through 32

- Group 3 rated products 33 through 48

- Group 4 rated products 9 through 24

- Group 5 rated products 25 through 40

- Group 6 rated products 1 through 8 and 41 through 48

For this study subjects were selected from the CSO panel. This panel contains over 5.000 people who have participated in flavor research before. This makes the panel members' population not representative of the general Dutch population. In this case that was not an impediment, because the questions were analytical, not hedonic, and dealt with the description of flavor characteristics. Although the respondents did not actually taste the products, they were nevertheless able to describe their characteristics, since all products were well known and commercially available. Considering the character of the questionnaire (the time to complete a questionnaire was estimated to be $30 \mathrm{~min}$.) a considerable non-response was expected and it was decided to initially distribute 100 questionnaires per group, 600 in total. The participants were recruited from the CSO's panel members' database (CSO is the Dutch Center of Flavor research). Care was taken to have an equal distribution among the groups in demographic variables. Furthermore, the minimum age criterion was 18 . This age constraint was used because people from the age of 18 onwards often independently determine what they eat, and have sufficient language skills to be able to participate in this type of research.

To validate this flavor classification model factor analysis was applied to the data (SPSS). The varimax was selected in order to generate an orthogonal rotation of factors with Kaiser Normalization. The convergence was achieved in 14 iterations. Next, the results were forced into three factors to evaluate the three-dimensional structure of the model. Because the orientation of dimensions in exploratory factor analysis is towards maximum variance rather then substantive interpretation. 
procrustes analysis was executed to rotate the factor structure towards the hypothesized target structure depicted in table 3-3. This analysis enabled us to locate each product's position vis à vis the hypothesized FSC dimensions and to identify its flavor style from consumer ratings. These product positions were subsequently compared to their expected flavor styles as evaluated by expert judges (see table 3-4).

\subsection{Results}

\subsubsection{Subject characteristics}

In total 166 valid questionnaires were returned (response rate: $29.8 \%$ ). Within the different groups the number of respondents varied from 23 to 31 . Gender and demographic variables did not differ between the groups. $41.6 \%$ were male and $58.4 \%$ female. The major part of the respondents $(84.3 \%)$ was 50 years or younger. The age class 36-50 was best represented with $36.1 \% .26$ respondents were over 50. All respondents had the Dutch nationality. The largest group of respondents $(32.3 \%)$ had intermediate vocational education as maximum educational level.

\subsubsection{The hypothesized eight factorial structure of the FSC}

To expose the factorial structure underlying the consumer ratings, a factor analysis was performed, forcing the $\mathbf{2 4}$ characteristics of the FSC into eight factors. Three attributes were not used by the respondents. It was concluded that these characteristics did not contribute to the eight dimensional structure. Therefore on the basis of low communalities these three attributes 'subtle', 'stable', and 'explosive' were excluded from further the analysis, leaving 21 flavor characteristics (see table 3-5). The eight dimensional factor structure accounted for $70,7 \%$ of the variance in consumer ratings. The results are shown in table 3-5; for reasons of clarity only loadings $>0,1$ are shown.

The hypothesized structure is well reproduced in this analysis. Our dimensional interpretation is based on factor loadings greater than 0.3 . In six of the eight cases the highest factor loadings per factor came from variables that belong to one flavor style of the FSC. 'Creamy' (Flavor style 2) has a high loading on both factors E and F. This double loading is explained by the fact that flavor style 6 is right above flavor style 2 in the cube. The difference between the two flavor styles was explained by the characteristics 'supple' and 'smooth' (low richness of flavor) of flavor style 2 and 'full flavor' and 'ripe flavor' (high richness of flavor) that characterized flavor style 6. The same applies to factor $H$ (flavor style 3) and factor $G$ (flavor style 7). Again, both 


\begin{tabular}{|c|c|c|c|c|c|c|c|c|}
\hline \multirow[t]{3}{*}{ Table 3-5 } & \multicolumn{8}{|c|}{ ROTATED FACTOR MATRIX } \\
\hline & \multicolumn{8}{|c|}{ FACTOR } \\
\hline & A & B & C & $\mathbf{D}$ & $E$ & $\mathbf{F}$ & G & $H$ \\
\hline Spicy (8) &, 819 & .189 & & & & & .125 & \\
\hline Hot (8) & .797 & .200 & $-, 11\}$ & .119 & & & & \\
\hline Powerful (5) & .503 & .432 &,- 169 & .149 & .196 & .117 & .141 & .254 \\
\hline Differentiated (7) & .436 & .282 & & .107 & & .275 & .386 & \\
\hline Robust (5) & .349 & .684 & & .141 & .109 & .148 & & \\
\hline Solid (5) & .186 & .619 & & & & .104 & & \\
\hline Ripe flavor (6) & .372 & .401 & & .166 & .116 & .344 & .123 & \\
\hline Light flavored (1) & & & .723 & & .104 & & & .176 \\
\hline Neutral (1) & & .183 &, 579 & & &,- 166 & -.202 & \\
\hline Light (1) & & & .579 & & .183 & .164 & & \\
\hline Sour (4) & .103 & & &, 798 & & & & \\
\hline Contracting (4) & .230 & .210 & & .593 & & & & \\
\hline Fresh (4) & & -.138 & .238 &, 563 & .280 & & & .239 \\
\hline Smooth (2) & & & .120 & .202 & .749 & & & .115 \\
\hline Supple (2) & & .147 & .264 & & .629 & .166 & & \\
\hline Full flavor (6) & .162 & .319 & & & .197 & .632 & & .165 \\
\hline Creamy (2) & & & & & .494 & .539 & & \\
\hline Filling (6) & & .285 & &,- 108 & & .287 & & \\
\hline Complex (7) & .213 & .312 & & & & .137 &, 573 & \\
\hline Simple (3) & -.157 & & .320 & & & &,- 397 &, 340 \\
\hline $\begin{array}{l}\text { Can be eaten/ } \\
\text { drunk continually (3) }\end{array}$ & & & .220 & & & & & .535 \\
\hline Is determined by style & 8 & 5 & 1 & 4 & 2 & 6 & 7 & 3 \\
\hline
\end{tabular}

Table 3-5: Factor analysis. Extraction Method: Principal Axis Factoring.

Rotation Method: Varimax with Kaiser Normalization. Rotation converged in 14 iterations.

flavor styles are on the same side of the cube, which explains some of the double loading. As 'simple' (factor $\mathrm{H}$ ) is the opposite of 'differentiated' and 'complex' (factor $G)$, the factor loading was negative in this case. Factor $A$ and $B$ showed an overlap in characteristics. The difference in these two factors is characterized by 'spicy' and 'hot' (factor A) and 'solid' (factor B). In the FSC factor A was therefore labeled 'pungent' and characterizes flavor style 8 , while factor B fits flavor style 5 . The eight factors that were found characterized the flavor styles of the FSC. 


\subsubsection{Restructuring the three dimensional FSC structure}

The next step in the analysis was to test whether these eight factors remained clustered with their characteristics in a three-dimensional structure. A factor analysis that forces a three-factor solution is shown in table 3-6. It accounted for $45.8 \%$ of the variance. Table 3-6 shows that factor $X$ was mainly determined by the characteristics of flavor styles $5,6,7$ en 8 . Consequently, factor $X$ is best described as 'high richness of flavor'. Factor $Z$ is best described as 'contracting mouthfeel', because this factor was mainly determined by the characteristics of flavor style 4. Factor $Y$ was mainly determined by the characteristics of flavor styles 1, 2 and 3. Apparently, 'coating mouthfeel' and 'low richness of flavor' were categorized together under this factor. One would expect the characteristics of flavor style 1 to have a negative loading on all three dimensions. However, factor analysis searches first for similarities between items. In the ratings, there must have been similarities between the characteristics of flavor styles 1 . 2 and 3 . In a four-factor analysis flavor style 1 came out separately. This implies that the eight factors can be reduced to a three-dimensional model based on contracting, coating and richness of flavor.

\begin{tabular}{|c|c|c|c|}
\hline \multirow[t]{3}{*}{ Table 3-6 } & FACTO & MATRI & \\
\hline & \multicolumn{3}{|c|}{ FACTOR } \\
\hline & $x$ & $Y$ & $z$ \\
\hline Powerful (5) &, 710 & & \\
\hline Robust (5) & ,704 & & \\
\hline Differentiated (7) & .666 & & \\
\hline Ripe flavor (6) & .658 & & \\
\hline Spicy (8) & .649 & & \\
\hline Hor (8) & .638 &,- 265 & \\
\hline Full flavor (6) & .575 & & \\
\hline Solid (5) & .539 & & \\
\hline Complex (7) & .538 & & \\
\hline Filling $(6)$ & .328 & & \\
\hline Supple (2) & &, 583 & \\
\hline Light flavored (1) & &, 581 & \\
\hline Lighr (1) & &, 557 & \\
\hline Smooth (2) & & .529 & .285 \\
\hline Neutral (1) & & .434 & \\
\hline Creamy (2) & .319 & .428 & \\
\hline Simple (3) & & .370 & \\
\hline \multicolumn{4}{|l|}{ Can be eaten/ } \\
\hline drunk continually (3) & & .277 & \\
\hline Sour (4) & & &, 765 \\
\hline Contracting (4) & .292 & & .584 \\
\hline Fresh (4) & & .447 &, 566 \\
\hline $\begin{array}{l}\text { Extraction Method: } \\
\text { Principal Axis Factori } \\
\text { Rotation Method: } \\
\text { Varimax with Kaiser N } \\
\text { a Rotation converged }\end{array}$ & alizatio & & \\
\hline
\end{tabular}

Table 3-6:Three factor analysis confirms threedimensional structure

The number in parentheses after each item in the first column refers to the flavor styles in the Flavor Styles Cube of which the item is a characteristic. For the sake of clarity only numbers $>0.25$ were included in the table. 


\subsubsection{Confirming the three factor structure of the FSC}

Exploratory factor analysis with varimax rotation orients the three dimensionai structure in the direction of maximum variance in product ratings. For our purposes this is in a sense an arbitrary orientation in space. At this stage it is tested whether the factor analysis solution is an orthogonal rotation of the target solution structure of the FSC. The axes were rotated to assess the fit of the found structure. The data fit the hypothesized structure quite well as is evidenced by the procrustes fit idices. The sum of squares from origin accounted for (with shrinkage factor) is 0,67 and the tucker coefficients (Zegers \& Ten Berge, 1985) per dimension are respectively 0,75 for coating, 0,77 for contracting and 0,91 for richness.

Table 3-7 shows the results; the values over 0,500 are put in bold, and together they show a good fit of the found structure. There are also interesting negative correlations: the dimension 'coating' is defined as not spicy, hot, or sour; the dimension 'contracting' is not simple, light flavored, filling, or neutral; and 'flavor richness' is not simple. fresh, smooth, light flavored, light, neutral, or sour.

\begin{tabular}{|l|c|c|c|}
\hline \multicolumn{4}{|c|}{ COATING } \\
Table 3-7 \\
\hline $\begin{array}{l}\text { Complex } \\
\text { Can be } \\
\text { eaten/drunk }\end{array}$ & .194 & .128 & .488 \\
\hline continually & .298 & .045 & .027 \\
\hline Simple & .297 & -.053 & -.292 \\
\hline Fresh & .371 & .557 & -.274 \\
\hline Smooth & .518 & .309 & -.098 \\
\hline Powerful & .188 & .313 & .642 \\
\hline Spicy & -.042 & .254 & .660 \\
\hline light flavored & .517 & -.058 & -.296 \\
\hline Light & .550 & .030 & -.107 \\
\hline Filling & .275 & -.116 & .282 \\
\hline Contracting & .012 & .622 & .200 \\
\hline Neutral & .388 & -.089 & -.217 \\
\hline Hot & -.077 & .297 & .651 \\
\hline Differentiated & .175 & .201 & .618 \\
\hline ripe flavor & .298 & .235 & .565 \\
\hline Robust & .255 & .203 & .633 \\
\hline Creamy & .501 & .076 & .168 \\
\hline Supple & .611 & .152 & .006 \\
\hline Solid & .218 & .004 & .504 \\
\hline full flavor & .377 & .117 & .472 \\
\hline Sour & -.042 & .767 & -.037 \\
\hline
\end{tabular}

Table 3-7: result of procrustes analysis: rotation to target matrix; SS from origin accounted for (with shrinkage factor): 0,67: Tucker correlation coefficients per dimension: coating 0.75 ; contracting 0.78 ; richness 0.91 


\subsubsection{Evaluation of product positions in the Flavor Styles Cube}

It is now possible to locate the products against the procrustes-rotated factor structure to validate their position and to compare it with their hypothesized flavor style. We have taken an (arbitrary) cut-off point for each dimension to classify products as high versus low on that particular dimension (see table 3-1). Based on that information each product can uniquely be classified into a distinct flavor style and compared to the hypothesized flavor style. The results of this analysis are presented in table $3-8$. In doing so, 32 out of the 48 products scored as theoretically expected. However, the cut-off value where low becomes high is arbitrary. Therefore, a few aspects need to be addressed.

Firstly, in the design of the study, basically flavor characteristics were selected that were supposed to describe the flavor styles of the FSC, then well known consumer products were chosen to be scored on these attributes. The products were not specifically selected to represent a certain flavor style. Consequently, the set of products in this study is not evenly distributed or balanced. This is illustrated for instance in the absence of hot, spicy products that could be classified as 'pungent'.

Secondly, well-known products were used, but the products were not actually tasted. Differences in cooking habits may lead to different flavor styles of products which are the result of a cooking process, such as spaghetti and white rice. To mention an example: well cooked spaghetti is soft and coating; a shorter cooking time ( $a$ dente) gives another texture which is not as coating as the first. The expected flavor styles were determined by two of the authors and based on their judgment of the products and without the use of traditional panels. This illustrates the practical use of flavor styles.

Two products, Brie and white rice (identified with ") scored exactly 0.00 , which indicates that these products could also have been classified as flavor style 6 (Brie) and 1 (white rice), which also would not be unfitting. 


\begin{tabular}{|c|c|c|c|c|c|c|}
\hline \multicolumn{7}{|c|}{ Table 3-8 } \\
\hline \multirow[t]{2}{*}{ NR } & \multirow[t]{2}{*}{ PRODUCT } & \multicolumn{2}{|c|}{ COATING } & \multicolumn{2}{|c|}{ RICHNESS } & \multirow{2}{*}{ EXPECTED } \\
\hline & & \multicolumn{3}{|c|}{ CONTRACTING } & FOUND & \\
\hline 1 & egg, hard boiled & $-0,21$ & $-0,62$ & -0.05 & 1 & 1 \\
\hline 2 & Potato chips & -0.39 & -0.38 & $-0,16$ & 1 & 1 \\
\hline 3 & Carrot, raw & $-0,12$ & $-0,02$ & -0.55 & 1 & 1 \\
\hline 4 & Chocolate custard & 0.81 & $-0,20$ & $-0,12$ & 2 & 2 \\
\hline 5 & Green peas & 0,05 & $-0,49$ & $-0,31$ & 2 & 2 \\
\hline 6 & milk (low fat) & 0,65 & $-0,07$ & $-0,91$ & 2 & 2 \\
\hline 7 & Young Gouda Cheese & 0,48 & $-0,32$ & $-0,34$ & 2 & 2 \\
\hline 8 & ice cream & 1.08 & -0.03 & $-0,51$ & 2 & 2 \\
\hline 9 & Cream puffs & 0,82 & $-0,36$ & $-0,39$ & 2 & 2 \\
\hline 10 & Spagherti & 0,13 & -0.79 & -0.84 & 2 & 2 \\
\hline 11 & Vanilla custard & 1.03 & $-0,24$ & -0.49 & 2 & 2 \\
\hline 12 & White rice $^{*}$ & 0,00 & $-0,81$ & $-0,45$ & 2 & 2 \\
\hline 13 & Strawberry yogurt (low fat) & 0.75 & 0,51 & $-0,54$ & 3 & 3 \\
\hline 14 & Boiled potato & 0.16 & 0,48 & $-0,35$ & 3 & 3 \\
\hline 15 & Yogurt, full & 0,72 & 1,00 & $-0,51$ & 3 & 3 \\
\hline 16 & Pickle & -0.76 & 2,18 & $-0,34$ & 4 & 4 \\
\hline 17 & Buttermilk & $-0,06$ & 1.45 & $-0,92$ & 4 & 4 \\
\hline 18 & Orange soda & $-0,35$ & 0.73 & $-0,82$ & 4 & 4 \\
\hline 19 & fresh orange juice & -0.15 & 1.39 & $-0,27$ & 4 & 4 \\
\hline 20 & Pickled onions & $-0,86$ & 1.85 & -0.22 & 4 & 4 \\
\hline 21 & Tea & $-0,27$ & -0.66 & 0,26 & 5 & 5 \\
\hline 22 & Salted peanuts & $-0,64$ & $-0.4 \overline{3}$ & 0,49 & 5 & 5 \\
\hline 23 & Prawn crackers & $-0,45$ & $-0,41$ & 0,04 & 5 & 5 \\
\hline 24 & Breakfast cake & $-0,32$ & -0.39 & 0.52 & 5 & 5 \\
\hline 25 & pure chocolate & $-0,31$ & $-0,08$ & 0,84 & 5 & 5 \\
\hline 26 & Speculaas & $-0,52$ & -0.37 & 0,97 & 5 & 5 \\
\hline 27 & Honey & 0,05 & $-0,14$ & 0,14 & 6 & 6 \\
\hline 28 & Whipped cream & 0,09 & -0.36 & 0,44 & 6 & 6 \\
\hline 29 & Vanilla yogurt & 0.59 & -0.30 & 0.10 & 6 & 6 \\
\hline 30 & apple turnover & 0,07 & 0.26 & 0,03 & 7 & 7 \\
\hline 31 & brie $^{*}$ & 0,48 & 0.00 & 0,88 & 7 & 7 \\
\hline 32 & cottage cheese & $-0,75$ & 0.33 & 1,52 & 8 & 8 \\
\hline 33 & sweet popcorn & $-0,09$ & $-0,7 \overline{4}$ & $-0,21$ & 1 & 2 \\
\hline 34 & Rusk & 0,03 & -0.87 & -0.76 & 2 & 5 \\
\hline 35 & Carbonated min. water & 0.51 & 0,03 & $-1,52$ & 3 & 4 \\
\hline 36 & Iceberg lettuce & 0,08 & 0.03 & -1.05 & 3 & 4 \\
\hline 37 & Plain beer & 0,08 & 0,71 & $-0,06$ & 3 & 4 \\
\hline 38 & Frankfurter & $-0,45$ & $-0,31$ & 0,13 & 5 & 3 \\
\hline 39 & Currant bun & $-0,38$ & $-0,58$ & 0.18 & 5 & 3 \\
\hline 40 & Liver sausage & $-0,32$ & $-0,16$ & 0,47 & 5 & 6 \\
\hline 41 & milk/hazelnut chocolate & $-0,04$ & $-0,40$ & 0,53 & 5 & 2 \\
\hline 42 & Licorice & -0.46 & $-0,02$ & 0.18 & 5 & 3 \\
\hline 43 & Treacle wafer & $-0,30$ & $-0,52$ & 0,39 & 5 & 7 \\
\hline 44 & Wheat bread & 0,24 & $-0,59$ & 0,16 & 6 & 1 \\
\hline 45 & Cucumber & 0,10 & 0,26 & 0,86 & 7 & 1 \\
\hline 46 & Mocha & $-0,29$ & $0,0 \overline{4}$ & 1,04 & 8 & 5 \\
\hline 47 & Russian salad & -0.07 & 0,60 & 0.56 & 8 & 7 \\
\hline 48 & old Gouda cheese & $-0,40$ & 0,26 & 1.64 & 8 & 5 \\
\hline
\end{tabular}

Toble 3-8: the repositioning of the products in the FSC, comparison between expected and found flavor style 
Analysis of the products that did not score as expected showed that in some cases the found values that cause disturbance are low. To mention a few examples: sweet popcorn, milk chocolate with hazelnuts and Russian salad scored $-0,09,-0.04$ and $-0,07$ respectively on coating; the value to score as expected should have been $>0,00$. Conversely plain draft beer and iceberg lettuce both scored 0,08 on coating, where it should have been $<0,00$ to score as expected. Likewise, mocha scored 0,04 on contracting; where it should have been $<0,00$ to score as expected. Therefore, six out of sixteen misclassified products scored close to expectation.

Rusk and wheat bread were both positioned on the coating side. This could be explained by the fact that these products are often eaten with butter and a topping. Currant bun, frankfurter, licorice, and treacle wafer did not score on coating. Apparently in these cases other product characteristics were judged as being more important, just as in the case of cucumber and old Gouda cheese. However, the high number of products that scored as expected adds much to the credibility of the FSC.

To further illustrate the results of table 3-8, examples of products that scored lowest and highest on each single dimension were put together in table 3-9.

\begin{tabular}{|l|l|l|}
\hline \multirow{2}{*}{$\begin{array}{l}\text { Table 3-9 } \\
\text { DIMENSION }\end{array}$} & \multicolumn{2}{|l|}{ PRODUCTS } \\
\cline { 2 - 3 } & LOW SCORES & HIGH SCORES \\
\hline COATING & Pickled onions, pickles, & Vanilla custard, chocolate \\
\hline & cottage cheese, saited & custard, cream puffs, milk, \\
\hline & peanuts, speculaas & vanilla yogurt \\
\hline CONTRACTING & Rusk, white rice, & Pickie, pickled onions, \\
\hline & spagherti, sweet & buttermilk, fresh orange \\
\hline & popcorn, hard boiled egg & juice, plain beer \\
\hline RICHNESS & Mineral water, iceburg & Old Gouda cheese, cottage \\
\hline & letruce, low fat milk, & cheese, mocha, speculaas, \\
\hline & spaghetti, rusk & pure chocolate \\
\hline
\end{tabular}

Table 3-9: examples of low and high scoring products on each dimension

\subsection{Conclusion}

This study was a first attempt to find empirical support for the FSC as a practical scheme to classify flavors. Within the FSC flavor styles can be determined as clusters 
of flavors that have similar characteristics in terms of 'coating', 'contracting', and 'flavor richness'. The cube is shown as figure 3-3. Support was found from different angles and based on a large consumer survey. Based on the results of the analysis, the flavor styles were labeled by one characteristic word, which may facilitate communication and the use of the FSC. The words in italics are meant to be supportive and descriptive.

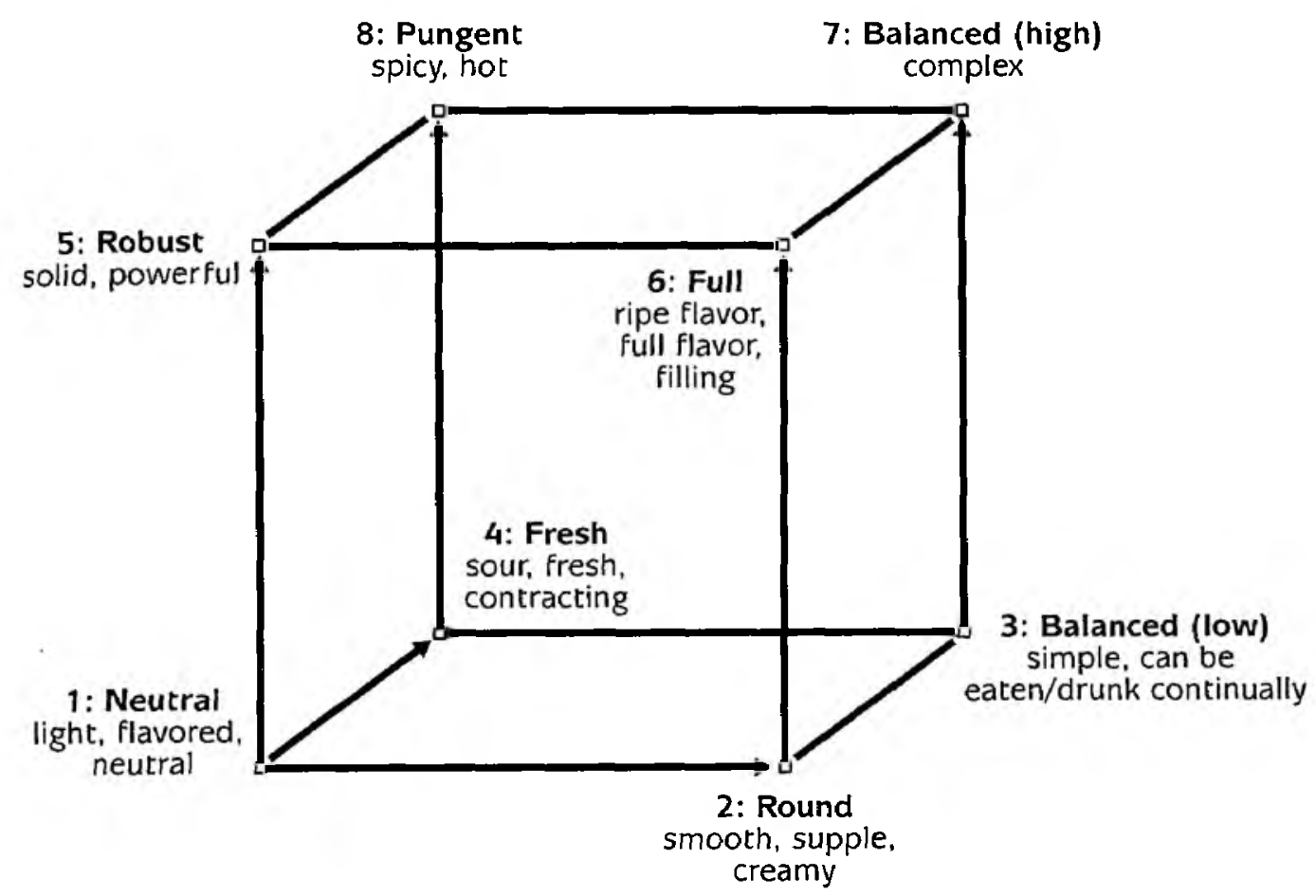

Figure 3-3: the Flavor Styles Cube

This scheme sheds new light on the world of flavor. Up to now flavor is often described and studied in terms of the so-called 'four basic flavors' sweet, acidic, salty and bitter. The ISO definition puts flavor in a broader perspective and considers it as a multi-sensory experience of gustation, olfaction and trigeminal effects. The described model of FSC is based on this integration of sensorial experiences. The difference of this system compared to the traditional one is the level of abstraction. 
Sweet, salty, acidic and bitter are more or less specific compounds, whereas contracting, coating and flavor richness are impressions resulting from the three sensory systems that are involved in the registration of flavor. The traditional 'basic flavors' find their place in the model. Not as substance but as an effect on mouthfeel and flavor richness. In this scheme sweet has a coating effect; salty, acidic and bitter are rather contracting. Their respective intensity in a distinct flavor influences flavor richness. From this model it is clear that flavors, just as colors, are considered to be on a continuum. Furthermore, flavors can be dynamic as their place within the cube is the resuit of a specific mixture of components. This model helps to get a better understanding of flavor (of a product) as the resuit of a dynamic combination of different components.

In conclusion we propose the Flavor Styles Cube as a model to classify flavors. This model communicates fundamental sensory attributes to the potential consumer and enables a segmentation of food products upon their objective, thus measurable sensory qualities. It should not be regarded as an attempt to give direct answers on palatability or liking. Palatability refers to a flavor that is pleasing to the palate, while liking can be defined as the positive human response to a certain flavor. Neither are issues in this classification. However, there is a relation as it has been shown that in making food choices people categorize foods and eating situations to simplify their decision making (Connors, Bisogni, Sobal \& Devine, 2001). There are many factors that influence food choices. Nine factors were recognized: health, mood, convenience, sensory appeal, natural content, price, weight control, familiarity and ethical concern (Steptoe, et. al., 1995). Also, expectations can exert powerful influences on sensory judgments (Tepper \& Trail, 1998). In these respects flavor classification may prove to be useful. Flavor classification could enable consumers to make their good choice. This offers a new marketing challenge: to quantify flavor segments for specific food categories and potentially to develop products for specific segments. The advantage of this model is in this respect, that non identical products are classified upon their flavor style. Information about the popularity of a flavor style in one category may give an indication of the size of the segment in other categories.

Experiences based on the empirical model of flavor styles (Klosse, 2003) show that the concept of flavor styles is indeed useful in the selection of flavors that fit the individual preference of consumers or the situation they are in. Flavor styles may facilitate consumers in selecting foods that correspond to their expectation. This holds especially for product categories in which various flavor styles can be distinguished within the same category. At present food labels do not give the information that is required to enable consumers to compare and select foods on the 
basis of flavor properties (Monro, 2000). In other words: Burgundy wines do not have the same flavor, neither do all wines made from the Chardonnay grape taste similar. Brand names serve, in regard to flavor, only a purpose for people that are acquainted with the brand from previous experiences.

The food industry is the third largest industry in the world and supermarkets are flooded with food choices. In such circumstances the failure of a new product is more likely than it would have been under less crowded conditions. Therefore the pressure on successful food product development is high and a reduction of failed products is desirable (Poulsen et al., 1996; Redmond, 1995). For food products to be successful they should first be in line with the expectation that is provoked by what the consumer sees. Products should look like their flavor. Designers are able to express flavor in package design and color (Smets \& Overbeeke, 1995). The flavor styles could therefore facilitate the process of product development as they communicate flavor characteristics. Further research is encouraged.

\section{References}

Bartoshuk, L.M. (1978). History of taste research. In Carterette, E.C. \& Friedman. M.P. Handbook of perception, volume VIA, Tasting and Smelling (pp. 3-18). New York, Academic press

Beardsworth, A., Haslam, C., Keil, T., Goode, J. \& Sherratt, E. (1999). Contempary. nutritional attitudes and practices: a factor analysis approach. Appetite, 32 , 127-143

Breslin, P.A.S. (2001). Human gustation and flavour. Flavour and fragrance Journal, 16, 439-456

Carstens, E., Carstens, M.I., Dessirier, J.-M., O'Mahony, M., Simons, C.T., Sudo, M., Sudo, S. (2002). It hurts so good: oral irritation by spices and carbonated drinks and the underfying neural mechanisms. Food Ouality and Preference, 13 (7-8), 431-443

Connors, M., Bisogni. C.A., Sobal, J. \& Devine, C.M. (2001). Managing values in personal food systems. Appetite, 36, 189-200

Costa, A.I.A, Dekker, M., Beumer, R.R., Rombouts, F.M., Jongen, W.M.F. (2001). A consumer-oriented classification system for home meal replacements. Food Quality and Preference, 12, 229-242

Delwiche, J. (1996). Are there 'basic' tastes? Trends in Food Science \& Technology, 7 (special issue on flavour perception), 411-415

Drewnowski, A. and Gomez-Carneros, C. (2000). Bitter taste, phytonutrients, and the consumer: a review. Am. J. Clin. Nutrition, 72, 1424-1435 
Erickson, R.P. (2000). The evolution of neural coding ideas in the chemical senses. Physiology \& Behavior 69 (1-2), 3-13

Fuke, S. \& Ueda, Y. (1996). Interactions between umami and other flavor characteristics. Trends in Food Science \& Technology, 7, 407-411

Gawel, A., Iland, P.G., Francis, I.L. (2001) .Characterizing the astringency of red wine: a case study. Food Quality and Preference, 12, 83-94

Gilbertson, T.A., Damak, S., \& Margolskee, R.F. (2000). The molecular physiology of taste transduction. Current Opinion in Neurobiology, 10 (4), 519-527

Guinard, J-X., Mazzucchelli, R. (1996). The sensory perception of texture and mouthfeel. Trends in Food Science \& Technology, 213-219

Guinard, J.-X., Zoumas-Morse, Chr. \& Walchak, C. (1998). Relation between parotid saliva flow and composition and the perception of Gustatory and Trigeminal stimuli in foods. Physiology \& Behavior, 63(1), 109-118

Kallithraka, S., Bakker, J., Clifford, M.N. Vallis, L. (2001). Correlations between saliva protein composition and some T-l parameters of astringency. Food Quality and Preference, 12, 145-152

Klosse, P.R. (2003). Het Proefboek, de essentie van smaak. Baarn, the Netherlands (Tirion Publishers) (Dutch)

McCleskey. E.W., Gold, M.S. (1999). Ion channnels of nociception. Annual Review on Physiology 61: 835-856

Monro, J.A. (2000) Evidence-based food-choice: the need for new measures of food effects. Trends in Food Science and Technology. 11, 136-144

Moskowitz, H. (1994). Food Concepts and Products, just-in-time development. Tumball, Connecticut, USA (Food \& Nutrition press, Inc)

Powers, J.J. (1984). Current Practices and Application of Descriptive Methods. In Pigott, J.R. Sensory Analysis of foods. Barkin, Essex, England (Elsevier Applied Science Publishers Ltd)

Poulsen, C.S., Juhl, H.J., Kristensen, K., Bech, A.C. \& Engelund, A. (1996). Quality guidance and quality formation. Food Quality and Preference, 7, 127-135

Prescott, J. (1999) Flavour as a psychological construct: implications for perceiving and measuring the sensory qualities of foods. Food Quality and Preference, $10,349-356$

Redmond, W.H. (1995). An ecological perspective on new product failure: the effects of competitive overcrowding. J. of Product Innovation Management, 12, 200 213

Rolls, E.T., Critchley, H.D., Browning, A.S., Hernadi, I., Lenard, L. (1999). Responses to the sensory properties of fat of neurons in the primate orbifrontal cortex. Journal of Neuroscience, 19 (4), 1532-1540 
Schiffman, S.S. (2000a). Taste quality and neural coding: Implications from psychophysics and neurophysiology. Physiology \& Behavior 69, 147-159

Schiffman, S.S. (2000b). Intensification of sensory properties of foods for the elderly. Supplement to the Journal of Nutrition, 130, 927S-930S

Smets, G.J.F. \& Overbeeke, C.J. (1995). Expressing taste in packages. Design studies, 16, 349-365

Smith, D.V., \& Margolskee, R.F. (2001). Making Sense of Taste. Scientific American, march, 26-33

Steptoe, A., Pollard, T.M., Wardle, J. (1995). Development of a measure of the motives underlying the selection of food: the Food Choice Questionnaire. Appetite, 25, 267-284

Tepper, B.J. \& Trail, A.C. (1998). Taste or health: a study on consumer acceptance of corn chips. Food Quality and Preference, 9, 267-272

Valentova, H. \& Pokorný, J. (1998). Effect of edible oils and oil emulsions on the perception of basic tastes. Nahrung, 42 (6), 406-408

Wardle, J., Sanderson, S., Gibson, E.L., Rapoport, L. (2001). Factor-analytic structure of food preferences in four-year-old children in the UK. Appetite, 37, 217-223

Williams, A.A. \& Arnold, G.M. (1984). The use of free-choice profiling for the evaluation of commercial ports. J. Sci. Food Agric., 35, 558-568

Zegers, F.E. \& ten Berge, J.M.F.A. (1985). A family of association coefficients for metric scales. Psychometrika, 50, 17-24 
Chapter 4

\section{The formulation and evaluation of Culinary Success Factors (CSFs) that determine the Palatability of Food}

P.R. Klosse, J. Riga, A.B. Cramwinckel, W.H.M. Saris

Kevwords: taste, flavor, nutrients, food, culinary success factors, palatability, product development

Submitted

\section{Abstract}

The concept of palatability refers to fiavors that are pieasing to the palate. It is easily confounded with 'liking', which is defined as the human response to a certain flavor. As such liking is a subjective concept. Palatability on the other hand, is product-related, and can be considered as a successful combination of product characteristics. Therefore the aim of the two studies presented was to objectify palatability. In the first study renowned chefs in the Netherlands were qualitatively interviewed about their most successful dishes. These interviews were analyzed to search for 'common denominators'. In total eighteen chefs were interviewed and sixty-three dishes were analyzed. We found six product characteristics that were present in at least $80 \%$ of the described dishes:

- name and presentation fit the expectation

- appetizing smell that fits the food

- good balance of flavor components in relation to the food

- presence of the umami, also called the fifth basic taste

- in mouthfeel a mix of hard and soft textures

- high flavor richness

These factors were defined as Culinary Success Factors (CSFs). We hypothesized that that palatability is determined by the presence of each of these factors. To assess this hypothesis a second study was conducted. A Michelin-star chef was asked 
The formulation and evaluation of Culinary Success Factors (CSFs) that determine the palatability of food

to develop three dishes based on the CSFs and two variants of each dish where systematically one of the CSFs was left out, under the condition that the variant was still restaurant-worthy. In a tasting these nine dishes were served to a group of 26 experienced restaurant guests. In the tasting the dishes in which most CSFs were united, were preferred to the variants. It is concluded that the formulated CSFs can help chefs in the development of new dishes and improvement of existing ones. These factors can be studied in future research to verify if they apply to industrially produced foods and in other cultures.

\subsection{Introduction}

Palatability is defined as flavors that are pleasing to the palate. It is brought about by a successful combination of product qualities. Flavor and palatability are important drivers of liking. However, both concepts are quite different and it is functional to distinguish the two concepts. Liking is defined as an affective human response to a certain food or drink. Palatability is product related while liking is related to what humans think of it. This raises the question if liking must be considered as a coincidence, happening haphazardly or as the predictable outcome when certain product qualities are present. We hypothesized that there must be factors that determine the palatability and that such factors are critical for the potential success of food products. Once such Culinary Success Factors (CSFs) are defined, they could be used in product development to evaluate the potential success of new products or in the improvement of existing ones.

Food is available in an infinite variability, based on ail kinds of ingredients, and produced both industrially and according to traditional methods, in commercial restaurants or at home. In studying palatability a choice has to be made for the products to be analyzed. The popularity of commercial food products could be a criterion. Some food products are a success throughout the world and it is hard to imagine that they are not found to be palatable. However, advertising is crucial in this highly competitive industry and commercial success of these products is highly influenced by it. Therefore, we decided not to choose for popular industrial foods that are consumed on a large scale.

As objects of our study we chose for restaurant dishes that have been on the menu for quite some time and are prepared by well-known chefs, many of which are decorated with one or more Michelin stars. This focus was chosen because these dishes are known to be palatable, while their popularity is hardly influenced by marketing forces. Yet the popularity of these dishes is such that they have to stay on 
the menu as not to disappoint the people that have come especially to savor them. Most of the best restaurants in any country have at least a few of such dishes. We suppose these dishes must have something special and possibly could have 'common denominators', collective qualities that make them special.

There is quite another argument for using these dishes as starting point. Flavor research generally takes place in laboratories. Results based on studies in laboratory settings, be it on specific components, like salt or bitter, or on tests using animais. are in general not well applicable in daily life (Cardello, Schutz, Snow, Lesher, 2000). Some of the strategies employed in laboratory research produce results that are valid for the laboratory but miss essential variables that make the difference between the laboratory and the real world. According to the DeCastro (2000) naturalistic research settings are better in that respect, but they give the researcher less control. He qualifies the high degree of control that characterizes the laboratory setting as both its virtue and its curse. Conclusions found in natural settings are likely to be trustworthy, if they have been derived carefully (Abdi, 2002).

Our research involved two studies. The first involved an inventory of dishes from highly ranked restaurants that have proven to be palatable in practice. The aim of this study was to search for common denominators in these dishes whereupon factors could be formulated which supposedly determine palatability. As these factors are supposed to be critical to success, they are called Culinary Success Factors (CSFs). In the second study the formulated CSFs were evaluated in a tasting. We hypothesized that the CSFs determine the palatability of dishes and that, consequently, the CSF dishes would be preferred over the others, with higher marks for palatability.

\subsection{Materials and methods}

\subsubsection{Study 1}

Eighteen of the best Dutch chefs (table 4-1) were personally interviewed about their most successful dishes, defined as being popular and having been on the menu for at least three years. Sixty-three dishes were fully described, including the recipe and their flavor profile. Additional information was given on seasonality, regionalism, and price. The nature of the interviews allowed for the introduction of aspects that were considered important by the chefs. There was ample opportunity for chefs to give their views on the palatability of their dishes. On average the interviews lasted 1.5 hours. Appendix 1 shows the open questions that were asked about each dish. The interviews were all conducted by the same person who was trained in the concept of profiling flavor using the Flavor Styles Cube (Klosse, et al., 2003). 
The formulation and evaluation of Culinary Success Factors (CSFs) that determine the palatability of food

\begin{tabular}{|l|l|}
\hline $\begin{array}{l}\text { Table 4-1: } \\
\text { MICHELIN RATING }\end{array}$ & NR. OF CHEFS \\
\hline 0 star & 5 \\
\hline 1 star & 10 \\
\hline 2 stars & 2 \\
\hline 3 stars & 1 \\
\hline Total chefs interviewed & 18 \\
\hline
\end{tabular}

Table 4-7: chefs interviewed and their rating in the Michelin guide 2002 (Michelin S.A., 2002)

The authors anaiyzed the interviews to establish if there were factors in common. No specific statistical techniques or methods were used. As our objective was to formulate CSFs that can be applied generally, we were not specifically interested in the ingredients used, the micro level. In the analysis our interest was on the macro level. We studied the flavor profiles, and other factors that successful dishes might have in common. For a factor to be accepted as a CSF we decided that such a factor should be present in at least $80 \%$ of the dishes described, thus in at least 50 out of the 63 dishes analyzed.

\subsubsection{Study 2}

After having formulated the CSFs, verification was the aim of our second study. Can a professional chef compose dishes using the CSFs, and - if so - are these dishes considered to be more palatable than other dishes? A Michelin-star chef composed three dishes based on all CSFs. Two variants were made of each dish in which systematically one CSF was changed under the condition that the variant was still worthy to be served in a top restaurant. Different main ingredients were used: prawn, turbot, and beef.

In a tasting session in a restaurant the three dishes and their alternatives were presented to experienced restaurant-guests and evaluated. The subjects received a general invitation to particjpate in a tasting; the purpose of the tasting and the CSFs were not explained until after the tasting. Plates were unmarked and the tasters were given no other indications. The CSF dish and the two variants were served simultaneously. As a first course the three prawn dishes were presented, then the three turbot dishes and finally the three beef dishes. After every course the guests were asked to note their preference for one of the three variants of the dish and to give a mark for it. Differences in preference and palatability were tested. Appendix 2 shows the form that was used in the tasting. 
Twenty-six individuals participated in the tasting with no other instruction than to give their preference and to score the palatability of each dish on a scale from 1-10. One form of the first course was invalid and discarded. The relevance of the preference was analyzed by establishing the Pearsons Chi-square of the results of each course. In the total judgment the variance (Anova score) was calculated.

\subsection{Results}

\subsubsection{Results study 1: Culinary Success Factors}

In the analysis of the described dishes six common qualities were found:

Factor 1: name and presentation fit the expectation

The description of the dishes conveyed adequately what to expect; no false expectations are raised. During the years the name and presentation of the dishes were not changed, except for minor adjustments and improvements. The main ingredient is clearly visible and in general the presentation is pleasing and appetizing. Evidently, the flavor should always be the same. If the recipe changes drastically the name should change as well.

\section{Factor 2: appetizina smell that fits the food}

Smell is an important driver of palatability. Just as there are bad smells can prevent from eating, there are attractive good smells. Chefs mentioned specifically the importance of those attractive aromas, but also for unpleasant odors not to be present. Palatability increases if smell and taste fit together.

\section{Factor 3: aood balance in flavor components in relation to the food.}

In palatable foods the flavor components are well balanced, never too sweet, salty, acidic, or bitter. Acidity and a certain bitterness were often mentioned as being important gustatory components. 'Too ripe' was also mentioned as a potential disturber. To illustrate: meat that has been baked or grilled too long, bread that has been toasted too long. French fries that have been fried too long or a wine that has been aged in a wooden cask too long. In every one of these cases ripe flavor notes prevail, while the original flavors are masked; the complexity of the flavor diminishes.

\section{Factor 4: presence of the umami}

In analysis, it was striking to see how often natural ingredients were used that are rich in glutamate acid or fermented products that acquire glutamate in the process. In table 4-2 the ingredients of success dishes related to umami are listed. 


\begin{tabular}{|l|l|}
\hline \multicolumn{2}{|l|}{ Table 4-2: EXAMPLES OF INGREDIENTS CONTRIBUTING TO UMAMI TASTE } \\
\hline NATURAL INGREDIENTS & FERMENTED/AGED PRODUCTS \\
\hline Tomato & Soy sauce \\
\hline Corn & Oyster sauce \\
\hline Spinach & Aged cheese (Parmesan!) \\
\hline Onion & Emmentaler cheese \\
\hline Carrot & Cured Ham \\
\hline Mushroom (all kinds) & Broth \\
\hline Green Pea & Stock \\
\hline Green asparagus & 'Glace de Viande' \\
\hline Scallops & Marmite \\
\hline Alaska king crab & Trassi \\
\hline Cod & \\
\hline Salmon & \\
\hline Chicken meat & \\
\hline Milk/cream & \\
\hline Eggs & \\
\hline
\end{tabular}

Table 4-2: Examples of 'Umami ingredients'

Enctor 5: combination of hard and soft textures.

The chefs often mentioned to look for a contrast in mouthfeel, with a combination of hard and soft textures. The combination of 'crispy' or 'crunchy' on one side and 'juicy', 'creamy', or 'moist' on the other seems crucial in palatability.

\section{Factor 6: flavor richness is high.}

The last factor that was identified from the interviews was a high flavor richness of the dishes. Within flavor richness 'fiavor intensity' and 'ripe' were the factors that characterized the flavor of palatable dishes.

\subsubsection{Results study 2: Evaluation of CSF concept}

We hypothesized that dishes based on these CSFS are palatable, and preferred over other dishes, and implicitly, that a professional chef can create successful dishes with these CSFs. The CSF dishes and the variants were designed to be served in a Michelin star restaurant and to be tasted by people that visit such restaurants. Tables $4-3,4-4$, and $4-5$ show the scores for the respective dishes. 


\section{A. Prawn variations}

Table 4-3 shows the prawn dishes that were designed.

In the CSF dish the prawn was clearly visible, the flavor components were well balanced, the dry texture of the prawn was compensated with the potato mousseline and the lobster oil, the color of which added to the overall presentation. Umami was present in the form of the prawns themselves and green asparagus.

In variant 1 the principal change is the structure of the prawn which was sliced and presented like a carpaccio. The mousseline was changed in potatoes cut in small balls. Both changes attributed a change in mouthfeel, the mix of hard and soft textures was partly lost.

In variant 2 adding ripe tones coming from morels and the grilling of the prawns changed the flavor balance.

The results of the tasting showed a preference for the CSF dish. It was preferred by 15 tasters, while $87 \%$ of the tasters scored 8 or higher, resulting in a palatability score of 8,2 . One form was not valid $(n=25)$.

\begin{tabular}{|c|c|c|c|c|c|}
\hline \multirow{2}{*}{$\begin{array}{l}\text { Table 4-3: } \\
\text { PRAWN DISHES }\end{array}$} & \multirow[b]{2}{*}{ TYPE } & \multicolumn{3}{|c|}{ PREFERENCE } & \multirow{2}{*}{$\begin{array}{l}\text { TOTAL } \\
\text { JUDGMENT }(0-10)\end{array}$} \\
\hline & & $1 s t$ & 2nd & 3rd & \\
\hline $\begin{array}{l}\text { Fried prawn with Noilly } \\
\text { Prat sauce and lobster oil, } \\
\text { potato mousseline and } \\
\text { green asparagus }\end{array}$ & CSF & 15 & 9 & 1 & 8,2 \\
\hline $\begin{array}{l}\text { Warm carpaccio of prawn } \\
\text { with saffronated potato, } \\
\text { slices of asparagus and } \\
\text { lobster oil }\end{array}$ & Variant 1 & 2 & 7 & 16 & 6.4 \\
\hline $\begin{array}{l}\text { Grilled prawn with lobster } \\
\text { sauce, morels, saffronated } \\
\text { potato mousseline }\end{array}$ & Variant 2 & 8 & 9 & 8 & 7,4 \\
\hline Significance (count $n=25$ ) & & \multicolumn{3}{|c|}{$\begin{array}{l}\text { Pearsons Chi- } \\
\text { square } p<0,01\end{array}$} & $\begin{array}{l}\text { Anova } \\
\mathrm{p}<0,01\end{array}$ \\
\hline
\end{tabular}

Table 4-3: tasting results Prawn dishes

\section{B. Turbot variations}

In this course the main ingredient was kept exactly the same in all three dishes. The CSF dish was designed to be complex with ripe tones from truffle, mushrooms and the celeriac chips. All CSF factors were present. 
In variant 1 the mousse of shallots added a characteristic sweet flavor to the dish that did not match well with the other flavors, impairing the flavor balance and partly expectation as sweetness was not to be expected.

In variant 2 the fresh tones from fennel replaced the ripe tones of the CSF dish.

The results show that the CSF dish and the two variants scored high in palatability (resp. 8.0, 7.0, and 7.3, see table 4-4). Yet the CSF dish was preferred by the majority. The result of variant 2 may be positively influenced by situational conditions may have influenced this result, as the tasting was held in the afternoon of a relatively warm day $\left(25^{\circ} \mathrm{C}\right.$.); circumstances in which fresh flavor notes are instinctively liked.

\begin{tabular}{|c|c|c|c|c|c|}
\hline \multirow{2}{*}{$\begin{array}{l}\text { Table 4-4: } \\
\text { TURBOT DISHES }\end{array}$} & \multirow[b]{2}{*}{ TYPE } & \multicolumn{3}{|c|}{ PREFERENCE } & \multirow{2}{*}{$\begin{array}{l}\text { TOTAL } \\
\text { JUDGMENT (0-10) }\end{array}$} \\
\hline & & ist & 2nd & $3 \mathrm{rd}$ & \\
\hline $\begin{array}{l}\text { Sautéed turbot with } \\
\text { aniseed-mushrooms, and } \\
\text { chanterelles, braised } \\
\text { shallots, celeriac chips and } \\
\text { truffle sauce }\end{array}$ & CSF & 13 & 9 & 4 & 8.0 \\
\hline $\begin{array}{l}\text { Sautéed turbot with } \\
\text { aniseed-mushrooms and } \\
\text { a mousse of shallors, } \\
\text { celeriac and chanterelles }\end{array}$ & Variant 1 & 4 & 11 & 11 & 7.0 \\
\hline $\begin{array}{l}\text { Sautéed turbot with } \\
\text { mousse of fennel, braised } \\
\text { fennel, aniseed-mushrooms, } \\
\text { shallots and fennel sauce }\end{array}$ & Variant 2 & 9 & 6 & 11 & 7,3 \\
\hline \multicolumn{2}{|l|}{ Significance (count $n=26$ ) } & \multicolumn{3}{|c|}{$\begin{array}{l}\text { Pearsons Chi- } \\
\text { square } p<0,05\end{array}$} & $\begin{array}{l}\text { Anova } \\
p<0.05\end{array}$ \\
\hline
\end{tabular}

Table 4.4: tasting results Turbot dishes

\section{Beef variations}

In the final course we used the classical name for the CSF dish 'Beef Rossini', which stands for a roasted fillet served with fried goose-liver and a fried egg. A traditional dish that sustained time and, not surprisingly, the CSFs are all present. interestingly, after the tasting some of the tasters remarked that the classical name gave them a negative impulse, which turned to positive in tasting the dish. 
In variant 1 the same ingredients are used as in the CSF dish, but the fillet is not roasted, but poached at a low temperature in a strong beef stock. Tenderness and flavor are there, but in mouthfeel it lacks the bite of the crust of the roast, the odor of the Maillard effect and the ripe flavor notes.

In variant 2 the same ingredients were used as well; the fillet was minced as a 'steak tartare' which was served at room temperature (as one would expect). Overall flavor richness was not as high as in the other dishes.

The results (table 4-5) show that the CSF dish was found to be very palatable (score 8.2 ) and preferred by 20 tasters over the variants.

\begin{tabular}{|c|c|c|c|c|c|}
\hline \multirow{2}{*}{$\begin{array}{l}\text { Table 4-5: } \\
\text { BEEF DISHES }\end{array}$} & \multirow[b]{2}{*}{ TYPE } & \multicolumn{3}{|c|}{ PREFERENCE } & \multirow{2}{*}{$\begin{array}{l}\text { TOTAL } \\
\text { JUDGMENT }(0-10)\end{array}$} \\
\hline & & $1 \mathrm{st}$ & $2 \mathrm{nd}$ & 3rd & \\
\hline Roasted fillet 'Rossini' & $\mathrm{CSF}$ & 20 & 4 & 2 & 8,2 \\
\hline $\begin{array}{l}\text { Poached fillet with } \\
\text { goose liver, fried egg } \\
\text { and vegetables }\end{array}$ & Variant 1 & 3 & 11 & 12 & 6,3 \\
\hline $\begin{array}{l}\text { 'Steak tartare' with goose } \\
\text { liver and poached egg }\end{array}$ & Variant 2 & 3 & 11 & 12 & 6.6 \\
\hline Significance (count $n=26$ ) & & \multicolumn{3}{|c|}{$\begin{array}{l}\text { Pearsons Chi- } \\
\text { square } p<0,001\end{array}$} & $\begin{array}{l}\text { Anova } \\
p<0,001\end{array}$ \\
\hline
\end{tabular}

Table 4-5: tasting results Beef dishes

\subsection{Discussion}

The results of these studies indicate that flavor has a structural base that determines palatability. This base was found by analysis of dishes that have proven to be highly palatable. These dishes had six factors in common which were presumed to be critical for success. The CSFs were tested in a tasting which showed that 'CSF dishes' were not only preferred, but also best liked, despite the fact that variants of the CSF dishes were optimal, except for one or two CSFs. The CSFs that we formulated can therefore be considered to be drivers of liking and palatability, which make them relevant to food professionals.

We analyzed specialty dishes that are known to be highly appreciated, served in restaurants. It is important to note that their popularity is principally based on their flavor. One may argue that the reputation of a prominent chef or the atmosphere of 
a reputed restaurant will positively influence the flavor perception of the dishes served. Yet these influences will apply to ail menu-items and not only to the specialty dishes alone. More likely it is the other way around: the renown of the restaurant is acquired by the grace of the quality of the specialty dishes. Extrinsic factors are therefore limited to their description on the menu, which must be accurate and can be promising and surely raises an expectation. After being selected and presented to the guest, the appearance of the dish can also be considered to be an extrinsic factor.

The results are based on the free choice and subsequent descriptions of dishes by professional chefs. No sweet dishes, desserts, were mentioned and therefore we should address the question how this affects the results. First, in our analysis we looked for similarities on the macro level and consequently the CSFs are formulated at that level. Next, if we consider the CSFs, in regard to desserts there are few differences to be expected. Expectation should still be met, smells should also be appetizing (although in cold dishes this influence will be less), the balance of flavors components is still important, the mouthfeel mix of hard and soft textures will also apply, just as the richness of flavor. The only factor that is likely to be of little influence is the Umami factor. Generally, monosodium glutamate (MSG) is not used for sweet products (Yamaguchi \& Nonimiya, 2000).

We believe that although the CSFs were formulated based on specialty restaurant dishes, they will apply to flavor in general, both for foods that are produced traditionally and industrially. However, we encourage further research on this subject to verify the CSFs that we formulated. In the verification of the CSFs we concluded that all factors should be present in a dish to achieve maximum result. Study 2 showed that both palatability and preference go down if one of the CSFs is eliminated. Nevertheless this result may not be interpreted in the sense that there is only room for foods that fully comply with the CSFs. If foods are consumed functionally, or without specific intentions, hedonics is not really an issue. If, on the contrary, foods are meant for enjoyment, the CSFs become increasingly relevant and will enhance the chance of pleasure.

In relation to the different CSFs:

A. Expectation and palatability. A first prerequisite in liking a flavor is that it fits expectation. Sensory evaluation generally focuses on the intrinsic flavor components. However, the results of this study underline the importance of extrinsic factors. The name, price, image, packaging, advertising, and promotion predispose the consumer to purchase, whilst product sensory attributes confirm liking and may determine repeat purchases. The package and name of a product 
are not just a source of brand identification, product category identification, and product positioning; they actually are the product in virtual reality. They provide all the information needed for a decision on trial, or repeat (Angeli, 1995). Products should therefore convey their sensory character by the extrinsic factors in such a way that the generated consumer expectations will be met. If the fiavor and sensory expectations are not confirmed, the likelihood of product success in the targeted market is poor (Poulsen, et al. 1996; Lesschaeve, Norris, Lee, 2001; Murray, Delahunty, 2000). Food companies must therefore be extremely careful in their choice of marketing claims to ensure that any information, product comparisons or category schemata be accurate in terms of the product's ability to match the claims when seeking to introduce novel foods into the marketplace (Tourilla et al., 1998).

These extrinsic aspects of food are likely more important than thought. Our study shows a significant influence of situational conditions in regard to fiavor appreciation. The description of the food on the menu or otherwise should be such that choices can be made appropriately. This holds especially for the naming of fresh or ripe flavor notes. If the food has been chosen before and is re-chosen, then the expectation is influenced by the recollection of the previous experience, which implies that once a food has a certain name, it is closely related to its flavor. Changes in either the name or the flavor of a successful product will prove to be detrimental.

B. Smell and palatability. Much of what we taste is in fact registered through the olfactory system. Smell is a major contributor of fiavor richness, which implies that the flavor of food products owes its depth and variability to smell. In the human neural anatomy there is a high level of functional connectivity between olfaction and the limbic system of the brain, which also processes emotions and memories. It is therefore plausible that from the intrinsic fiavor components, smell is potentially the most important contributor to pleasure and palatability. A reversed argument that shows the importance of smell in fiavor is seen in the decline of olfactory capabilities of older people, which tends to begin around 60 years of age and becomes more severe in persons above 70 years of age. The enjoyment of eating is reported to go down, potentially leading to inadequate dietary intake (Brand, Millot, Henquell, 2001). One study involving elderly showed that when the smell of food was enhanced, natural intake increased (Schiffman, 2000).

Certain odors have the potential to arouse and increase appetite. A good example is the specific aroma of the Maillard reaction like in roasting meat, coffee beans or almonds, and the baking of bread and cakes (Martins, Jongen \& Van Boeckel, 2001). 
C. Balance of gustatory flavors and palatability. In food product development it is beneficial to distinguish consumer segments and to consider the drivers of liking within such a segment. An inverted U-shape curve characterizes the typical course of preference. There is a certain optimum, making dosage crucial in flavor composition. Different consumer segments are likely to have a different optimum level of preference in the inverted U-curve. (Moskowitz \& Krieger, 1998). Too little is almost just as bad as too much. Although in some cases, like sait, components can easily be added to suit individual preference. The right dose of a certain component is food-dependant. A salad is expected to be fresh and acidic, and a cake is expected to be sweet. If it is acidic, edibility is questionable. Of all basic flavor components there is a general misconception about bitter Many chefs consider bitter an essential element as it makes food 'lighter' and more interesting. As is also illustrated by the food products that are universally popular: beer, chocolate, coffee, tea and wine. In ail of these products bitter is rather present. At the same time sensory scientists generally presume bitter to be a negative component that deserves to be expelled. How does this relate to the popularity of foods in which bitter is strongly present?

A similar presumption involves sugar. It is supposedly the most popular of the basic flavors and its use tends these days to be exaggerated, making certain foods (e.g. mayonnaise, and salad dressing) sweeter and therefore less typical.

D. Umami and palatability. The results of this study confirm the importance of umami in relation to palatability. Umami or glutamate flavor is identified as an individual basic flavor, next to the basic four (sweet, salty, acidic, and bitter). It is therefore often referred to as the 'fifth basic flavor'. The name and the scientists that discovered umami are Japanese, but as a flavor component Umami has no specific relation with Asian cuisine. In fact it is a new word for an old flavor component that has always been valued as important. Umami has not a distinct flavor of itself. In reports it is called 'brothy'. 'savory' or 'meaty'. Depth and fuliness are also mentioned. Moreover, Umami gives a strong aftertaste. An agreeable aftertaste is an important determinant of the overall pleasantness of a meal. When translated from Japanese, umami means 'delicious' (Fuke \& Ueda, 1996).

Glutamic acid is an amino acid and a major constituent of food proteins and is naturally present in most foods. Best known is the sodium salt of glutamic acid, MSG, that is widely used in the food industry. Next to glutamate, 5'-ribonucleotides also contribute to Umami taste: Inosinate (IMP) is found primarily in meat. guanylate (GMP) is more abundant in plants and mushrooms, whereas adynalate (AMP) is found in fish and shellfish. There is a strong taste synergism between MSG 
and nucleotides. In many of the analyzed dishes in study 1 ingredients were used that contribute to umami (table 4-2) (Yamaguchi, 2000; Fuke, 1996; Bellisle, 1999). It is not quite clear how umami substances increase palatability, yet many reports show that they do (e.g. Schiffman, 2000; Bellisle, 1999). Umami also influences the perception of other 'basic' flavors. MSG increases the perception of saltiness, which implies that the actual amount of salt used can be lower in combination with MSG. MSG reduces the perception of sourness and bitterness, but has little apparent influence on the perception of sweetness. Preference for umami is likely to be innate - just as sugar and fatty acids - as breast milk is rich in glutamic acid.

E. Mouthfeel and palatability. Crispy is associated with freshness. For example: within a relatively short time the crispness is gone In the crust of freshly baked bread, roasted steak, toast, French fries or even a salad. As soon as it is gone, these products have lost much of thelr appeal (Duizer, 2001). In our study this effect was clearly demonstrated in the beef dishes, where the traditional preparation scored high.

As the soft textures are concerned, fat is an important factor. Foods owe much of their flavor to fat. Fats serve a variety of functions. In some cases fat contributes a desirable mouthfeel or texture, in others fat enhances the flavor. Both influences attribute to palatability and liking, which is demonstrated by the abundance and popularity of high-fat foods. The negative consequence is that these foods are often over-consumed, leading to chronic diseases like obesity (Astrup, Grunwald, Melanson, Saris, 2000). There are reports that there is an additional, sixth, 'basic' flavor involving selected fatty acids. Such a new flavor system could - at least to some extent - explain the positive human response to fat (Bray, 2000; Rolls, Critchley. Browning, Hernadi, Lenard, 1999). For a food product or a dish to be successful though, the softness in whatever textural form apparently needs to be compensated by textures that have 'bite', according to the professional chefs interviewed. In general, texture is a positive quality attribute denoting freshness of produce, excellence of food preparation and contributing to the enjoyment of eating (Szcsesniak, 2002)

F. Flavor richness and palatability. It is conceivable that this result is biased by our scudy design. Palatable, but non-complex dishes and flavors are not to be expected on the menu of exclusive restaurants. The guests of these restaurants are often in a certain frame of mind: relaxed and enjoying themselves: jdeal circumstances to savor complexity. Earlier we mentioned the influence of 
siruational aspects on preference: flavor profiles that are fresh and slightly acidic fit warm weather. The perception of complexity is also likely to be situational, as it requires rest. The relaxed atmosphere in top restaurants is therefore an important ingredient in the overall enjoyment of the food. In other senses this phenomenon is known as well.

\subsubsection{Palatability objectified}

The CSFs of flavor are the result of an attempt to objectify palatability. It is important to note the CSFs do not dictate how a food product should be made, and also do not impair creativity. The chef that was instructed to compose dishes based on the CSFs, had no problem in doing so; they served as guidelines. CSFs make the composition of flavor visible, and are as such useful in modifying existing products or formulating new ones. Up to now the fundamentals of flavor composition have not been formulated and the search for it may well have been neglected. Without a solid backbone, cooking and food-product development can easily get the character of 'cook and look'. We have not studied the causes of the high failure rate of many industrial food products but the absence of knowing the fundamentals may well be part of the explanation.

According to Cardello (1995) food quality can be considered both the most welldefined and the least well-defined concept in the food industry today. Food scientists or professional chefs are likely to define food quality from a product point of view. This definition does not necessarily correspond with consumer opinion. For commercial food products it is essential that a product has a high quality from a consumer point of view. Earlier we noted that palatability is by definition related to food products and that it is a strong driver of liking, which is defined as the affective consumer response. A driver of liking can be defined as a product characteristic (sensory attribute) which, when changed, affects liking (Moskowitz \& Krieger, 1998). In this respect the CSFs may prove to be an asset to sensory science. For commercial food companies, restaurants included, it is essential to know the 'drivers' of product acceptance.

There may be an interesting analogy with architecture, art, music and biology. In all of these areas the mathematical rule of the golden section has been proven to apply. It is the natural order with its harmonious proportions. In the old ages they were called the proportio divina, divine proportions. Of some architects (le Corbusier), painters (Leonardo da Vinci) and sculptors (Michelangelo) it is known that they actively used the golden section in their compositions (Lipovetsky, Lootsma, 2000). The 'divine proportions' have also been found to apply in the structure of musical compositions (Bach and Mozart), in the ratios of harmonious 
sound frequencies, in the dimensions of the human body and in the structure of plants. The ancient Greek had the same word, techne, for both 'art' and 'technique'. Art was defined as 'the right way of making things'. In all art. technique is essential. There may be technique without art, but there is no art without technique (Hegarty. O'Mahony, 2001). Palatability is in flavor what 'beauty' is in art. If the golden section provides an objective backbone in art, why would there not also be a natural order in flavor that determines palatability?

In conclusion, formulating CSFs can be seen as a first step in getting a better understanding of flavor and the components that drive liking. The chosen research format was based on a different orientation than traditional sensory research. We focused on actual consumers eating real foods in real dining situations. This approach is essential in getting a better understanding of taste as a sense and all concepts that are related to it. The results show that the palatability of food is not a coincidence. It is the predictable outcome when the CSFs of food are present. The formulated CSFs will help chefs in the development of new dishes and improvement of existing ones. An interesting prospect for future research is to verify if these factors apply to industrially produced foods and in other cultures.

\section{References}

Abdi, H. (2002). What can cognitive psychology and sensory evaluation learn from each other? Food Quality and Preference, 13, 445-451

Angeli, P. (1995). Thinking out of the box: a new approach to product development. Business Horizons (May - June), 18-22

Astrup, A., Grunwald, G.K., Melanson, E.L., Saris, W.H.M. (2000). The role of low-fat diets in body weight control: a meta-analysis of ad-libitum dietary interveillion studies. Int. J. of Obesity, 24, 1545-1552

Bellisle, Fr. (1999). Glutamate and the Umami taste: sensory, metabolic, nutritional and behavioral considerations. A review of the literature published in the last 10 years. Neuroscience and Biobehavioral Reviews, 23, 423-438

Brand, G., Millot, J.-L., Henquell, D. (2001). Complexity of olfactory lateralization processes revealed by functional imaging: a review. Neuroscience and Biobehavioral Reviews, 25, 159 - 166

Bray, G.A. (2000). Afferent signals regulating food intake. Proceedings of the Nutrition Society, 59, 373-384

Cardello, A.V. (1995). Food quality: relativity, context and consumer expectations. Food Quality and Preference, 6, 163-170 
Cardello, A.V., Schutz, H., Snow, C., Lesher, L. (2000). Prediction of food acceptance, consumption and satisfaction in specific eating conditions. Food Quality and Preference, 11, 201-216

De Castro, J.M. (2000). Eating Behavior: lessons from the real world of humans. Nutrition, 16, 800-813

Duizer, L. (2001). A review of acoustic research for studying the sensory perception of crisp, crunchy and crackly textures. Trends in Food Science \& Technology, 12, 17-24

Fuke, S. \& Ueda, Y. (1996). Interactions between umami and other fiavor characteristics. Trends in Food Science \& Technology, 7, 407-411

Hegarty, J.A., O'Mahony, G.B. (2001). Gastronomy: a phenomenon of cultural expressionism and an aesthetic for living. Int. J. Hospitality Management, 20, 3-13

Klosse, P.R. (1998). Smaak. Baarn, the Netherlands (Tirion Publishers) (Dutch)

Klosse, P.R. (2000). Smaakstijlen. Baarn, the Netherlands (Tirion Publishers) (Dutch)

Klosse, P.R., Cramwinckel, A.B., Schevers, F., Saris, W.H.M. (2003). A proposal for the classifications of flavors. Unpublished material.

Laing, D.G. \& Jinks, A. (1996). Flavour perception mechanisms. Trends in Food Science \& Technology, 7, 387-391

Lipovetsky, S., Lootsma, F.A. (2000). Generalized golden sections, repeated bisections and aesthetic pleasure. Eur. J. Operational Research, 121, 213-216

Lesschaeve, 1., Norris, L.N., Lee, T.H. (2001). Defining and targeting consumer preferences. 11th Australian Wine Industry Technical Conference proceedings. October 7-11

Martins, S.I.F.S., Jongen, W.M.F. \& Van Boeckel, M.A.J.S. (2001). A review of Maillard reaction in food and implications to kinetic modeling. Trends in Food Science and Technology, 11, 364-373

Michelin Guide 2002, édition Benelux, Brussels (Michelin S.A.)

Moskowitz, H. \& Krieger, B. (1998). International product optimization: a case history. Food Quality and Preference, 9, 443-454

Murray, J.M., Delahunty, C.M. (2000). Mapping consumer preference for the sensory and packaging attributes of Cheddar cheese. Food Quality and Preference, $11,419-435$

Poulsen, C.S., Juhl, H.J., Kristensen, K., Bech, A.C. \& Engelund, E. (1996). Quality guidance and quality formation. Food Quality and Preference, 7, 127-135

Rolls, E.T., Critchley, H.D., Browning, A.S., Hernadi, I., Lenard, L. (1999). Responses to the sensory properties of fat of neurons in the primate orbifrontal cortex. J. of Neuroscience, 19, 1532-1540 
Schiffman, S.S. (2000). Intensification of sensory properties of foods for the elderly. J. of Nutrition, 130, 927S-930S

Szczesniak, A.S. (2002). Texture is a sensory property. Food Quality and Preference, 13, 215-225

Tourilla, H.M., Meiselman, H.L., Cardello, A.V. \& Lesher, L.L. (1998). Effect of expectations and the definition of product category on the acceptance of unfamiliar foods. Food Quality and Preference, 9, 421-430

Yamaguchi, S. \& Nonimiya, K. (2000). Umami and food palatability. J. of Nutrition, 130, $9215-9265$

\section{Appendix 1: Questionnaire Chefs}

Name chef:

Name dish:

Presentation:

Flavor profile

- Mouthfeel:

- Flavor intensity:

- Fresh flavor cones:

- Ripe flavor tones:

Seasonality of the dish:

Regionalism of the dish

Consumer price:

- less than 70 Euro

- between 10 and 25 Euro

- more than 25 Euro

How long has the dish been on the menu (min. 3 years):

Was it immediately successful?

Has the dish been changed over time?

What is your explanation for its success? 


\section{Appendix 2: Tasting forms}

\begin{tabular}{|c|c|c|c|}
\hline ROUND 1. DISHES & $\begin{array}{l}\text { Preference } \\
1,2 \text { or } 3\end{array}$ & $\begin{array}{l}\text { Judgment } \\
\text { Scale } 1-10\end{array}$ & $\begin{array}{l}\text { Order of eating } \\
1,2 \text { or } 3\end{array}$ \\
\hline $\begin{array}{l}\text { Fried prawn with Noilly Prat } \\
\text { sauce and lobster oil, potato } \\
\text { mousseline and green asparagus }\end{array}$ & & & \\
\hline $\begin{array}{l}\text { Warm carpaccio of prawn } \\
\text { with saffronated potato, slices } \\
\text { of asparagus and lobster oil }\end{array}$ & & & \\
\hline $\begin{array}{l}\text { Grilled prawn with lobster } \\
\text { sauce, morels, saffronated } \\
\text { potato mousseline }\end{array}$ & & & \\
\hline ROUND 2. DISHES & $\begin{array}{l}\text { Preference } \\
1,2 \text { or } 3 \\
\end{array}$ & $\begin{array}{l}\text { Judgment } \\
\text { Scale } 1-10\end{array}$ & $\begin{array}{l}\text { Order of eating } \\
1,2 \text { or } 3\end{array}$ \\
\hline $\begin{array}{l}\text { Sautéed turbot with aniseed- } \\
\text { mushrooms, and chanterelles, } \\
\text { braised shallots, celeriac chips } \\
\text { and truffle sauce }\end{array}$ & & & \\
\hline $\begin{array}{l}\text { Sautéed turbot with aniseed- } \\
\text { mushrooms and a mousse of } \\
\text { shallots, celeriac and } \\
\text { chanterelles }\end{array}$ & & & \\
\hline $\begin{array}{l}\text { Sautéed turbot with mousse } \\
\text { of fennel, braised fennel. } \\
\text { aniseed-mushrooms, shallots } \\
\text { and fennel sauce }\end{array}$ & & & \\
\hline ROUND 3. DISHES & $\begin{array}{l}\text { Preference } \\
1,2 \text { or } 3\end{array}$ & $\begin{array}{l}\text { Judgment } \\
\text { Scale } 1-10\end{array}$ & $\begin{array}{l}\text { Order of eating } \\
1,2 \text { or } 3\end{array}$ \\
\hline Roasted fillet 'Rossini' & & & \\
\hline $\begin{array}{l}\text { Poached fillet with goose } \\
\text { liver, fried egg and vegetables }\end{array}$ & & & \\
\hline $\begin{array}{l}\text { Tartare of fillet with goose } \\
\text { liver and poached egg }\end{array}$ & & & \\
\hline
\end{tabular}




\title{
conous 5 \\ Umami in wine
}

\author{
Submitted.
}

\section{Abstract}

The positive effects of umami on flavor are widely documented, but the link to its effect on the flavor of wine has apparently not been made. As far as the authors are aware, wines were not mentioned in umami related literature, and vice versa in wine related scientific publications umami was never mentioned. Yet, in the fermentation and subsequent ageing of wines there is ample opportunity for umami compounds to develop. Umami refers to the flavor of glutamic acid (GLU), an amino acid that can be present in the flavor of wine as a resuit of the grapes that are used and the applied vinification techniques. Some techniques are likely to enhance the presence of GLU in wines; especially fermentation on yeast lees, a common procedure in many prestigious Chardonnay wines. During the malolactic fermentation the relative content of GLU is also likely to increase. Sweet wines like Port and Madeira are also reported to have considerable amounts of GLU. In dairy fermentations, such as in cheese, there is sophisticated knowledge about the specific flavors and textures that are formed by different starter lactic acid bacteria. They provide desired enzymes that yield small peptides and free amino acids that give a certain cheese its specific character. As amino acids are also precursors of various volatile flavor compounds such as aldehydes and alcohols the development of specific wine yeasts that could impart specific desirable characteristics to a wine could prove to be an important venture the production of successful wines.

\subsection{Umami and flavor}

Umami was discovered in Japan in 1908 by lkeda who noticed a flavor compound that was distinctly different from sweet, sour, bitter and sait. It is not an outstanding flavor and often hard to identify, but indispensable in harmonizing with other flavors. It gives mouthfullness and roundness. It is also described as "balancing, and blending', giving 'continuity', thickness, and in general a feeling of satisfaction. These effects on flavor are attributed to glutamic acid (GLU), one of the most abundant of all amino acids found in food protein (Yamaguchi \& Ninomiya, 1998). Umami does not need to be specifically identified by the consumer. Its flavor enhancing effect 
occurs even if the concentration is too low to allow the taster to discriminate its specific flavor (Bellisle, 1999). In Japanese, Ikeda named this flavor quality umami, which means delicious. In English he originally proposed 'glutamic taste'. This term was seldom used however, and at first umami as taste quality did not acquire much public attention. On the other hand, the food industry quickly discovered its interesting properties and the sodium salt of L-glutamic acid, MSG, was almost immediately produced commercially and is now manufactured worldwide on a large scale. MSG is increasingly used in processed foods in the Western as well as in the Eastern world, although traditionally in the East the per capita daily consumption in higher than in the West. In the USA the mean daily intake is estimated at $550 \mathrm{mg}$, in Korea at around $400 \mathrm{mg}$ (Yamaguchi, 1998: Bellisle, 1999).

The extensive use of MSG as an additive could lead to a one-sided picture of umami as a flavor quality. MSG and GLU are closely related, and yet they are different. The first is the sodium salt of the second. In respect to MSG it is suggested that there are health risks involved. Nevertheless the FDA and the WHO consider the use of MSG to be safe. MSG stands to umami as i.e. aspartame stands to sweetness. If there would be reasons to be suspicious about aspartame, it would be silly to condemn all compounds that elicit sweetness. Likewise, umami should not be condemned if MSG is suspected. There are many natural products and well-known fermented products that elicit the umami effect, many of which have been used for ages. In general the following categories of umami sources can be identified:

- Fermented sauces

- Lactic acid bacteria fermentations

- Ageing and ripening

- Concentrated extracts

- Natural producrs

Fermented Sauces. The Romans produced Garum or Liquamen in Pompeii: a fermented fish sauce, which was extensively used for seasoning. The procedure for making it was very similar to the way it is still done these days in many Asian countries: salt is mixed with fresh fish or shellfish and fermented for various lengths of time to enable enzymes to digest the meat. The residue is filtered and the obtained sauce is rich in GLU and is used to give the desired umami flavor to dishes. Fermented seasoning sauces have many origins, not only fish, but also meat or beans (soy) can be used. In fact commercial MSG is produced by hydrolysis of proteins in wheat gluten or soy or from sugar beet molasses. Kikkoman soy sauce is probably the best known example of this category (Yoshida, 1998). In such fermented sauces, 
free GLU is a result from an enzymatic process that decomposes proteins during fermentation.

Lactic acid fermentations can be another source of GLU. A well-known example of this category is aged cheese, and especially Parmesan, which matures for two years. In this maturation process freshly made cheese looses its firm, tough and curdy texture to become first soft and mellow. In further ripening it dries and the flavor concentrates. In this process proteins are progressively broken down to smaller peptides, while there is a graduai accumulation of free amino acids. Of these, the content of GLU is often predominant (Lawlor et al., 2002; Ninomiya, 1998). In culinary practice Parmesan cheese is not only savored as cheese, but also used as seasoning. Sauerkraut, cucumber and other vegetable pickles, and olives are other examples of lactic acid fermentations (Steinkraus, 1997).

Aaeing and ripening. GLU is also known to accumulate in the ripening of hams and sausages (Ninomiya, 1998; Hierro, de la Hoz, Ordón̉ez, 1999). In general, amino acids are common in microbiologically fermented foods and drinks, which implies that micro organisms like bacteria and yeasts are major, but not exclusive, sources of free amino acids (Brückner, et al. 1995)

Concentrated extracts. like broths and stocks are another source of GLU. Ail major world cuisines use some kind of stock as a basis. In Japan it is called dashi ('boiled extract'), in China tang, and in France glace de viande. Further reductions of stocks resuit in pastes like marmite, which is popular in the United Kingdom. The laborious process of making a good stock has always been an indispensable part of cook's training, wherever in the world (Yoshida, 1998).

Natural products. Next to the above mentioned types of products that provide umami flavor, free GLU is naturally present in all kinds of foods like milk (including human), eggs, beef, poultry, seafood, seaweed, tomato, potato, mushrooms, green asparagus, green peas, cabbage, cauliflower, garlic, and corn. Animal protein may contain from 11 to $22 \%$ and plants protein as much as $40 \%$ glutamate by weight (Tapiero et al., 2002). Of the vegetables, tomatoes are especially rich in GLU; the content of which progressively increases during ripening. High values are found in full ripe and overripe tomatoes and particularly in dried tomatoes (Ninomiya, 1998). Clearly, comato sauces of ail kind are the umami component of the Italian cuisine.

Next to its own flavor, GLU is known to affect the perception of other tastes: sweetness and especially saltiness are enhanced while sourness and bitterness are diminished (Tapiero et al., 2002). In literature there are many reports that oligopeptides also elicit umami taste. Although it may be expected that L-glutamyl 
oligopeptides do have umami taste, Van den Oord en Van Wassenaar (1997) reported that such peptides did not, implying that the umami effect of GLU is highly specific. Peptides have other organoleptic and 'functional' properties, like solubility, viscosity. gelation, emulsification and foam formation. As such they may be important for umami to arise (Siebert, 2001). However, of the amino acids and related structures it is exclusively the L-form of GLU which evokes the umami flavor. Besides GLU there are three kinds of 5 '-ribonucleotides that contribute to the umami sensation: IMP (inosinic acid, found in animal sources). GMP (guanylic acid, more abundant in plant based foods and mushrooms), and AMP (adenylic acid, which is present in fish and shellfish). There is a strong synergy between GLU and these ribonucleotides, implying that the umami flavor is strongly enhanced by a combination of the two (SclichtherleCerny, Grosch, 1998; van den Oord, van Wassenaar, 1997; Ninomiya, 1998).

Just small amounts are needed to enhance palatability. Yamaguchi (1998) reported that only $0.6 \mathrm{~g}$ of umami substances were needed to significantly increase the feeling of satisfaction for a meal. Foods with umami are considered to be more palatable and are spontaneously eaten in greater amounts, as indexed by a faster eating rate, less chewing, quicker swallowing and shorter times between bites (Bellisle, 1999). The presence of umami compounds is one of the Culinary Success Factors that determine the palatability of foods (Klosse et al., 2003). Remarkably. in the many umami-publications, wines were not mentioned, and vice versa in wine related scientific publications umami was never mentioned as far as we are aware of the literature. Yet, in the fermentation and subsequent ageing of wines there is ample opportunity for umami compounds to develop.

\subsection{Umami sources in wine}

The presence of amino acids in wines has been reported, as well as the presence of GLU specifically. Yet, in these reports no direct references are made to umami. Rather, amino acids seem to be considered as interesting differentiators to classify the origin of wines. This possibility is reported by j.e. Kim et al. (1996), Košir and Kidrič (2002), and Soufleros et al. (2003). Last mentioned cites many of such analysis in his report. Differences in grape variety, vintage years, grape growing region, fermentation, and ageing lead to different profiles of amino acids, and, subsequently, of peptides and other related compounds. As the focus of these studies was not on the effect that these compounds specifically have on the flavor of wine, no comprehensive overview of these effects was found. Results that were found are hard to compare due to differences in analysis and objectives. Fragments are presented here and put in relation to umami effects in other foods that have been described. 


\subsubsection{Grape variety and maturity}

The maturity of grapes is strongly related to both the amount and composition of amino acids to be found. Arginine (ARG), proline (PRO), alanine (ALA) and GLU have been reported to be the major free amino acids in many Vitis Vinifera grapes. Their concentration generally increases with berry maturity. GLU is predominantly found in the grape skin (Lamikanra \& Kassa, 1999).

Soufleros et al. (2003) reported that in his research of Greek wines, Chardonnay grapes yielded the highest mean concentration of primary amino acids (total of means: $618 \mathrm{mg} / \mathrm{l}$ ). ARG was highest, followed by ALA, GLU, and $\gamma$-AB ( $\gamma$-Amino Butyric acid). He compares these results to a study on chardonnay wines from the cool Somontano region in northern Spain (Pyrenees) where $265 \mathrm{mg} / \mathrm{l}$ was reported as a mean value, with the same four amino acids being dominant. The large difference between these mean values can possibly be attributed to the difference in climatic conditions in Somontano and Greece.

These observations tend to the conclusion that wine made from berries that were not fully mature due to climatic conditions or harvesting choices (i.e. harvest before full maturity is reached) have potentially less umami capabilities. Next, red wines are likely to be richer in GLU compared to white wines as grape skins are by definition included in the vinification. 'Skin contact' or in French macération pelliculaire before fermentation is likely to enhance the umami effect in white wines, as grapes are pressed before fermentation, leaving only the juice to ferment. Late harvest choices are likely to be beneficial to umami potentiality in both white and red wines. A prerequisite is that GLU is not (fully) consumed during the alcoholic fermentation.

\subsubsection{Alcoholic fermentation, influence of yeast}

Wine is the result of an alcoholic fermentation of grapes. Basically in this process, sugars are rapidly converted to ethanol and carbon dioxide by yeasts which are found on the grape skin. During the alcoholic fermentation amino acids are an important source of nitrogen for the yeast to grow. In this respect several amino acids undergo a series of biotransformations, giving higher alcohols, aldehydes, esters and ketonic acids. As such amino acids are both important for the success of the fermentation process as for the result of it in terms of aroma, flavor (including texture) and alcohol. After fermentation the same amino acids are as abundant in wine as in grapes. Generally ARG, $\gamma-A B, G L U$, and ALA are reported as being the primary free amino acids in wine (Soufleros et al., 2003). Although the amount of each amino acid in wine varies widely according to variety, yeast and bacteria strain, region, treatment and age, these differences withstand the alcoholic fermentation, which supports the use of amino acids analyses for differentiation purposes (Nouadje et al., 1997). 
The role of yeast in the alcoholic fermentation requires special attention. Indigenous yeasts are found on the surface of grape berries and they will spontaneously start a fermentation process. As the outcome of such a spontaneous process is highly unpredictable, most modern, professional winemakers use specially selected starter cultures of the saccharomyces cerevisiae. Pretorius \& Bauer (2002) reported that pioneering winemakers demand starter culture chains with a whole range of specialized properties that can add value to the final product. Such demands are common in the making of cheese where the use of special starter lactic acid bacteria is a common procedure. The authors stated that there is a need for the development of wine yeasts that could impart specific desirable characteristics to a wine and mentioned quite a few targets for the genetic improvement of wine-yeast strains. Typically, no specific references are made to contribution of yeast in the development of GLU. We propose to add this target to the already extensive list.

\subsubsection{Malolactic fermentation}

Yet another type of fermentation that can be applied to wines is the malolactic fermentation in which the organic malic acid is converted to the softer, also organic, lactic acid. Soufleros et al. (2003) reported that in this lactic bacteria action the amino acid concentration is generally reduced, from $490 \mathrm{mg} / \mathrm{l}$ to $315 \mathrm{mg} /$. Interestingly, the GLU content remained about intact $(36.3 \mathrm{mg} / \mathrm{l}$ vs. $36.5 \mathrm{mg} / \mathrm{l}$ after malo). This implies that its relative proportion increased with $70 \%$, from $7 \%$ to $12 \%$.

\subsubsection{Special types of fermentation: sweet wines and méthode traditionnelle}

Sweet wines are often made by stopping the fermentation naturally or by addition of alcohol and are characterized by much higher amino acid values than nonsweet wines. Soufleros et al. (2003) reported $810 \mathrm{mg} / \mathrm{l}$ for sweet wines and 351 $\mathrm{mg} / \mathrm{l}$ for dry wines. The use of overripe grapes, not fully fermented may account for this observation. In Port wines a mean value was reported of $1345 \mathrm{mg} / \mathrm{l}$ and in Port imitations $2016 \mathrm{mg} / \mathrm{l}$. (Herbert et al., 2000). Brückner et al. (1995) reported high amounts of GLU in fortified wines in general (Madeira, Sherry, Port) which is also related to the maturation of these wines for several years.

Sweet wines are also made from very mature grapes that have been affected by the botrytis cinerea or 'noble rot', a fungus which grows on the skin of the grapes. It gradually punctures the skin enabling moisture to escape, while concentrating other elements, like amino acids.

In the traditional method of making sparkling wines like Champagne a sweet substance with yeast is added to the still wine. A second fermentation takes place in the bottle, preventing the $\mathrm{CO}_{2}$ to escape and also leading to an increase of amino 
acids as a result of autolysis of dead yeast. Sparkling wines produced with the cuve close method (not in bottle, but in large recipients) exhibited lower amino acid concentrations (Soufleros et al., 2003). Prestigious Champagnes are aged up to five years or even longer on their lees. The flavor of these wines is notably softer and more complex than wines that have aged less long. We hypothesize that analysis will show a considerable rise in GLU in these wines.

\subsubsection{Other sources: ageing, 'sur lie and batonnage'}

The same process as mentioned above is seen in the vinification of white wines which are kept on 'their lees', such as white Burgundies and Muscadet sur lie. Wine lees consist mainly of dead yeast cells. After some weeks an enzymatic process called 'autolysis' commences. This process yields nitrogen compounds, polysaccharides, and glycoprotein's and can be enhanced by stirring the wine (French: batonnage), thus keeping the lees in suspension. Feuillat (1994) reported that in this process, the amount of amino acids is likely to increase over $60 \%$, but these were not specified in this paper. From an organoleptic point of view several studies have indicated that wine ageing on lees led to well-balanced and smooth wines (Salmon, et al., 2002).

The accumulation of amino acids is also reported to continue with ageing. However, this aspect has been poorly studied over a long period and the results are difficult to interpret due to the many variables involved (Nouadje, 1997. Ancín, 1996).

\subsection{Future ventures}

Wine is a complex mixture of several hundred compounds. Besides water, principal components are alcohol and organic acids. Residual sugars, $\mathrm{CO}_{2}$ and tannins may also be present. The flavor profile of a wine is the result of a balance between these principal components (Peynaud, 1980). Therefore, the flavor profile of wine cannot solely be explained with an analysis of amino acids, although their role in flavor is likely to be underestimated. The positive effects of GLU on flavor are well documented. Nevertheless umami connection in regard to the flavor of wine has apparently not been made. It is likely that GLU would render wines that are complex and rich in flavor. The potential amount of GLU is likely to be influenced by many variables such as grape variety, fermentation methods and ageing. In view of the fact that there is a chronic overproduction of wine, which is estimated at 5 billion liters a year, and that consumer preference has shifted from basic, bulk wines to premium wines or even better, the wine market has become highly competitive. To be 
commercially successful in such an environment wine producers must produce palatable wines that can meet consumer demands. innovation at all levels of the value chain is a necessity (Pretorius \& Bauer, 2002).

In this respect the wine world might benefit from years of experience and scientific development in the dairy sector. In dairy fermentations, such as in cheese, there is sophisticated knowledge about the specific flavors and textures that are formed by different starter lactic acid bacteria. They provide desired enzymes that yield small peptides and free amino acids that give a certain cheese its specific character. As amino acids are also precursors of various volatile flavor compounds such as aldehydes and alcohols, it is considered important to study the reactions of lactic bacteria, not only to ensure the required result, but also to prevent the development of undesirable, off-flavors (Van Kranenburg et al., 2002). Taking advantage of the biological properties has led to a substantial rise in value both organoleptically and in greater safety and nutritional value of bread and cheeses. They provide proof for what is possible when fermentation processes are well understood (Desiere et al., 2002).

\section{References}

Ancín, C., Ayestarán, B. \& Garrido, J. (1996). Sedimentation clarification of Garnacha musts. Consumption of amino acids during fermentation and ageing. Food research International, 29, 345-353

Bellisle, Fr. (1999). Glutamate and the umami taste: sensory, metabolic, nutritional and behavioral considerations. A review of the literature published in the last 10 years. Neuroscience and Biobehavioral Reviews, 23, 423-438

Brückner, H., Langer, M., Lüpke, M., Westhauser, T., Godel, H. (1995). Liquid chromatographic determination of amino acid derivatization with o-phthaldialdehyde and chiral thiols. Application with reference to food science. Journal of Chromatography A, 697, 229-245

Desiere, F., Germain, B., Watzke, H., Pfeifer, A. \& Saguy, S. (2002). Bioinformatics and data knowledge: the new frontiers for nutrition and foods. Food Science and Technology, 12, 215-229

Feuillat, M. (1994). Fermentation dans le bois et élevage sur lies des vins blanc Influence des macromolécules de levures sur les arômes. Revue des CEnologues, 71, 19-21

Herbert, P., Barros P., Ratola, N. \& Alves A. (2000). HPLC determination of amino acids in musts and Port wines using OPAFMOC derivates. Journal of Food Science, 65, 1130-1133 
Hierro, E., Hoz, L. de la, Ordóñez, J.A. (1999). Contribution of the microbial and meat endogenous enzymes to the free amino acid and amine contents of dry fermented sausages. J. Agric. Food Chem. 47, 1156-1161

Kim, K.R., Kim, J.H., Cheong, E., Jeong, C. (1996). Gas chromatographic amino acid profiling of wine samples for pattern recognition. Journal of Chromatography, 722, 303-309

Klosse, P.R., Riga, J., Cramwinckel, A.B., Saris, W.H.M. (2003). The formulation and evaluation of Culinary Success Factors (CSFs) that determine the palatability of food. Submitted

Košir, I.J. and Kidrič, J. (2002). Use of modern nuclear magnetic resonance spectroscopy in wine analysis: determination of minor compounds. Analytica Chimica Acta, 458, 77-84

Kranenburg, R. van, Kleerebezem, M., Hylckama Vlieg. J. van, Ursing, B.M., Boekhorst, J., Smit, B.A., Ayad, E.H.E., Smit, G., Siezen, R.J. (2002). Flavour formation from amino acids by lactic acid bacteria: predictions from genome sequence analysis. International Dairy Journal, 12, 111-121

Lamikanra, O. \& Kassa, A.K. (1999) Changes in the free amino acid composition with maturity of the noble cultivar of vitis rotundifolia Michx. grape. J. Agric. Food Chem. 47, 4837-4841

Lawlor, J.B., Delahunty, C.M., Wilkinson, M.G., Sheehan, J. (2002) Relationships between the gross, non-volatile and volatile compositions and the sensory attributes of eight hard type cheeses. International Dairy Journal, 12, 493-509

Ninomiya, K. (1998). Natural Occurrence. In Food Reviews International, 14, 177-213. New York, Marcel Dekker Inc

Nouadje, G., Siméon, N., Dedieu, F., Nertz, M., Puig, Ph., Couderc, F. (1997). Determination of twenty eight biogenic amines and amino acids during wine ageing by micelllar electrokinetic chromatography and laser-induced fluorescence detection. Journal of Chromatography A, 765, 337-343

Oord, A.H. van den, Wassenaar, P.D. van. (1997). Umami peptides: assessment of their alleged taste properties. Z Lebensm Unters Forsch A, 205, 125-130

Peynaud, E. (1980). Le goût du vin. Paris, Bordas

Pretorius, I.S. \& Bauer, F. (2002). Meeting the consumer challenge through genetically customized wine-yeast strains. Trends in Biotechnology, 20, 426-432

Salmon, J.M., Fornairon-Bonnefond. C. \& Mazauric, J.P. (2002). Interactions between wine lees and polyphenols: influence on oxygen consumption capacity during simulation of wine ageing. Journal of Food Science, 67, 1604-1609

Schlichtherle-Cerny, H, Grosch, W. (1998). Evaluation of taste compounds of stewed beef juice. $Z$ Lebensm Unters Forsch A, 207, 369-376 
Siebert, K.J. (2001). Quantitative structure-activity relationship modeling of peptide and protein behavior as a function of amino acid composition. J. Agric. Food Chem. 49, 851-858

Soufleros, E.H., Bouloumpasi, E., Tsarchopoulos, C., Biliaderis, C.G. (2003). Primary amino acid profiles of Greek white wines and their use in classification according to variety, origin and vintage. Food Chemistry, 80, 261-273

Steinksaus, K.H. (1997). Classification of fermented foods: a worldwide review of household fermentation techniques. Food Control, 8, 311-317

Tapiero, H., Mathé, G., Couvreur, P., Tew, K.D. (2002). Glutamine and glutamate. Biomedicine and Pharmacotherapy, 56, 446-457

Yamaguchi, S. \& Ninomiya, K. (1998). What is umami? In Food Reviews International, 14, 123-139. New York, Marcel Dekker Inc.

Yamaguchi, S. (1998). Basic properties of umami and its effects on food flavor. In Food Reviews International, 14, 139-177. New York, Marcel Dekker Inc.

Yoshida, Y. (1998). Umami taste and traditional seasonings. In Food Reviews International, 14, 213-247. New York, Marcel Dekker Inc. 


\title{
coresers \\ Analysis of glutamic acid in wine in relation to flavor: the link to umami
}

\author{
P.R. Klosse, W.H.M. Saris
}

Kevwords: wine, umami, amino acids, glutamic acid, palatability, quality, fermentation

Submitted.

\begin{abstract}
'Glutamic taste' or umami is reported to have a marked positive influence on flavor. Complexity, roundness and mouchfullness are often mentioned as flavor characteristics that describe the effect of umami in flavor. It was hypothesized that glutamic acid (GLU) is present in dry (non sweet) wines that are nevertheless mellow and rich in flavor. Ten wines, very different in flavor, were analyzed on amino acid profile and in particular GLU. This is one of the most important amino acids and it is generally found in fermented products. Amino acids were determined by highperformance liquid chromatography (HPLC). Regression analysis showed a strong relation between GLU and rich taste (ANOVA: $p<0,001$ ). In general, GLU enhances a mellow, coating mouthfeel and flavor richness. To verify this $2,5 \mathrm{gr}$. of monosodiumglutamate (MSG) was added to a full bottle of three of the sample wines. In a blind tasting $(n=19)$ the flavor was compared to the 'original' version. The wines with added GLU were found to be richer in flavor. Wines that were described as fresh with a contracting mouthfeel showed high amounts of arganine (ARG). It is possible that the flavor richness of GLU is 'counterbalanced' by ARG. In literature amino acid profiles are reported as a tool to classify wines from different regions or grape varieties. The results of our analysis suggest a major influence of vinification techniques. The application of specific techniques and starter yeast strains could be used to reach specific flavor characteristics.
\end{abstract}




\subsection{Introduction}

The important role in flavor of umami has been widely studied and documented. Foods with umami are considered to be more palatable and are spontaneously eaten in greater amounts, as indexed by a faster eating rate, less chewing, quicker swallowing and shorter times between bites (Bellisle, 1999). The presence of umami compounds is one of the Culinary Success Factors that determine the palatability of foods (Klosse et al., 2003a). Remarkably, in the many umami-publications, wines were not mentioned, and vice versa in wine related scientific publications umami was never mentioned as far as we are aware of the literature. Yet, in the fermentation and subsequent ageing of wines there is ample opportunity for umami to develop. Umami was discovered in Japan in 1908 by lkeda who noticed a flavor that was distinctly different from sweet, sour, bitrer and sait. It is not an outstanding flavor and even often hard to identify, but indispensable in harmonizing with other flavors. It enhances coating effects described as mouthfullness and roundness. it is also described as 'balancing, and blending', giving 'continuity', thickness, and in general a feeling of satisfaction. Umami does not need to be specifically identified by the consumer. Its flavor enhancing effect occurs even if the concentration is too low to allow the taster to discriminate its specific taste (Bellisle, 1999).

Glutamic acid is often found in all kinds of fermented products. During fermentation protein is decomposed in an enzymatic process which changes and increases the palatability of products. This may occur in a wide range of food products. Fermented sauces like soy sauce and oyster sauce are well-known examples. Lactic acid fermentation is another example. In aged cheese and especially Parmesan which matures for two years, high amounts of GLU are reported (Lawlor et al., 2002; Ninomiya, 1998). Sauerkraut, olives, cucumber and other vegetable pickles are other examples of lactic acid fermentations (Steinkraus, 1997). GLU is also known to accumulate in the ripening of hams and sausages (Ninomiya, 1998; Hierro, de la Hoz, Ordónez, 1999). In general, amino acids are common in microbiologically fermented foods and drinks, which implies that micro organisms like bacteria and yeasts are major, but not exclusive, sources of free amino acids (Brückner, et al. 1995).

The alcoholic fermentation of grape juice gives wine. Besides water, principal components are alcohol and organic acids. Depending on the vinification method residual sugars, $\mathrm{CO}_{2}$ and tannins may also be noticeably present. The flavor profile of a wine is the result of a balance between these principal components. Alcohol and residual sugars are coating influences in regard to the mouthfeel of wines, while acids, $\mathrm{CO}_{2}$, and tannins are contracting influences. The mouthfeel of a certain wine is 
the result of the proportional presence of these components (Peynaud, 1980). Next to mouthfeel, wines can be more or less rich in flavor. Again, the principal components are of influence, but they do not explain the full flavor profile. Two wines may be both moderate in alcohol and fully dry (no residual sugars), have moderate amounts of organic acids and/or tannins and yet there can be a big difference in flavor richness. Which specific compound is accountable for this kind of richness in flavor? Viewing the important role of GLU in the flavor of other foods, we hypothesized that this amino acid is an important contributor to the flavor of wine and especially in wines that are classified as 'balance, high'. If GLU is considered as an important element in the flavor of wine, it is interesting to test if the addition of monosodiumglutamate (MSG) to wines has similar effects. Therefore, as a second part of the study we selected three wines and added small amounts. These wines were blindly tested by 19 sommelier students and scored on flavor richness in comparison to the 'original' wines.

\subsection{Materials and methods}

\subsubsection{Wine samples}

Ten wines, 6 white and 4 red, were selected upon their organoleptic profile, representing different flavor styles. Of the samples two wines were made of the sauvignon blanc grape (Sancerre and Fransola), three wines of the chardonnay grape (Tieffenbrunner, la Provenquière, and la Colombette), and two wines of the pinot noir grape (Bourgogne Clos Margot, and Maranges ler Cru). Although in these cases the same grape was used, the applied vinification techniques and flavor style were different. Three wines were classified as 'fresh', another three as 'round', and four wines were characterized as 'balance, high' based on the Flavor Styles Cube classification (Klosse, 2003b). Table 6-1 gives a synopsis of the wine samples. The last column shows the pre-analysis expectation of the presence of GLU.

Considering the characteristic of Umami that small amounts are enough to give the desired effect it is to be expected that wines with low amounts of GLU should benefit from the addition of MSG and that this effect would be negligible in wines that already have high amounts of GLU. In the second study this was verified by selecting 3 wines of the samples: the Montepulciano d'Abruzzo (low GLU), the Chardonnay Tieffenbrunner (low GLU) and the Maranges 1er Cru (high GLU). In the tasting the original version was compared to a sample to which 2,5 grams of MSG (Ajinomoto, Japan) was added to a full bottle $(0,75 \mathrm{I})$. The wines were tasted blindly by a group of 19 sommelier students who were asked which of the samples had the richest flavor. 


\begin{tabular}{|c|c|c|c|c|c|c|c|}
\hline \multirow[t]{2}{*}{$\begin{array}{l}\text { Table 6-1: } \\
\text { WHITE WINES }\end{array}$} & \multicolumn{4}{|c|}{ VINIFICATION } & \multirow{2}{*}{$\begin{array}{l}\text { Rich } \\
\text { taste } \\
\left.(1-10)^{1}\right)\end{array}$} & \multirow{2}{*}{$\begin{array}{l}\text { Flavor } \\
\text { Style } \\
\left.{ }^{2}\right)\end{array}$} & \multirow{2}{*}{$\begin{array}{l}\text { Expected } \\
\text { GLU level } \\
\left.{ }_{3}\right)\end{array}$} \\
\hline & $\begin{array}{l}\text { Skin } \\
\text { contact }\end{array}$ & $\begin{array}{l}\text { Barrel } \\
\text { fermen- } \\
\text { tation }\end{array}$ & $\begin{array}{l}\text { Barrel } \\
\text { ageing }\end{array}$ & $\begin{array}{l}\text { Malo- } \\
\text { lactic } \\
\text { fermen } \\
\text { tation } \\
\end{array}$ & & & \\
\hline $\begin{array}{l}2001 \text { Sancerre, } \\
\text { A. Mellot (sauvignon } \\
\text { blanc) Loire, France }\end{array}$ & - & - & - & - & 4 & Fresh & - \\
\hline $\begin{array}{l}2001 \text { Fransola } \\
\text { (sauvignon blanc) } \\
\text { Torres. Penedes, Spain }\end{array}$ & $x$ & $x$ & $x$ & $x$ & 7 & $\begin{array}{l}\text { Balance } \\
\text { high }\end{array}$ & \pm \\
\hline $\begin{array}{l}2001 \text { Chardonnay } \\
\text { Tiefenbrunner, Alto } \\
\text { Adige, Italy }\end{array}$ & - & - & - & - & 3 & Fresh & - \\
\hline $\begin{array}{l}2001 \text { Chardonnay, } \\
\text { La Provenquière. } \\
\text { Languedoc, France }\end{array}$ & - & - & - & $x$ & 5 & Round & \pm \\
\hline $\begin{array}{l}1999 \text { Chardonnay Demi } \\
\text { Muid, la Colombetre, } \\
\text { Languedoc, France }\end{array}$ & + & $x$ & $x$ & $x$ & 9 & $\begin{array}{l}\text { Balance } \\
\text { high }\end{array}$ & + \\
\hline $\begin{array}{l}2000 \text { Roussanne, } \\
\text { Cante Perdrix, } \\
\text { Languedoc, France }\end{array}$ & - & $50 \%$ & $50 \%$ & $\mathrm{x}$ & 4 & Round & \pm \\
\hline RED WINES & & & & & & & \\
\hline $\begin{array}{l}2001 \text { Montepulciano } \\
\text { d'Abruzzo, Settembre, } \\
\text { Italy }\end{array}$ & $x$ & - & - & $x$ & 3 & Fresh & - \\
\hline $\begin{array}{l}1999 \text { Bourgogne } \\
\text { Pinot Noir Clos Margot, } \\
\text { Doudet-Naudin, France }\end{array}$ & $x$ & - & - & $x$ & 6 & Round & \pm \\
\hline $\begin{array}{l}1998 \text { Maranges 1er Cru } \\
\text { La Fussiere, V. Girardin } \\
\text { Bourgogne, France }\end{array}$ & $x$ & $x$ & $x$ & $x$ & 8 & $\begin{array}{l}\text { Balance } \\
\text { high }\end{array}$ & + \\
\hline $\begin{array}{l}2001 \text { Segada, Ribatejo, } \\
\text { DFJ Vinhos, Portugal }\end{array}$ & $x$ & $x$ & $x$ & $x$ & 9 & $\begin{array}{l}\text { Balance } \\
\text { high }\end{array}$ & + \\
\hline
\end{tabular}

Table 6-1: sample wines.

1) $I=$ low, 10= high; 2) according to Klosse (2003b); 3) - (GLU low): $\pm(G L U$ average); + (GLU high) 


\subsubsection{Chemical analysis}

Amino acids in the wine samples were determined by the fully automated highperformance liquid chromatography (HPLC) method, using 2-3 $\mu \mathrm{m}$ Spherisorb ODS II packing material and pre-column derivatization with ortho-phthaldialdehyde (OPA) as described previously (Van Eijk, 1993).

\subsubsection{Statistical procedures}

SPSS was used to execute a factor analysis to assess the factors that explain 'flavor richness'. Extraction method: Principal Component Analysis. Rotation Method: varimax with Kaiser Normalization. A Rotation converged in 5 iterations. The subsequent ANOVA and coefficient were also calculated in SPSS.

\subsection{Results}

Table 6-2 shows the top 5 amino acids of each wine: alanine (ALA) and GLU are top 3 in all samples. Other important amino acids are arginine (ARG), lysine (LYS), glycine (GLY), and asparagine (ASP). The total results of the chemical analysis of the ten sample wines are presented in table 6-3 (appendix). GLU is one of the most abundant amino acids in wine

\begin{tabular}{|c|c|c|c|c|c|}
\hline Table 6-2: & 1 & 2 & 3 & 4 & 5 \\
\hline 2001 Chardonnay Tiefenbrunner, Italy & ARG & ALA & GLU & LYS & ASP \\
\hline $\begin{array}{l}2001 \text { Chardonnay La Provenquiere, } \\
\text { Languedoc }\end{array}$ & GLU & LYS & ALA & LEU & ASP \\
\hline $\begin{array}{l}1999 \text { Chardonnay La Colomberte, } \\
\text { Languedoc }\end{array}$ & ALA & LYS & GLU & LEU & ASP \\
\hline 2001 Sancerre, A. Mellot (sauvignon), Loire & ARG & ALA & GLU & LYS & ASP \\
\hline 2001 Fransola (sauvignon) Torres, Penedes & ARG & ALA & GLU & ASN & GLY \\
\hline 2000 Roussanne, Cante Pedrix, Languedoc & LYS & GLU & ALA & LEU & ASP \\
\hline 2001 Segada tinto, Ribatejo, Portugal & ALA & GLU & GLY & ARG & ASP \\
\hline $\begin{array}{l}1999 \text { Bourgogne Clos Margot, } \\
\text { Doudet-Naudin }\end{array}$ & ALA & GLU & GLY & ASN & LYS \\
\hline $\begin{array}{l}1998 \text { Maranges Ter Cru La Fussière, } \\
\text { Bourgogne }\end{array}$ & ALA & GLU & GLY & ASN & ASP \\
\hline $\begin{array}{l}2001 \text { Montepulciano d'Abruzzo, } \\
\text { Settembre, ttaly }\end{array}$ & GLY & ALA & GLU & ASP & ASN \\
\hline
\end{tabular}

Table 6-2: the 5 most important amino acids of each sample wine 
Figure 6-1 shows graphically the absolute amount of GLU. The Montepulciano. Rousanne, Chardonnay Provenquière and Chardonnay Tieffenbrunner score below $300 \mu \mathrm{mol} / \mathrm{I}$, while the Maranges, Fransola, Segada tinto and Chardonnay Colombette score above $400 \mu \mathrm{mol} / \mathrm{l}$. The total amount of amino acids ranges from $1574 \mu \mathrm{mol} / \mathrm{l}$ (Montepulciano) to $5751 \mu \mathrm{mol} / 1$ for the Fransola. Fransola and the Sancerre are both Sauvignon wines and they have the highest amounts of total amino acids; a major contributor being ARG and ALA that both wines contain in extremely high amounts. However, GLU as a percentage of total amino acids is low for these wines (figure 6-2). Just as for the Chardonnay Tieffenbrunner in which ARG is also high. Interestingly, this wine is classified as fresh, just as the Sancerre.

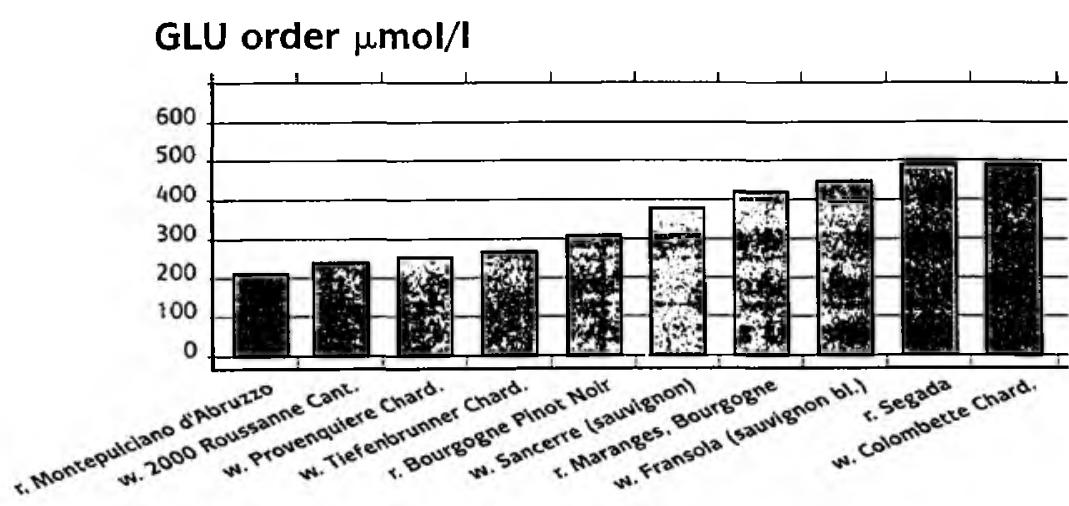

Figure 6-1:sample wines in absolute GLU order ( $\mu$ mol/l)

\section{GLU order \% of total Amino Acids}

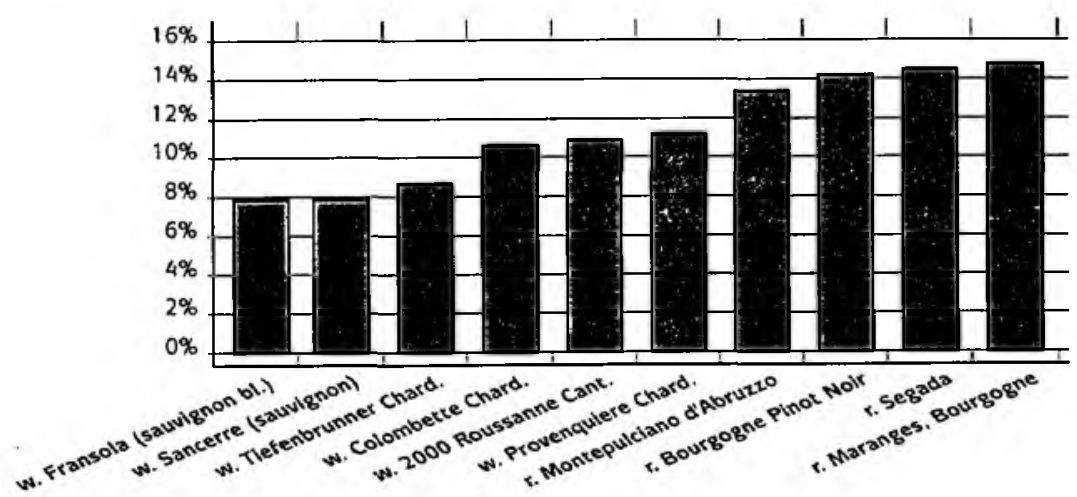

Figure 6-2: sample wines in relative GLU order as a \% of total amino acids 
A factor - and a regression analysis on the amino acid profiles were executed to establish if GLU is a precursor of rich taste. The results are shown in table 6-4, 6-5 and 6-6. Rich taste is mainly explained by factor 2. GLU, GLY, aAB (Amino Butyric acid) and ALA are the four main amino acids in factor 2 . Interestingly, 'rich taste' scores negatively in factor 3 where ARG and ornitine (ORN) are predominant. The regression analysis (table 6-5) shows a strong relation between GLU and flavor richness (ANOVA $p<0,001)$; the combination of GLU and CIT explains richness even more significantly (ANOVA: $p<0,000$ ). Compared to GLU the amount of CIT is low. However, its influence on 'rich flavor' may be significant. From table 6-6 the relation between GLU and richness can be deducted which is formulated as 'flavor richness $=$

$-0,618+0,018 \times$ GLU', which clearly indicates that insufficient amounts of GLU have a negative effect on flavor richness.

\begin{tabular}{|c|c|c|c|c|}
\hline \multirow[t]{3}{*}{ Table 6-4: } & \multicolumn{4}{|c|}{ ROTATED COMPONENT MATRIX(A) } \\
\hline & \multicolumn{4}{|c|}{ COMPONENT } \\
\hline & 1 & 2 & 3 & 4 \\
\hline LYS & .996 & & & \\
\hline MET & .981 & & & \\
\hline LEU & .971 & & & \\
\hline PHE & .916 & & & \\
\hline TYR & .898 & & & \\
\hline ASP & .885 & & .316 & \\
\hline ILE & .866 & & & .366 \\
\hline VAL & .856 & .417 & & \\
\hline SER & .748 & 608 & & \\
\hline GLY & & .929 & & \\
\hline GLU & .422 & .869 & & \\
\hline richness & & .832 &,- 378 & \\
\hline AAB & .502 & .783 & & \\
\hline ALA & & .758 & .390 & .415 \\
\hline THR & .679 & .685 & & \\
\hline ORN & & & .870 & \\
\hline ARG & & & .829 & .432 \\
\hline $\mathrm{CIT}$ & & & .814 & \\
\hline TAU & & & .684 & .656 \\
\hline HIS & & & .677 & \\
\hline TRP & & & & .938 \\
\hline GLN & .380 & & .363 & .765 \\
\hline ASN & &, 595 & & .734 \\
\hline
\end{tabular}

Table 6-4:Analysis of factors that explain 'flavor richness' 


\begin{tabular}{|c|c|c|c|c|c|c|}
\hline \multirow{2}{*}{\multicolumn{2}{|c|}{$\begin{array}{l}\text { Table 6-5: } \\
\text { MODEL }\end{array}$}} & \multicolumn{5}{|l|}{ ANOVA } \\
\hline & & \multirow{2}{*}{$\frac{\text { Sum of Squares }}{37.132}$} & \multirow{2}{*}{$\frac{\mathrm{df}}{1}$} & Mean Square & \multirow{2}{*}{$\frac{F}{23.825}$} & \multirow{2}{*}{$\frac{\text { Sig. }}{.001(a)}$} \\
\hline 1 & Regression & & & 37,132 & & \\
\hline & Residual & 12.468 & 8 & 1.559 & & \\
\hline & Total & 49,600 & 9 & & & \\
\hline \multirow[t]{3}{*}{2} & Regression & 47,675 & 2 & 23,837 & 86,667 & $.000(b)$ \\
\hline & Residual & 1.925 & 7 & 275 & & \\
\hline & Total & 49,600 & 9 & & & \\
\hline \multicolumn{7}{|c|}{ a Predictors: (Constant), GLU } \\
\hline \multicolumn{7}{|c|}{ b Predictors: (Constant), GLU, CIT } \\
\hline \multicolumn{7}{|c|}{ c Dependent Variable: richness } \\
\hline
\end{tabular}

Table 6-5: Regression analysis

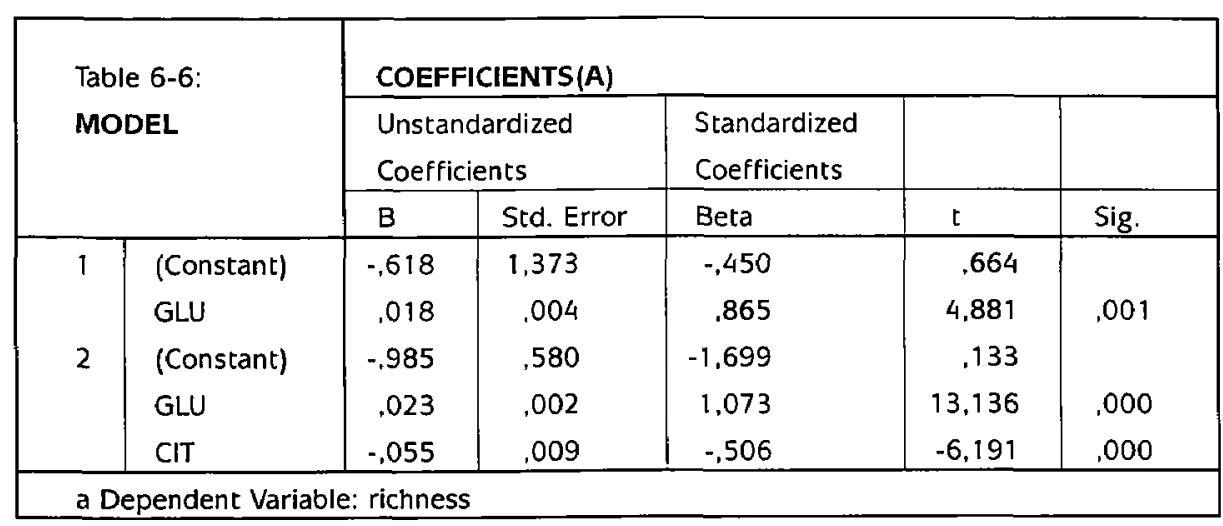

Table 6-6: coefficients of GLU

In table 6-7 the results are shown from the MSG addition-tasting experiment. From this experiment it can be concluded that the addition of MSG enhances the richness in flavor in wines that are low in GLU. The wine that was already rich in GLU did not profit from MSG, rather the effect was negative, richness in flavor decreased.

\begin{tabular}{|l|l|l|}
\hline $\begin{array}{l}\text { Table 6-7: } \\
\text { NAME WINE + 2,5 GR. MSG }\end{array}$ & $\begin{array}{l}\text { Flavor richness } \\
\text { higher }\end{array}$ & $\begin{array}{l}\text { Flavor richness } \\
\text { not higher }\end{array}$ \\
\hline Tiefenbrunner Chardonnay & 18 & 1 \\
\hline Montepulciano d'Abruzzo & 13 & 6 \\
\hline Maranges ler Cru & 3 & 16 \\
\hline
\end{tabular}

Table 6-7: Effect on flavor by adding MSG to sample wines ( $N=19$ ) 


\subsection{Discussion}

This research was initiated to explain the richness in flavor of wines that are classified as 'balance, high' (corner 7) of the Flavor Styles Cube. The Flavor Styles Cube was developed as a classification system. Its three dimensions were defined as coating mouthfeel, contracting mouthfeel and flavor richness. Different combinations of these dimensions result in eight specific groups of flavor: the flavor styles. From this system it was deducted that wines with a flavor style labeled as 'balance, high' would contain relatively high amounts of GLU. The flavor profile of wine cannot solely be explained with an analysis of amino acids, although their role in flavor is likely to be underestimated. Wines were selected that represent this flavor style, as well as alternatives that mostly differ in applied vinification technique. Based on such organoleptic selection we hypothesized that the Chardonnay la Colombette. Maranges and Segada tinto would score high in GLU. In GC analysis these wines indeed scored high, together with the Fransola. Organoleptically last mentioned wine was classified as 'balance, high' which fits the GLU-hypothesis, but in flavor richness it was judged lower than the other three. Figure 6-2 shows the amount of GLU relative to the total amount of amino acids. Fransola, Sancerre and Chardonnay Tieffenbrunner score below $9 \%$. When viewed relatively the Fransola is lowest in GLU which indicates that probably other amino acids are of importance, and especially ARG. Organoleptically, the Tieffenbrunner and the Sancerre were classified around corner 4 of the flavour styles cube (fresh), which suggests that ARG may also be an amino acid that influences flavor in a specific way. The richness in flavor that is related to GLU may well be 'counterbalanced' by ARG. Support for this assumption is found in the factor analysis in table 6-4 where ARG was grouped together with a negative value on rich flavor. Further support is found in the results of the Montepulciano. This wine is classified as 'fresh' (corner 4) just as the Sancerre and the Tieffenbrunner; it is the lowest in GLU and contains almost no ARG.

The Chardonnay la Provenquière, Rousanne and Bourgogne Clos Margot were selected as examples of wines where GLU would be moderately present. Their flavor style was classified as round, which implies that in mouthfeel the coating effects prevail over the contracting ones. Especially the relative GLU order supports this assumption: from low to high these wines rank 5, 6 and 8. In absolute GLU order they rank from low to high 2, 3, and 5 . This can be explained by the fact that in mouthfeel other factors are more important than GLU and especially the balance between alcohol and residual sugars on the one side and acidity and tannins on the other. The analysis of the Rousanne for instance shows a residual sugar content of $3 \mathrm{gr} . / \mathrm{l}$ and an alcohol of $13^{\circ} 9$. There is only $2,4 \mathrm{~g} / \mathrm{l}$ of total acidity and there are no 
tannins to balance these coating aspects, leaving mouthfeel on the coating side. The mouthfeel of this wine has 'fullness', but lacks sufficient depth to be rich in flavor.

The results of the analysis of the ten different wines indicate that vinification techniques can be considered as major instruments in attaining the umami component in the flavor of wine. In literature we found references that support this assumption. It should be noted however, that generally amino acid profiles seem to be considered as interesting differentiators to classify wines (Kim et al. (1996); Košir $\&$ Kidrič (2002); Soufleros et al. (2003). No specific references were found in relation to their role on the flavor of wine. Yet, the following aspects in the process of winemaking may be of influence:

A. Grape varietv and maturitv. The maturity of grapes is strongly related to both the amount and composition of amino acids to be found. GLU is predominantly found in the grape skin (Lamikanra \& Kassa, 1999). This implies that winemaking techniques where there is 'skin contact' are prone to be higher in GLU. This is by definition the case for all red wines. The GLU content of white wines is likely to be enhanced by skin contact or in French macération pelliculaire before fermentation. Late harvest choices are likely to be beneficiai to umami potentiality in both white and red wines. A prerequisite is that GLU is not (fully) consumed during the alcoholic fermentation.

B. Alcoholic fermentation. influence of veast. During the alcoholic fermentation several amino acids undergo a series of biotransformations. giving higher alcohols, aldehydes, esters and ketonic acids. As such amino acids are both important for the success of the fermentation process as for the result of it in terms of aroma, flavor (including texture) and alcohol. Generally ARG, $y-A B, G L U$, and ALA are reported as being the primary free amino acids in wine (Soufleros et al., 2003). However, although our study basically confirms the importance of ARG, ALA and GLU, only one of the Chardonnay wines (Tieffenbrunner) scored high in ARG. In the other two Chardonnay wines ARG did not rank within the first five most important amino acids. This implies that a certain care should be applied in classifying grapes upon their amino acid profile. This profile is likely to be influenced by climatic and regional circumstances and vinification.

C. Maiolactic fermentation. After the alcoholic fermentation the malolactic fermentation can be applied to wines. Soufleros et al. (2003) reported that in this lactic bacteria action the amino acid concentration generally reduced, from $490 \mathrm{mg} / \mathrm{l}$ to $315 \mathrm{mg} / \mathrm{l}$. Interestingly, the GLU content remained about intact ( $36.3 \mathrm{mg} / \mathrm{l}$ vs. $36.5 \mathrm{mg} / \mathrm{l}$ after malo). This implies that its relative proportion increased with $70 \%$, from $7 \%$ to $12 \%$. 
D. Special tvpes of fermentation: sweet wines and méthode traditionnelle. Sweet wines are characterized by much higher amino acid values than dry wines. Soufleros et al. (2003) reported $810 \mathrm{mg} / \mathrm{l}$ for sweet wines and $351 \mathrm{mg} / \mathrm{l}$ for dry wines. The use of overripe grapes, not fully fermented may account for this observation. In Port wines a mean value was reported of $1345 \mathrm{mg} / \mathrm{l}$ and in Port imitations $2016 \mathrm{mg} / \mathrm{l}$. (Herbert et al., 2000). Brückner et al. (1995) reported high amounts of GLU in fortified wines in general (Madeira, Sherry, Port) which is also related to the maturation of these wines for several years. Another type of sweet wines are made from very mature grapes that have been affected by the botrytis cinerea or 'noble rot'. A fungus which grows on the skin of the grapes, which gradually punctures the skin enabling moisture to escape, while concentrating other elements, like amino acids. In the traditional method of making sparkling wines such as Champagne, yeast in a sweet substance is added to still wine. It provokes a second fermentation which takes place in the bottle, preventing the $\mathrm{CO}_{2}$ to escape and also leading to an increase in amino acids as a result of autolysis of dead yeast. Sparkling wines produced with the cuve close method (not in bottle, but in large recipients) exhibited lower amino acid concentrations (Soufleros et al., 2003). Prestigious Champagnes are aged up to five years or even longer on their lees. The flavor of these wines is notably softer and more complex than wines that have aged less long. We hypothesize that analysis will show a considerable rise in GLU.

E. Other sources: ageina. 'sur lie and batonnage'. The same process as mentioned above is seen in the vinification of white wines which are kept on 'their lees', consisting mainly of dead yeast cells. After some weeks an enzymatic process called 'autolysis' commences. This process yields nitrogen compounds, polysaccharides, and glycoprotein's and can be enhanced by stirring the wine (French: batonnage), thus keeping the lees in suspension. Feuillat (1994) reported that in this process, the amount of amino acids is likely to increase over $60 \%$, but these were not specified in this paper. From an organoleptic point of view several studies have indicated however, that wine ageing on lees yielded complex, wellbalanced and smooth wines (Salmon, et al., 2002). Considering the results of our study we find it highly likely that it is the amount of GLU that is positively affected by this technique.

The accumulation of amino acids is also reported to continue with ageing. However, this aspect has been poorly studied over a long period and the results are difficult to interpret due to the many variables involved (Nouadje, 1997. Ancín, 1996). 
In general it can be concluded that GLU is an important, though not the only, amino acid that influences the flavor of wine, and it is a precursor of rich taste that characterizes corner 7 of the flavor styles cube, classified as 'balance, high'. Small amounts of GLU are sufficient to attain this effect as was shown in the tasting of wines where the sodium salt MSG was added.

The role of yeast in the alcoholic fermentation requires special attention. Most modern, professional winemakers use specially selected starter cultures of the saccharomyces cerevisiae. Pretorius \& Bauer (2002) reported that pioneering winemakers demand starter culture chains with a whole range of specialized properties that can add value to the final product. Such demands are common in the making of cheese where the use of special starter lactic acid bacteria is a common procedure. They suggest the need for the development of wine yeasts that could impart specific desirable characteristics to a wine and mentioned quite a few targets for the genetic improvement of wine-yeast strains. Typically, no specific references are made to the contribution of yeast in the development of GLU. However, based on the results presented here, it could be an interesting addition to the target list. Further research is therefore encouraged to elucidate these effects. For instance, it would be useful to establish how much GLU is required to yield a positive effect on the flavor of wine and how fermentation and ageing processes can be influenced to enhance the presence of umami compounds in wine. Also, the role of other amino acids like ARG and GLY needs further elucidation.

\section{References}

Ancín, C., Ayestarán, B. \& Garrido, J. (1996). Sedimentation clarification of Garnacha musts. Consumption of amino acids during fermentation and ageing. Food research International, 29, 345-353

Bellisle, Fr. (1999). Glutamate and the umami taste: sensory, metabolic, nutritional and behavioral considerations. A review of the literature published in the last 10 years. Neuroscience and Biobehavioral Reviews, 23, 423-438

Brückner, H., Langer, M., Lüpke, M., Westhauser, T., Godel, H. (1995). Liquid chromatographic determination of amino acid derivatization with o-phthaldialdehyde and chiral thiols. Application with reference to food science. Journal of Chromatography A, 697, 229-245

Desiere, F., Germain, B., Watzke, H., Pfeifer, A. \& Saguy, S. (2002). Bioinformatics and data knowledge: the new frontiers for nutrition and foods. Food Science and Technology, 12, 215-229 
Eijk, H.M.H. van, Rooyakkers, D.R. \& Deutz, N.E.P. (1993). Rapid routine determination of amino acids in plasma by high-performance liquid chromatography with a 2-3 mm Sperisorb ODS II column. Journal of Chromatography, 620, 143-148

Feuillat, M. (1994). Fermentation dans le bois et élevage sur lies des vins blanc Influence des macromolécules de levures sur les arômes. Revue des CEnologues, 71, 19-21

Herbert, P., Barros P., Ratola, N. \& Alves A. (2000). HPLC determination of amino acids in musts and Port wines using OPA/FMOC derivates. Journal of Food Science, $65,1130-1133$

Hierro, E., Hoz, L. de la, Ordónez, J.A. (1999). Contribution of the microbial and meat endogenous enzymes to the free amino acid and amine contents of dry fermented sausages. J. Agric. Food Chem. 47, 1156-1161

Kim, K.R., Kim, J.H., Cheong, E., Jeong, C. (1996). Gas chromatographic amino acid profiling of wine samples for pattern recognition. Journal of Chromatography, 722, 303-309

Klosse, P.R., Riga, J., Cramwinckel, A.B., Saris, W.H.M. (2003a). The formulation and evaluation of Culinary Success Factors (CSFs) that determine the palatability of food. Submitted.

Klosse, P.R., Cramwinckel, A.B., Schevers, F, Saris, W.H.M. (2003b). A proposal for the classifications of flavors. Submitted.

Košir, I.J. and Kidrič, J. (2002). Use of modern nuclear magnetic resonance spectroscopy in wine analysis: determination of minor compounds. Analytica Chimica Acta, 458, 77-84

Kranenburg, R. van, Kleerebezem, M., Hylckama Vlieg, J. van, Ursing. B.M. Boekhorst, J., Smit, B.A., Ayad, E.H.E., Smit, G., Siezen, R.J. (2002). Flavour formation from amino acids by lactic acid bacteria: predictions from genome sequence analysis. International Dairy Journal, 12, 111-121

Lamikanra, O. \& Kassa, A.K. (1999) Changes in the free amino acid composition with maturity of the noble cultivar of vitis rotundifolia Michx. grape. J. Agric. Food Chem. 47, 4837-4841

Lawlor, J.B., Delahunty, C.M., Wilkinson, M.G., Sheehan, J. (2002) Relationships between the gross, non-volatile and volatile compositions and the sensory attributes of eight hard type cheeses. International Dairy Journal, 12, 493-509

Ninomiya, K. (1998). Natural Occurrence. In Food Reviews International, 14. 177-213. New York, Marcel Dekker Inc

Nouadje, G., Siméon, N., Dedieu, F., Nertz, M., Puig, Ph., Couderc, F. (1997). Determination of twenty eight biogenic amines and amino acids during wine agieng by micelllar electrokinetic chromatography and laser-induced fluorescence detection. Journal of Chromatography A, 765, 337-343 
Oord, A.H. van den, Wassenaar, P.D. van. (1997). Umami peptides: assessment of their alleged taste properties. Z Lebensm Unters Forsch $A, 205,125-130$

Peynaud, E. (1980). Le goût du vin. Paris, Bordas

Pretorius, I.S. \& Bauer, F. (2002). Meeting the consumer challenge through genetically customized wine-yeast strains. Trends in Biotechnology, 20, 426-432

Salmon, J.M., Fornairon-Bonnefond, C. \& Mazauric, J.P. (2002). Interactions between wine lees and polyphenols: influence on oxygen consumption capacity during simulation of wine ageing. Journal of Food Science, 67, 1604-1609

Schlichtherle-Cerny, $H$, Grosch, W. (1998). Evaluation of taste compounds of stewed beef juice. $Z$ Lebensm Unters Forsch A, 207, 369-376

Siebert, K.J. (2001). Quantitative structure-activity relationship modeling of peptide and protein behavior as a function of amino acid composition. J. Agric. Food Chem. 49, 851-858

Soufleros, E.H., Bouloumpasi, E., Tsarchopoulos, C., Biliaderis, C.G. (2003). Primary amino acid profiles of Greek white wines and their use in classification according to variety, origin and vintage. Food Chemistry, 80, 261-273

Steinkraus, K.H. (1997). Classification of fermented foods: a worldwide review of household fermentation techniques. Food Control, 8, 311-317

Tapiero, H., Mathé, G., Couvreur, P., Tew, K.D. (2002). Glutamine and glutamate. Biomedicine and Pharmacotherapy, 56, 446-457

Yamaguchi, S. \& Ninomiya, K. (1998). What is umami? In Food Reviews International, 14, 123-139. New York, Marcel Dekker Inc.

Yamaguchi, S. (1998), Basic properties of umami and its effects on food flavor. In Food Reviews International, 14, 139-177. New York, Marcel Dekker Inc.

Yoshida, Y. (1998). Umami taste and traditional seasonings. In Food Reviews International, 14, 213-247. New York, Marcel Dekker Inc. 


\section{Appendix: table 6-3}

\begin{tabular}{|c|c|c|c|c|c|c|c|c|c|}
\hline \multirow{2}{*}{$\begin{array}{l}\text { Table 6-3 } \\
\text { WINES }\end{array}$} & & & & & & & & & \\
\hline & $\begin{array}{l}1 . \\
\text { ASP } \\
\end{array}$ & $\begin{array}{l}2 . \\
\text { GLU }\end{array}$ & $\begin{array}{l}3 . \\
\text { ASN } \\
\end{array}$ & \begin{tabular}{|l}
4. \\
SER \\
\end{tabular} & $\begin{array}{l}5 . \\
\text { GLN } \\
\end{array}$ & $\begin{array}{l}6 . \\
\text { HIS } \\
\end{array}$ & $\begin{array}{l}7 . \\
\text { GLY }\end{array}$ & $\begin{array}{l}8 . \\
\text { THR } \\
\end{array}$ & $\begin{array}{l}9 . \\
\mathrm{Cl} \\
\end{array}$ \\
\hline $\begin{array}{l}\text { (white) } 2001 \text { Tiefenbrunner } \\
\text { Chardonnay Alto Adige, Italy }\end{array}$ & 206 & 259 & 130 & 113 & 9 & 83 & 200 & 128 & 21 \\
\hline $\begin{array}{l}\text { (white) } 2001 \text { Domaine La } \\
\text { Provenquière Chardonnay. } \\
\text { Languedoc. France }\end{array}$ & 190 & 242 & 121 & 91 & 5 & 54 & 158 & 95 & 0 \\
\hline $\begin{array}{l}\text { (white) } 1999 \text { Domaine la } \\
\text { Colombette Chardonnay, } \\
\text { Demi Muid. Languedoc. } \\
\text { France }\end{array}$ & 349 & 490 & 244 & 204 & 6 & 41 & 311 & 202 & 16 \\
\hline $\begin{array}{l}\text { (white) } 2001 \text { Sancerre, } \\
\text { A. Mellot (sauvignon), } \\
\text { Loire, France }\end{array}$ & 313 & 398 & 149 & 146 & 4 & 99 & 227 & 155 & 70 \\
\hline $\begin{array}{l}\text { (white) } 2001 \text { Fransola } \\
\text { (sauvignon blanc) } \\
\text { Torres, Penedes, Spain }\end{array}$ & 226 & 452 & 448 & 121 & 13 & 81 & 341 & 140 & 50 \\
\hline $\begin{array}{l}\text { (white) } 2000 \text { Domaine } \\
\text { Cante Pedrix Roussanne, } \\
\text { Languedoc, France }\end{array}$ & 168 & 240 & 112 & 100 & 4 & 68 & 150 & 110 & 8 \\
\hline $\begin{array}{l}\text { (red) } 2001 \text { Segada, DFJ } \\
\text { Vinhos, Ribatejo, Portugal } 235\end{array}$ & 490 & 182 & 159 & 0 & 94 & 381 & 160 & 10 & 330 \\
\hline $\begin{array}{l}\text { (red) } 1999 \text { Bourgogne } \\
\text { Pinot Noir, Clos Margot. } \\
\text { Doudiet-Naudin, France } \\
\end{array}$ & 115 & 312 & 190 & 96 & 0 & 75 & 234 & 125 & 11 \\
\hline $\begin{array}{l}\text { (red) } 1998 \text { Maranges 1er } \\
\text { Cru "La Fussière, V. Girardin, } \\
\text { Bourgogne, France }\end{array}$ & 178 & 432 & 203 & 149 & 0 & 3 & 331 & 154 & 21 \\
\hline $\begin{array}{l}\text { (red) } 2001 \text { Settembre, } \\
\text { Montepulciano } \\
\text { d'Abruzzo, Italy }\end{array}$ & 127 & 209 & 106 & 55 & 0 & 64 & 302 & 94 & 8 \\
\hline
\end{tabular}

Table 6-3: HPLC analysis of amino acids in sample wines 
Analysis of glutamic acid in wine in relation to flavor: the link to umami

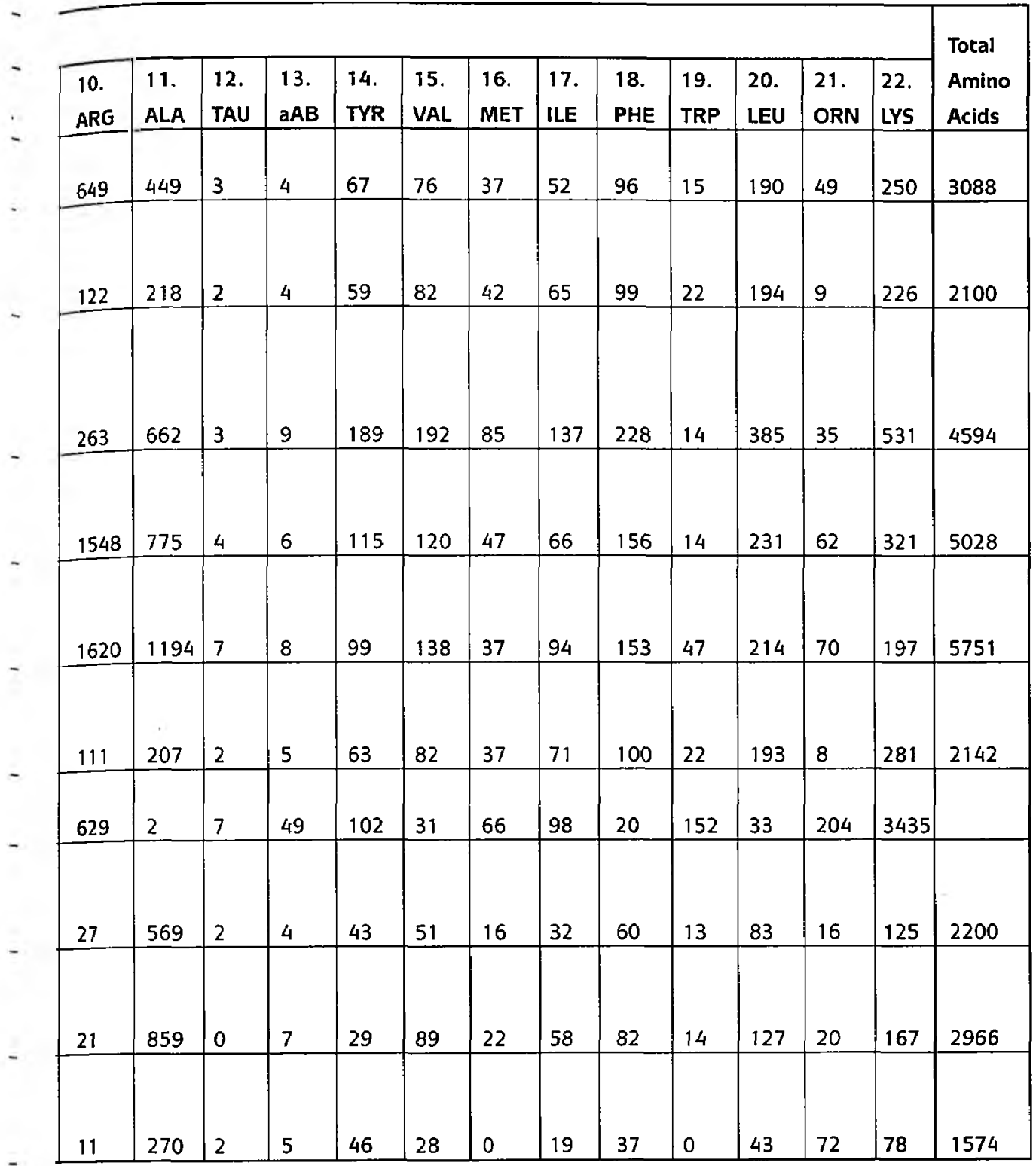




\section{Dowe \\ Discussion and general conclusions}

\subsection{Only 'gustation' is a sense; flavor registration is a sublimation af senses}

Flavor and taste are two different concepts and it is important to differentiate the two. Flavor is used in regard to products, while taste is related to the human perception of flavor. In line with this differentiation the concepts palatability and liking can be distinguished, which makes it possible to understand that even palatable products need not necessarily be liked. Although these definitions are not new, it is remarkable to note how often in literature the concepts are mixed. And if in articles flavor is used in regard to foods or drinks, then it is likely that it is interpreted as just the combination of the gustatory and olfactory elements (Prescott, 1999). The trigeminal elements are rarely included. Yet the 1SO definition leaves no room for such interpretations and clearly states that flavor is the combination of gustatory, olfactory and trigeminal elements (Birch, 1999). In a sensorial context 'taste' can be considered as the gustatorial part of flavor registration, principally involving papillae on the tongue and registering (as far is now known) sweet, salt, sour, bitter, umami, and fatty acids (e.g. Bray, 2000). It should be noted that the tongue is not the exclusive 'organ' of gustation. It is also involved in the registration of trigeminal components with as instrument, among others, a distinct kind of papillae, the filiform ones (figure 7-1).

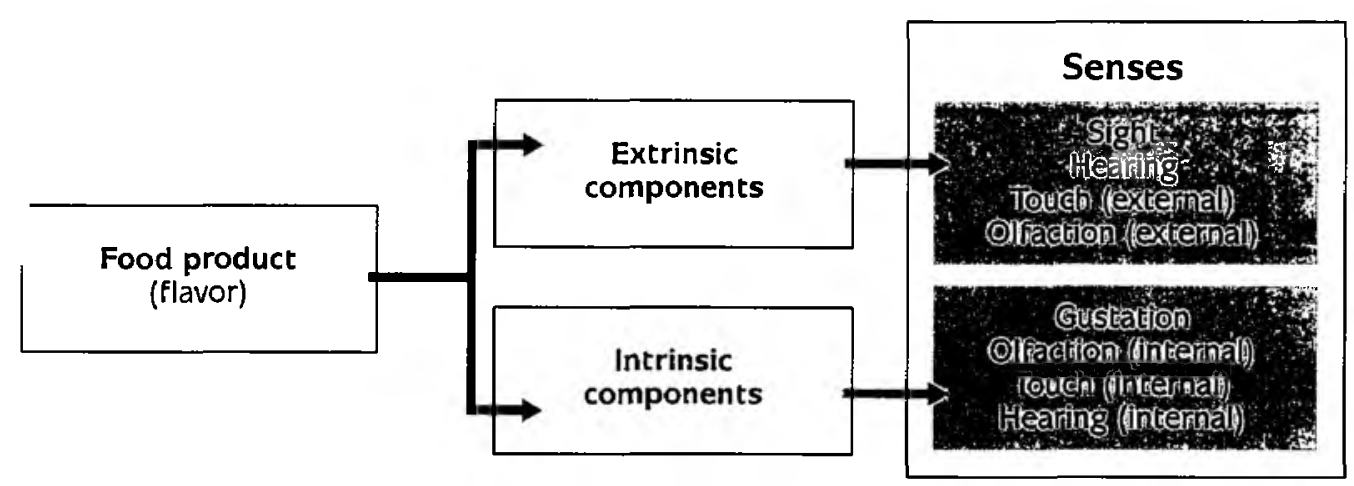

Figure 7-1: flavor is a sublimation of sensorial experiences 
For the purpose of clarification it can be argued that only gustation, and not taste is a sense of itself, as it has its own neural system which registers components that are not registered through other sensory systems. If gustation is considered as just one part, flavor registration comprises gustatory, olfactory and trigeminal components. All of these components are registered by singular neural systems that cooperate intricately. In the human brain the information from the different systems is assembled into one new percept: flavor. The sensorial systems of sound and sight do not necessarily have to be involved, but they often are. Among others, they are part of a defense system that protects the biological organism against potential problems. The likely palatability of foods and beverages is first judged by looking at them, smelling or touching them. Flavor registration is therefore not a sense but rather a magnificent sublimation of our senses. If one of the senses does not function well, the perception of flavor changes. Flavor registration is therefore an example of a cross-modal integration of senses, which provides information about the environment that is unobtainable from any sense in isolation. Such a multi-sensory approach fits the organization of the brain better than the singular senses approach. Modern brain research using i.e. FMRI sheds more and more light on the functioning of the human brain in this respect (Calvert, 2001).

There is fundamental sensorial difference between gustation and the other senses. The sensory signals of smelling, hearing. seeing and touch may, but do not specifically require any human activity to 'enter the body'. There is little unintentional in tasting; something has to be done. A decision has to be made before a food or a drink is introduced in the mouth. This aspect alone adds much to the complexity of taste research. Everyday tasting is done as a result of free will and any research setting tampers this free will. Once a consumer is in a sensory laboratory, $s /$ he is not a 'consumer' anymore, but a sensory panelist (DeCastro, 2000). This implies that consumer behavior in regard to food choice must be regarded as a major area of study in flavor registration. In section 7.4 the behavioral process of food choice is introduced, first the 'ingredients' of this process are presented.
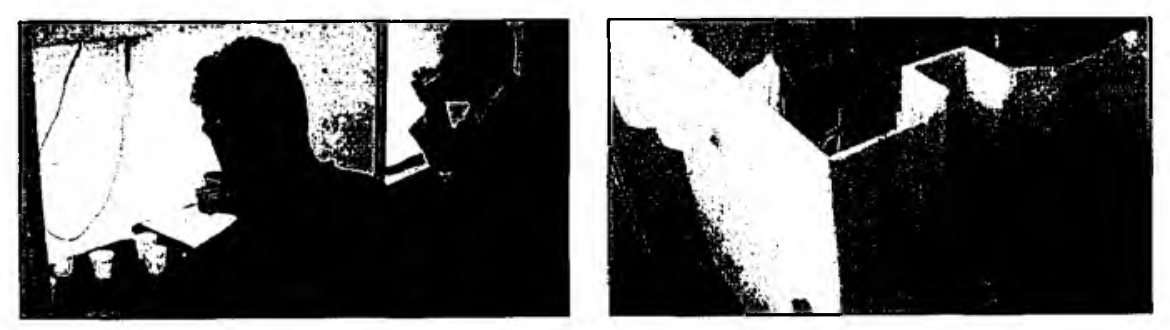

Mlustration 1: Consumers? 


\subsection{Formulating the physics of flavor perception}

'Complexicy' is obviously a poor excuse in explaining why tasting - or rather flavor registration for that matter - remains poorly understood. Clearly, to find answers the proper questions need to be asked to start with. Scott and Giza (2000) stated that progress in vision and hearing was so much more rapid because the physics underlying the perception was understood. The relationship between each wavelength and its associated color or sound was easily determined. Thus, it was quite straightforward to stimulate the subject's eye or ear with a known set of wavelengths and record the resultant activity. Taste researchers followed this model. However, there are many examples of fundamental taste research with a gustatorial orientation and where just sweet. sour, salty and bitter tasting elements were used as stimuli. As these tastants represent only one part no conclusive answers may be expected on flavor registration. Evidently one will find (and has found) parts of the integrated system. Yet, to get a better understanding of flavor registration and possibly solve some of its complexity, it must be regarded holistically to evaluate how the parts fit. The traditional representatives of the gustatorial system could not serve as the 'physics of flavor perception' and, consequently, have not provided sufficient answers. Rather 'the four basic taste assumption' has profoundly limited the stimuli that are used in research and heavily influenced the way data has been interpreted (Delwiche, 1996). Flavor transduction is studied based on the assumption of the existence of four basic tastes. Surprisingly however, this assumption has not been formally examined (Erickson, 2000). As new gustatory flavors are being 'discovered' the assumption loses more ground.

The formulation of another base was needed in which the gustatory, olfactory and trigeminal aspects of flavor are integrated. This base was found by distinguishing mouthfeel and flavor richness as primary flavor factors. In this model 'mouthfeel' comprises all tactile elements, volatile and non-volatile, that are neurologically registered by the trigeminal pathway, while 'flavor richness' is basically the combination of gustation and olfaction. A result of this view is the classification of flavors and the formulation of the Flavor Styles Cube in which each of the eight corners represents a specific mix of variables in terms of mouthfeel and flavor richness. The traditional basic flavors easily find their place within this model, but from another perspective and including their olfactory and trigeminal effects. Some acids are sufficiently volatile to be perceived by olfaction (Siebert, 1999). Salts are supposed to be non volatile and yet several animal species are reported to discriminate $\mathrm{NaCl}$ and $\mathrm{LiCl}$ through olfaction (Uebayashi et al., 2001). Humans have difficulty discriminating salt and sweet water when olfaction is blocked (Vroon, 
1994). The mouthfeel of saltiness and acidity is contracting, while sweetness produces a coating sensation, just as fats. The bitterness or astringency resulting from tannins has a drying effect. Putting the 'touch of taste' or 'mouthfeel' in the focus of attention is also in line with the etymological roots of the word 'taste' (Latin: tastare, touch).

\subsection{Liking: product and human perspective}

\subsubsection{Product values and liking}

In this thesis Culinary Success Factors have been defined that determine palatability. These factors can be beneficial in the development of new products and in the improvement of existing ones. Basic hedonic reasoning suggests that consumers are pleasure seekers and will always select and prefer the most palatable products and avoid the displeasure of bad tasting foods. Producers, either in industry or in trade devote much time in creating or improving the flavor of their products. It is generally accepted that both intrinsic and extrinsic factors (i.e. packaging and image) contribute to the flavor of a product (Guinard et al., 2001a). The result is that many available foods are palatable, which implies that palatability as such is no longer a strong driver of food choice. It has a large impact on the amount that is eaten or drunk, but it is only one of many influences in food selection (DeCastro, 2001). To explain liking, other factors need to be taken into account, both on the product side and on the environmental side.

There are three types of value that products can yield: instrumental, symbolic and hedonic values. Most products provide each of these value types to a certain degree. Food provides instrumental value when it functions as a means to an end like alleviating hunger or maintaining a healthy body; a symbolic value when it is eaten to mark a special occasion (Friday: fish) and a hedonic value when it is associated with liking and pleasure. As consumers evaluate values differently, their choices are likely to be different as well. An expensive wine (high symbolic value) that a consumer does not like (low hedonic value) may in some cases be preferred over a cheap wine (low symbolic value) that the consumer likes (high hedonic value) (Wong, Ahuvia, 1998).

Instrumental values are in regard to food and drinks more closely related to biological needs. The results of an experiment in the Netherlands that was held in October (2000) demonstrate that situational circumstances influence food values and subsequent preference (Klosse, unpublished data). Five groups of subjects (non-professional volunteers, total $N=238$ ), across the country, were first asked to rate the flavor of a mousse of smoked salmon and minced fresh salmon (summary of the results: table $7-1$ ). 


\begin{tabular}{|l|l|l|}
\hline \multirow{2}{*}{$\begin{array}{l}\text { Table 7-1: } \\
\text { SENSORY JUDGMENT }\end{array}$} & \multicolumn{2}{|c|}{} \\
\cline { 2 - 3 }$(\mathbf{N}=\mathbf{2 3 8})$ & MOUSSE SMOKED & $\begin{array}{l}\text { MINCED FRESH } \\
\text { SALMON }\end{array}$ \\
\hline Mouthfeel Contracting & - & + \\
Mouthfeel Coating & ++ & - \\
Flavor richness & + & 0 \\
Fresh flavor tones & - & + \\
Ripe flavor tones & + & - \\
Palatability (scale 1-10) & 7.8 & 7.3 \\
My choice for a hot day & & $212(89 \%)$ \\
on a terrace & $26(11 \%)$ & \\
\hline
\end{tabular}

Table 7-1: Sensory judgment of two salmon dishes

(- -: not at all present; - hardly present; $O$ indifferent; + present; ++ very present)

The flavor profile indicates that the mousse was clearly more coating in mouthfeel. with ripe flavor tones, while the profile of the minced salmon scored oppositely in mouthfeel, but not in flavor richness. The flavor style of the mousse can be characterized as 'rich' (corner 6 of the cube), while the minced salmon can be characterized as 'fresh' (corner 4 of the cube). Both dishes scored positive on palatability $(7.8$, resp. 7.3 on a 10 point scale). Subjects agreed remarkably in their response to the question 'which of the two would you prefer on a hot day on a terrace': $89 \%$ chose the minced salmon. Apparently its flavor profile was considered to fit better to the situation of warm weather than the mousse, even though the mousse was considered to be slightly more palatable. If this experiment had involved milk and ice cream this result would surprise nobody. Ice cream would be a logical choice for a hot day on a terrace; a glass of milk is not appealing. Minced salmon can hardly be considered to be such a 'logical' and well-known choice. Nevertheless. people are very clear in their preference, which leads to the conclusion that objective product properties are at the origin of this preference. Apparently, the minced salmon and ice cream have things in common, making them instrumentally preferable for a hot day on a terrace. The common denominators of ice cream and the minced salmon are their contracting mouthfeel and freshness. Evidently, humans know instinctively and accurately that those sensory characteristics, or rather the 'fresh' flavor style, suit a hot day well. The function of flavor styles in this respect is discussed in section 7.5.1.

The instrumentality of food choices is supported by biological pathways. As knowledge at the receptor level of taste gets more sophisticated, new receptors are identified and genetic differences between people are recognized. Young black adults are reported to desire more sweetness in comparison to their white counterparts. 
This phenomenon is generally referred to as 'sweet tooth' (Schiffman, et al. 2000). Such differences are also reported in the perception of bitter and related flavors (Tepper \& Nurse, 1998, Bartoshuk, 2000). As infants (0-18 months) have markedly more taste buds than adults they are also likely to perceive tastes differently (Guinard. 2001). Age and gender are generally recognized as factors that explain differences in perception (Stevens, 1996). Diversity in receptor repertoire may therefore not be neglected as driver of liking and subsequent food choice (Whitfield, 2002).

This argument fits evolutionary philosophy. The acquisition of foods and the avoidance of toxins is one of the most fundamental behaviors to survive (Scott, 2001). It seems highly logical to presume that, in order to survive, the taste system of the first primates had two basic functions:

- to distinguish foods from toxins. Smell and sight are very functional in this respect, as these senses work as a first selector;

- to recognize specific foods/nutrients that are essential for the functioning of the biological system.

If these functions form the basis of the human taste system, an examination of chemosensory needs and the behavioral response would provide an interesting starting point (Erickson, 2000). This line of reasoning is followed by Zuker (2002), who discovered the receptor for amino acids. Amino acids are essential building blocks of proteins. Their biological importance makes it likely for there to be a taste pathway that would make amino acids attractive to consume. Continuing this logic it can be assumed that over the course of evolution, when food has been relatively scarce, the brain has developed adaptive mechanisms to ensure that high-energy foods containing fats and simple carbohydrates are found palatable and thus avidly consumed when they are encountered (Kelley et al., 2002). The mouthfeel that is common in all these high fat compounds is found to be pleasant which can be considered as another clue for the importance of mouthfeel. But not only mouthfeel is important. The evolutionary approach links essential components to receptors on the tongue. Proteins and their amino acids, mineral salts and organic acids, all of which are also biologically important, are registered on the tongue and add much to flavor richness. It is clear that this evolutionary orientation comes up with different insights about the functioning of the human taste system. Interestingly, this approach can be applied to the Flavor Styles Cube and particularly to the classes of food ingredients. The vertical ribs of the Cube represent different classes: rib 1-5: starch; rib 2-6: sugars and lipids (energy); rib 3-7: proteins and rib 4-8: salt and acidity (ions, protons). The correlation between these food classes and the flavor 
cube can be coincidental and does also not imply that the distinct classes are not present elsewhere; it can be considered as a general tendency that is interesting to notice.

\subsubsection{Human values and liking}

Pavlov was supposedly the first to demonstrate that food choices are not only motivated by product values or biological needs. His experiment showed the importance of cognition, which was later referred to as 'classical conditioning'. In psychology the principles of classical conditioning, stimulus - response, have developed into behaviorism, a concept that is associated with the work of Skinner. Humans are individuals and at the same time a part of the environment. The study of behaviors involves the interaction between organism and environment. A person is first of all an organism. In becoming a person the organism acquires a repertoire of behavior. This framework determines his 'operant behavior'; this is always under control of a current setting (Skinner, 1974). Tasting can be seen as operant behavior which takes place within a certain setting. In fact, at the human side there are many forces that influence food behavior.

The process of food choice is provoked by either internal or external stimuli. Internal, biological and physiological forces like hunger or thirst and more complex signals that stimulate the intake of specific foods have always attracted much attention. However, they can not explain many aspects of eating behavior (Levitsky, 2002). Environmental factors such as visibility, smell, verbal appraisal or plain availability and convenience can stimulate food behavior (Painter et al., 2002). Expatriates showed a loss of 'oral pleasure', liking, due to unfamiliarity with local eating and drinking habits and depriving them from favorite foods and drinks. This loss is aggravated by language barriers (Usunier, 1998).

The human brain plays a central role in the taste process. It is active in all aspects of tasting, both in the choice of the substance to be eaten or drunk and in the physiological registration of flavor. The free will and availability guide this choice. Aspects like the time of the day, personal circumstances and preferences, past experiences, culture, physical needs and wants, presence of substances, etc. will influence the ultimate food choice (Drewnowski, 1997). The influences upon food selection are versatile and strong as is confirmed in a study about the food choices of adolescents. The findings suggest that if programs concerned with adolescent nutrition are to be effective, they need to address a broad range of factors, in particular environmental factors (Neumark-Sztainer et al., 1999).

Eating habits are a part of a cultural way of life and such habits may have personal influences. Adaptation to i.e. alcohol and spicy food is one example; the use of milk in northern European countries is another. To digest milk the body needs the 
enzyme lactase that is normally only active in children until the age of about three. People that are not accustomed to milk will have difficulty digesting it (McGee. 1984). Likewise, the traditional use of insects as food continues to be widespread in tropical and subtropical countries where they serve as an important source of protein in the daily diet. Westerners should be aware of the fact that their bias against insects as food has an adverse impact, resulting in graduai reduction in the use of insects, without replacement of lost nutrition and other benefits (DeFoliart, 1999).

If there are so many factors involved in making food choices that they like, how do individuals cope with this complexity? They use a personal food system, which is a dynamic set of processes constructed to enact food choices. Connors et al. (2001) defined five main values: flavor, health, cost, time and social relationships. Less prominent values were: symbolism, ethics, variety, safety, waste, and quality. Three main processes were analyzed to be used in their personal food systems:

- Categorizing foods and eating situations

- Prioritizing conflicting values for specific eating situations

- Balancing prioritizations across personally defined time frames

Personal food choices are determined by all kinds of environmental and individual circumstances, which implies that in food selection there is not one, rational good choice. Consumers make their good choice, considering the circumstances. Categorizing foods is an important instrument in these personal food systems, which raises the question how this is done. One needs to know the food before it can be categorized. The proposed Flavor styles can be particularly useful in food identification, which facilitates categorization and may therefore prove to make food choices more nearly in line with expectation.

\subsection{Behavioral process of food choice}

What is tasted is the outcome of some kind of decision making process that preludes flavor registration. 'Liking' implies being satisfied about the choices that have been made. Consequently, the perception of quality must also be closely related to this process. Product and personal values are integrated in the "behavioral process of food choice". Although the word 'food' is used, it covers the selection of beverages as well. Tasting can best be regarded as a dynamic process with a continuous interaction between mind and matter. This orientation implies that the important aspects of i.e. cognition, situation, physical circumstances, needs and wants in regard to the product are automatically taken 
into account. Food choices are made and expectation is set. In the actual tasting the result is evaluated. It is highly likely that the brain will pass a favorable judgment (liking, quality) on those nutrients that fulfill or exceed the set expectation. The human mind files these results and as such they will be a part of the next round of decision making. The perception of both product characteristics and product



Figure 7-2: the behavioral process of food choice quality is influenced by these factors. This process is illustrated in figure 7-2:

This process shows that flavor registration takes place within a frame that is shaped by biological, psychological, economical, social and cultural forces. The process of food choice commences within the brain and is stimulated by either internai (e.g. hunger. thirst) or external stimuli (e.g. smelling, seeing, hearing about potentially attractive nutrients). Then, the following stages can be distinguished in the process:

A. Yielding to a stimulus, which implies food choice and the selection of a food product. Information goes from mind to food and from food to mind. It is important to note that the food is first selected upon its extrinsic components (e.g. package, smell, name). These raise expectation.

$B$. The actual tasting and flavor registration

C. Evaluation in the human mind; does the food live up to expectation and does it satisfy needs or wants?

D. The result of this evaluation leads to acceptance or rejection, and may influence the pace of eating

E. The filing of information about the food, cognition, which becomes a part of next food choice processes. 


\subsection{The function of flavor classification in the process of food choice}

The process of food choice elucidates that there are many subjective variables involved, resulting in personal food systems. Food preference is therefore considered to be one of the problematic areas in the study of consumer behavior (Grunert, 1997). A product that satisfies or exceeds expectation has quality from a consumer point of view. It is the subjective quality, which can be quite different from the objective quality which is defined as the total of measurable attributes of a product. The two kinds of quality can be paraphrased as in what the consumer gets (subjective quality) versus what the product has (objective quality) (Bech et al., 2000). It is evident that producers have an interest in delivering and developing products that correspond to the subjective quality. At the same time the consumer has an interest in making the right choice that satisfies wants and ideally exceeds expectations. The proposed classification of flavor is based on the objective qualities of products and can prove to be a valuable communicator between these two distinct types of quality. This prospect offers new perspectives that can be grouped in the following categories:

- Product identification

- Product development

- Cross-cultural differences

- Combination of flavors

\subsubsection{Flavor classification and product identification}

Categorization is used as a principal method in personal food systems. This raises the question: what do consumers have as a basis for making food choices? The flavor of foods or drinks is generally described based on:

- product category (e.g. meat, fish, beer, coffee)

- ingredients (e.g. fillet of beef, salmon, grape-variety)

- origin (e.g. Brie-cheese, Bordeaux wine)

- brand name (e.g. Coca-Cola, Heineken, Mars, Heinz tomato ketchup).

Except for the last category, the problem with these generally used notions is that they say very little about the flavor of a specific product within a certain category. In other words: wines coming from the Bordeaux region do not have the same flavor, neither do ail wines made from the Chardonnay grape taste similar, nor 
do all salmon dishes or Brie-cheeses, to mention just a few examples. Brand names serve, in regard to flavor, only a purpose for people that are acquainted with the brand from previous experiences. At present food labels do not give the information that is required to enable consumers to compare and select foods on the basis of flavor properties (Monro, 2000). Flavor style labeling could solve at least part of this problem. Take wines for example. Wine labels traditionally feature the regional origin and/or the grape variety as identification. Both are poor indicators of the flavor, which can therefore be quite different from that what is expected. Potentially this will lead to disappointment that can be prevented by mentioning the flavor style of the wine on the label. The flavor style would enable the consumer to select the wine that suits his preference. The objective product qualities of the wine (flavor style) are conveyed to the consumer giving him the opportunity to make the right choice. There are wines that are suitable to drink on a terrace, just as there salmon dishes that fit such a situation. It is therefore essential for potential consumers to get a good notion of the flavor to be expected, before they make their food choice.

Advertisements may be designed to raise consumer's expectation of a product and consequently evaluate these products higher. Care should be taken that these expectancies are in line with the product's capabilities of fulfilling these promises. in general, expectancies play an important role

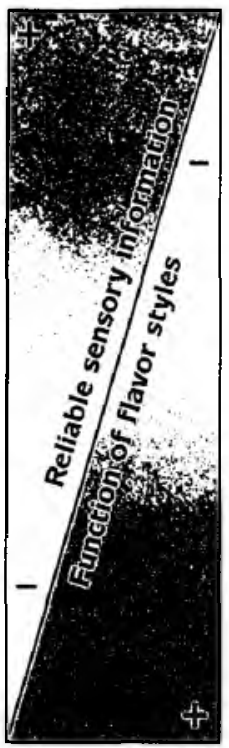

Figure 7-3: the theorem of flavor styles in liking. They are reported to be able to modify people's actual perceptual experiences, similar to placebo effects in medicine. The magnitude of this effect is related to the availability and reliability of sensory information. If there is ample reliable information the role of expectancy is smaller than when sensory information is less available and less reliable. In those cases expectation plays a greater role in evaluating product quality (Dougherty, Shanteau, 1999). Flavor Styles can prove to be particularly useful in those cases where the amount of reliable sensory information is low. This applies especially in product categories where the flavor of individual products varies strongly within the category, and to products that are unfamiliar to the consumer, or products of which the flavor can hardly be assessed prior to tasting, i.e. new products, wines and prepared dishes. Flavor Styles provide reliable sensory information for these kinds of products. Wellknown brands have little need for a flavor style as identification. The brand name itself serves as identification. Based on these observations, following theorem of flavor styles can be formulated: the value of flavor styles increases as the amount of reliable sensory information decreases. Figure 7-3 illustrates this. 
Broadly defined product categories without further specification run the risk of being categorically disliked if one, or a few products within that category are not liked. In a study of Wardle et al. (2001) such broad categories emerged in a factor analysis of food preferences in young children. Wide-ranging categories as 'meat and fish', 'vegetables', 'fruit', and 'desserts' could explain no more than $24 \%$ of the variance. Children tended consistently to like or dislike foods within each of these factor categories. Such preferences could not be linked to simple sensory preferences such as sweetness, saltiness or creaminess. For instance, many sweet foods (e.g. chocolate) failed to load on the factor 'dessert', and many savory foods (e.g. sausages and burgers) did not load in the meat and fish factor. The authors suggested that these results support the notion that foods are recognized as a synthesis of many sensations, including gustation, olfaction and aspects that are involved in mouthfeel (texture, fluidity and temperature). Foods can have very different profiles and broad categories are therefore hardly suitable as basis for identification as is illustrated in this study. As flavor Styles are based on this so-called 'synthesis of many sensations' a different structure of preferences is likely to emerge, that are not broadly defined but more specific.

The results of a study in another broad category, Cheddar cheese, confirm this assumption. Murray et al. (2000) report the flavor of these cheeses can be separated on the basis of their maturity level: mature cheeses have more flavor richness and a different mouthfeel. Using these same parameters as are proposed in this work, four clusters of consumers were identified that were homogenous in the preference for certain types Cheddar. The important role of packaging was noted. Consumers will become increasingly demanding, seeking greater convenience and having less time for shopping. Probably the consumer will demand product information which makes food choice right at the first time by conveying product characteristics on a sensory basis.

\subsubsection{Flavor classification and product development}

The food sector is third largest of world economy. The failure rate of products in this sector is reported to be around $80 \%$. This is much higher compared to other sectors, where failure rates are reported of around $30 \%$. It would be highly presumptuous to state that the proposed flavor classification will improve the current situation. Many factors are involved. Many food companies seek growth through the development and introduction of new products, resulting in crowded markets flooded with food choices. Consequently, the failure of a new product is more likely than it would have been under less crowded conditions. Nevertheless transforming consumer requirements into product characteristics is basic to market driven product design, and errors in the process of product development may be responsible for failures (Poulsen et al., 1996; Redmond, 1995). 
This is not the place to cover the complete process of product development. However, the study of Cheddar cheeses points at the importance of package and appearance. In the behavioral process of food choice (figure 7-2), such aspects belong to the external stimuli that are at the basis of food choice. For industrial food products to be successful they should be in line with the expectation that is provoked by what the consumer sees. Products should look like their flavor. The intrinsic and extrinsic components of flavor belong together and should fit to each other. Designers are able to express flavor in package design and color (Smets \& Overbeeke. 1995), which leads to the conclusion that extrinsic factors should be integral part of product development, and not the end of the process.

The consumer population for a given product is often heterogeneous in its likes and dislikes. Differences in preference may represent distinct consumer segments that expect specific product attributes. There is no 'average' consumer, although some segments of homogeneous preferences may be larger than others. If consumer segments are large enough to be commercially interesting specific products could be developed that suit the preferences of that segment. Flavor Styles can help to define such segments. This was confirmed in a beer study that concluded - fully in line with the proposed classification of flavor - that ratings of flavor and mouthfeel properties alone could be used to classify lager beers. They were regarded as 'sensory dimensions' that drive consumer liking (Guinard, et al. 2001a).

Although different terms are used, similar results are reported in a study of Bech et al. (2000) involving the product development of peas. In this article 'texture' and 'flavor' were determined as having approximately the same effect on the consumers' perception of overall quality. These observations imply that the support for the proposed classification of flavor is found on two grounds: mouthfeel and flavor richness are considered both as drivers of consumer liking and as communicators of product characteristics. Bech's recommendations for plant breeders were based on improvement of both mouthfeel and flavor (for instance, a higher sugar content was suggested). A good illustration of how the classification of flavor can be applied and lead to better products. Well-defined flavor styles add to the identification of flavor and broaden the basis for packaging, labeling and marketing food products. Therefore, all aspects should be fully integrated as a total process of product development. If this is not the case it can be considered as an error in the process that will potentially lead to failures (Meroni, 2000).

\subsubsection{Flavor classification and cross-cultural differences}

Different cultures display different food behavior. Are these differences determined by environmental factors or by genetic influences which lead to markedly 
different perceptions of product characteristics? If this would be true, the proposed classification of flavor would lose much of its ground, as it is based upon objective product characteristics, which are supposedly universally registered in the same way. Studies indicate that chemosensory perception is largely similar across cultures. Preferences however, tend to differ between cultures. (Jaeger et al., 1998; Prescott et al., 1998a). Hence, these differences must be the result of environmental influences.

From a marketing point of view, cultures can be regarded as macro segments which can be treated as discussed above. In many parts of the world regional or cultural patterns are seen to diminish due to the globalization of the food market. Flavor styles serve a purpose in that respect as well. Within changing patterns one can still find one's preference, or - at least as important - suitable replacements. As such, flavor styles fit in the modern tendency of globalization. However, further studies are needed to confirm this supposition.

\subsubsection{Flavor classification and combination of flavors}

In addition to their usefulness in the above fields, flavor styles have value in quite a different field as well. In everyday consumption it often happens that several products are eaten or drunk more or less at the same time. Real world eating and drinking evidently is very different from laboratory experiments. In the real world foods are complex systems that furthermore are freely and carelessly mixed. Not ail combinations are successful. Unpleasant flavor reactions may arise from undesired and perhaps badly understood chemical reactions. Clearly, such interactions between products may strongly influence flavor appreciation. For instance, products that are high in flavor richness will dominate products which are lower in that respect. In practical terms: a strongly flavored dish will dominate a wine that has less flavor richness. Objectively the flavor of each product is the same, but flavor appreciation will be different. In another example consider the idea of taking a sip of fresh orange juice, next a spoonful of honey and then a sip of orange juice again. Most people instantly realize that the second sip of orange juice will be perceived as being much more acidic after the honey. This phenomenon can be explained with the primary flavor factors as well. A principal characteristic of orange juice is its fresh and cleansing influence (contracting). The first sip of juice will clean the mouth and change its neutrality to the fresh/acidic side. The honey has an opposite effect. Its mouthfeel is round and coats the mouth with a layer of sweetness. The balance in our mouth has moved towards sweet. In the registration of the second sip this difference is perceived as being more acidic. Other viscous elements like cream will give a similar effect. Using flavor styles one can say that in the mouth 'fresh' styles 
do not mix well with wines that are 'round' or 'full'. Other examples include the use of sugar or cream to mask the bitterness of coffee, for instance. These examples are important clues in understanding the pairing of wine and food. Especially if one realizes that these flavor effects have a technical, thus objective origin.

\subsection{Conclusions}

As stated in the introduction, the concept that flavor can be classified by using mouthfeel and flavor richness as parameters could be accepted if:

- the human registration is equipped to register both these sensorial characteristics

- these characteristics can be found by asking consumers to characterize wellknown food products

The review on flavor registration (chapter 2) made clear that the tactile, trigeminal system is totally involved in flavor registration, and basically registers mouthfeel. Flavor richness is the combined registration of the olfactory and gustatory system. Mouthfeel and flavor richness were found in a factor analysis based on a consumer survey $(n=166)$. Eight factors representing the eight flavor styles were found, explaining $70.7 \%$ of the variance. The three-dimensional structure, depicted as the Flavor Styles Cube was proposed and verified with a cluster analysis statistical procedure (chapter 3 ). In chapter 4 , these flavor characteristics were used to find Culinary Success Factors (CSFs) that explain palatability. These were confirmed in a tasting experiment: dishes in which all CSFs were present were found to be more palatable and were also preferred to dishes in which one CSF was systematically left out. It was hypothesized based on the Flavor Styles Cube that wines that are characterized as having the Flavor Style 'balance, high', would contain glutamic acid, the amino acid that is reported to give the umami flavor. Wine samples were analytically studied and the presence of glutamic acid in wines was confirmed in the wines that were characterized as 'balance, high'. It is concluded that the concept of classifying flavors using mouthfeel and flavor richness as parameters is attractive and valid to use as a tool; to inform the consumer about the flavor of a specific food product. In the general discussion potential benefits were discussed. Furthermore, references were found that support the concept from independent angles and studies. Flavor styles can help consumers to make their personal good choices, which fit the situation and are prone to be liked and perceived as having good quality. At the same time Flavor Styles can help food producers to make better 
products, be it in restaurants, wineries, airline catering or the food industry in general. The potential success of food products can be better assessed which will potentially lead to a reduction of failures.

Are the results of this work solid enough to form the basis of a new theory that sheds new light in the functioning of the human registration of flavor and on flavor itself? Who is to judge? If sound theories should be applicable in practice, it has already proven its worth and merits to be known outside the Dutch borders. The flavor styles cube can be considered as an elegant model that explains the complex world of flavor better than the hypotheses that have dominated the field up to now. And, by the way, are there not many, even very popular theories (gravity, evolution) that are also accepted until proven otherwise?

Therefore, next to presenting support for and making this theory acceptable, this work must also be considered as a call upon distinguished scientists to carefully examine the concept of flavor styles to classify flavor and either agree with the concept or show good reason why it should not be valid.

\subsection{Craftsmen of flavor and Sensory scientists}

Science and trade appear not to mix well together. Historically there has been a true dislike by the craftsmen of flavor (especially cooks) for everything that even remotely resembles science. Supposedly science would negatively affect the hedonic side of taste. Brillat Savarin, the famous French writer on Gastronomy published his 'Physiology du Goût' in 1826. Although the orientation of the book is clearly hedonic, more than once he stresses the need for knowing more about the physical processes that take place in cooking.

"Yesterday I heard you moan over that magnificent sole, when you served it to us pale, flabby, and bleached. This misfortune happened because you have neglected the theory of frying, whose importance you do not recognize. The phenomena which occur in your 'laboratory' (i.e. the kitchen) are nothing more than the execution of the eternal laws of nature, and certain things which you do inattentively, and only because you have seen others do them. are nonetheless based on the highest and most abstruse scientific principles".

Nothing much has changed since then. In a more contemporary work. McGee (1984) notes the same thing when he - contrary to the common opinion - states that i.e. knowledge about the coagulation of egg whites does not change the pleasure of 
eating roasted meat or a meringue. It merely helps to understand what goes on, and to prevent failures. In France, Hervé This explains fundamental culinary techniques in his 'Les secrets de la casserole' (1993). In the hedonic world of flavor, daily routine is predominant and rarely questioned; habits are continued even though the fundamentals of these habits may have changed.

At the same time there are scientific reports of conducted experiments of which any experienced cook could have supplied the answer immediately, or predicted its futility. Apparently in science, there is the same hesitation in taking the craftsmen seriously. The hedonic and the scientific worlds are quite separated. This thesis concludes therefore with a call upon craftsmen of flavor, including cooks, winemakers, restaurant owners, sommeliers, food and wine suppliers, 'culinary' writers and restaurant critics, to work more closely together with sensory scientists, and vice versa. There is much to be learnt from each other.

\section{Appendix: the Flavor Identification System (F.I.S.)}

The classification of flavor can be depicted as a cube in which the spectrum of flavor finds his place. Just as the color spectrum, flavors are in a continuum.

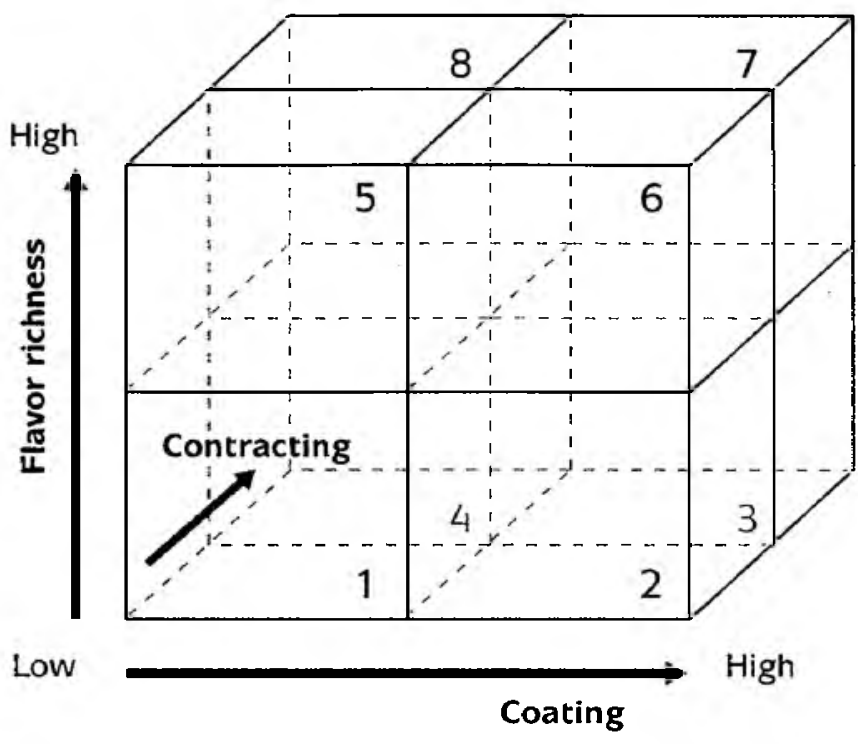

Figure 7-2: the behavioral process of food choice
Table 7-2 shows the basic characteristics of each flavor style. These characteristics typify the corners. the extremes of the cube. Products that are located here can be considered as the 'icons' of flavor. Many products are to be found more within the cube. Therefore a refined method was developed to locate the place of a certain flavor in the Flavor cube and to determine its Flavor Style: the Flavor Identification System (FIS) (figures 7-4, 7-5). 


\begin{tabular}{|c|c|c|c|}
\hline \multirow{2}{*}{$\begin{array}{l}\text { Table 7-2: } \\
\text { FLAVOR STYLE }\end{array}$} & \multicolumn{3}{|c|}{ PRIMARY FLAVOR FACTORS } \\
\hline & CONTRACTING & COATING & FLAVOR RICHNESS \\
\hline 1. (NEUTRAL) & Low & Low & Low \\
\hline 2. (ROUND) & Low & High & Low \\
\hline 3. (BALANCE LOW) & High & High & Low \\
\hline 4. (FRESH) & High & Low & Low \\
\hline 5. (ROBUST) & Low & Low & High \\
\hline 6. (FULL) & Low & High & High \\
\hline 7. (BALANCE HIGH) & High & High & High \\
\hline 8. (PUNGENT) & High & Low & High \\
\hline
\end{tabular}

Table 7-2: Flavor styles and their basic characteristics

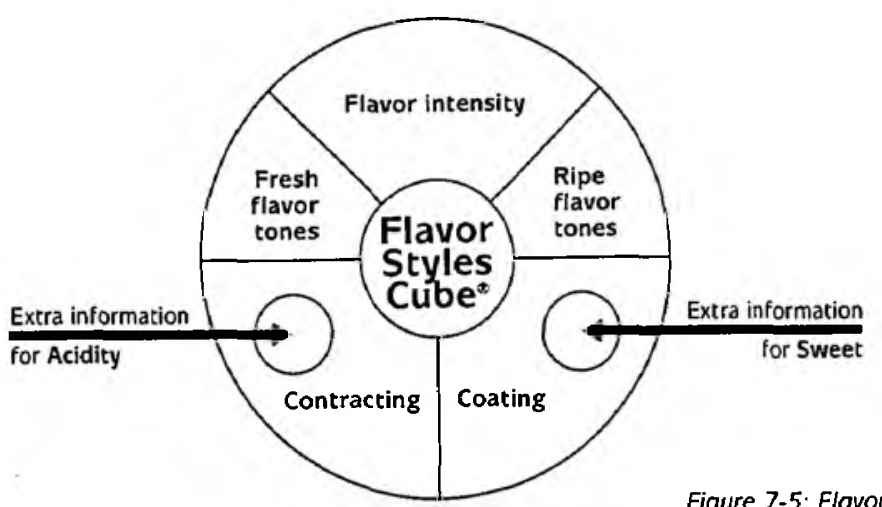

The five segments can be scored by giving a note 1-10. Extra information can be given by putting + or ++ in the circles if the contraction is caused by acidity or if coating is caused by sweet.

Figure 7-5: Flavor Identification System (CSO Wageningen)

\section{References}

Bartoshuk, L.M. (2000). Comparing sensory experiences across individuals: recent psychophysical advances illuminate genetic variation in taste perception. Chemical Senses, 25, 447-460

Bech, A.C., Juhl, H.J., Hansen, M., Martens, M., Andersen, L. (2000). Quality of peas modelled by a structural equation system. Food Quality and Preference, 11, 275-281

Birch, L.L. (1999). Development of food preferences. Ann. Rev. of Nutrition 19, 41-62

Bray, G.A. (2000). Afferent signais regulating food intake. Proceedings of the Nutrition Society, 59, 373-384

Brillat-Savarin, J.A., Physiologie du Goût. Sautelet, Paris (1826). American edition: M.F.K. Fisher's translation of Brillat Savarin's, The Physiology of Taste (1949), Knopf, New York 
Calvert, G.A. (2001). Crossmodal processing in the human brain: insights from functional neuroimaging studies. Cerebral Cortex. 11.1110-1123

Connors. M., Bisogni. C.A.. Sobal, J. \& Devine. C.M. (2001). Managing values in personal food systems. Appetite, 36, 189-200

DeCastro. J.M. (2000). Eating Behavior: lessons from the real world of humans. Nutrition, 16, 800-813

DeCastro, J.M. (2001). How genes control real world intake: palatability - intake relationships. Nutrition, 17. 266-268

DeFoliart, G.R. (1999). Insects as food. Why the western attitude is important. Ann. Rev. of Entomology. 44. 21-50

Delwiche. J. (1996). Are there 'basic' tastes? Trends in Food Science \& Technology. 7, 411-415

Dougherty. M.R.P.. Shanteau. J. (1999). Averaging expectancies and perceptual experiences in the assessment of quality. Acta Psychologica. 101. 49-67

Drewnowski. A. (1997). Taste preferences and food intake. Ann. Rev. of Nutrition. 17. 237-253

Erickson. R.P. (2000). The evolution of neural coding ideas in the chemical senses. Physiology \& Behavior, 69, 3-13

Grunert, K.G. (1997). What's in a steak? A cross-cultural study on the quality perception of beef. Food Ouality and Preference, 8, 157-174

Guinard, J.-X. (2001). Sensory and consumer testing with children. Trends in Food Science and Technology. 11, 273-283

Guinard, J.-X.. Uotani, B. Schlich, P. (2001a). Internal and external mapping of preferences for commercial lager beers: comparison of hedonic ratings by consumers blind versus with knowledge of brand and price. Food Quality and Preference. 12, 243-255

Kelley. A.E., Bakshi. V.P., Haber, S.N., Steininger, T.L., Will, M.J., Zhang, M. (2002). Opioid modulation of taste hedonics within the ventral striatum. Physiology and Behavior. 76, 365-377

Levitsky, D.A. (2002). Putting behavior back into feeding behavior: a tribute to George Collier. Appetite, 38, 143-148

McGee. H. (1984). On Food and Cooking. The science and lore of the kitchen. Dutch edition. Over eten en koken. Wetenschap en overlevering in de keuken. 1992, Bert Bakker. Amsterdam

Meroni. A. (2000). Active packaging as an opportunity to create package design that reflects the communicational, functional and logistical requirements of food products. Packaging lechnology and science. 13, 243-248

Monro, J.A. (2000) Evidence-based food-choice: the need for new measures of food effects. Trends in Food Science and Technology, 11, 136-144

Murray, J.M., Delahunty, C.M. (2000). Mapping consumer preference for the sensory and packaging attributes of Cheddar cheese. Food Quality and Preference, 11. 419-435

Neumark-Sztainer, D., Story, M., Perry, C., Casey. M.A. (1999). Factors influencing food choices of adolescents: Findings from focus- group discussions with adolescents. J. American Dietetic Association 99, 929-934+937

Painter, J.E., Wansink, B. \& Hieggelke, J.B. (2002). How visibility and convenience influence candy consumption. Appetite. 38, 237-238 
Poulsen, C.S., Juhl, H.J., Kristensen, K., Bech, A.C. \& Engelund, A. (1996). Quality guidance and quality formation. Food Quality and Preference, 7, 127-135

Prescott, J. (1998). Comparisons of taste perceptions and preferences of Japanese and Australian consumers: overview and implications for cross-cultural sensory research. Food Quality and Preference, 9, 393-402

Prescott, J., Bell, G.A., Gillmore, R., Yoshida, M., O'Sullivan, M., Korac, S., Allen, S. \& Yamazaki, K. (1998a). Cross-cultural comparisons of Japanese and Australian response to manipulations of sourness, saltiness and bitterness in foods. Food Quality and Preference, 9, 53-66

Prescott, J. (1999). Flavour as a psychological construct: implications for perceiving and measuring the sensory qualities of foods. Food Quality and Preference, 10, 349-356

Redmond, W.H. (1995). An ecological perspective on new product failure: the effects of competitive overcrowding. J. of Product Innovation Management, 12, 200-213

Schiffman, S.S., Graham, B.G., Sattely-Miller, E.A., \& Peterson-Dancy, M. (2000). Elevated and sustained desire for sweet taste in African-Americans: a potential factor in the development of obesity. Nutrition, 16, 886-893

Scott, T.R., Giza, B.K. (2000). Issues of neural coding: Where they stand today. Physiology \& Behavior, 69, 65-76

Scott, T.R. (2001). The role of taste in feeding. Appetite, 37, 111-113

Siebert, K.J. (1999). Modeling the flavor thresholds of organic acids in beer as a function of their molecular properties. Food Quality and Preference, 10, 129-137

Skinner, B.F. (1974). About behaviourism. Knopf, New York

Smets, G.J.F. \& Overbeeke, C.J. (1995). Expressing taste in packages. Design studies, 16. 349-365 Stevens, D.A. (1996). Individual differences in taste perception. Food Chemistry, 56. 303-311

Tepper, B.J., Nurse, R.J. (1998). PROP taster status is related to fat perception and preference. Annals New York Academy of Science, 855, 802-804

This, H. (1993). Les secrets de la casserole. Belin, Paris

Uebayashi, H., Hatanaka, T., Kanemura, F., Tonosaki, K. (2001). Acute anosmia in the mouse: behavioral discrimination among the four basic taste substances. Physiology and Behavior, 72, 291-296

Usunier, J.-C. (1998) Oral pleasure and expatriate satisfaction: an empirical approach. Int. Business Review, 7, 89-110

Vroon, P., Amerongen, van A., de Vries, H. (1994). Verborgen verleider, Psychologie van de reuk, Baarn (the Netherlands) Ambo (Dutch)

Wardle, J., Sanderson, S., Gibson, E.L., Rapoport, L. (2001). Factor-analytic structure of food preferences in four-year-old children in the UK. Appetite, 37, 217-223

Whitfield, J. (2002). Yum, amino acids. Nature science update, may 2002

Wong, N.Y., Ahuvia, A.C. (1998). Personal taste and family face: luxury consumption in Confucian and Western societies. Psychology \& Marketing, 15, 423-441

Zuker, C. (2002). Homing in on a receptor for the fifth taste. Howard Hughes Medical Institute: http://www.hhmi.org/news/zuker3.html 


\section{Summary}

Flavor is an intriguing theme which can be studied from many different angles. Taste, flavor, and related concepts are poorly defined which leads to the situation that in literature the same words are used for different concepts. In the first chapter the concepts are defined. It alone helps to reduce the complexity of the subject.

This thesis deals with the scientific validation of a proposed new system to classify flavor. Flavor can be classified based on the parameters mouthfeel and flavor richness. These parameters were discovered based on experience in daily practice and led to the depiction of the Flavor Styles Cube which is introduced to represent a systematic description of flavor. It is first based upon the distinction in two main characteristics of mouthfeel, coating and contracting. These are two dimensions of flavor, flavor richness is the third. Any of these dimensions can be classified from low to high, which gives eight possible combinations: the flavor styles. These can be considered as sub-cubes of the Flavor Styles Cube; products that are close to the corners of the cube can be considered as the 'icons' of flavor. It is important to note that these dimensions are defined at a level of abstraction that goes beyond the molecular properties of products or the human registration of these substances. For instance, there are many sources of contraction with very different origins, all of which have a similar effect on mouthfeel. Chapter 1, introduction, explains the empirical model and the aspects that are involved.

Support for this classification of flavor is found in the first place in the human physiology of flavor registration. Clearly, if humans were not equipped to register mouthfeel and/or flavor richness, it would be difficult to accept that these parameters can be used to classify flavor. An extensive review of the literature about the physiology of taste and flavor registration (chapter 2 ) revealed that flavor registration (tasting) relies on a simultaneous activity of three neural systems, the gustatory, olfactory and trigeminal system. Flavor information is gathered through these systems and communicated to the brain where it is assembled. With the current state of knowledge about the functioning of these systems it seems difficult to pinpoint exactly which system registers what; cross modal interactions impede interpretation. However, generally speaking, the gustatory and olfactory systems are likely to contribute to flavor richness, while the trigeminal system is mainly involved in the registration of mouthfeel. This system relies on three different kinds of receptors which lead to three main groups that influence mouthfeel: thermal (i.e. temperature of foods and drinks), pain (i.e. capsaicin and other irritant substances), and mechanical (textural elements like hard, soft, creamy and crispy).

Secondly, a consumer survey was executed to evaluate the practical model and to see if the supposed structure of the flavor styles cube could be found (chapter 3). Support was found using factor analysis and statistical procrustes analysis. The practical model was 
evaluated by choosing flavor characteristics (attributes) that could describe corners of the flavor styles cube. Well-known food products with a stable and brand-independent flavor profile, were selected and consumers were asked in a questionnaire to rate these products on the chosen attributes. The eight corners of the flavor styles cube could be identified, and when forced into three factors, the supposed three-dimensional structure emerged. These analyses confirmed the three factors coating, contracting, and flavor richness. The variance explained was $70,7 \%$, the least square method gave 0,65 , and the tucker coefficients were 0,76 (coating), 0,75 (contracting), and 0,91 (flavor richness). These are highly significant values for this kind of research, which adds to the scientific validity of the model. In further analysis products were positioned in the flavor styles cube and compared to their a-priori supposed position. $68,75 \%$ of the products were classified as expected.

Further support was found when the flavor styles cube was used to classify wines (chapters 5 and 6). One of the flavor styles, around corner 6 of the flavor styles cube, represents wines that are coating with high flavor richness. Such wines get their coating character from sweetness and are classified as 'full'. Yet wines can be rich in flavor, score high in coating elements, while being dry (no sweetness). If such wines are also high in contracting elements (acidity), they would fit in corner 7 . In other food products than wine this flavor style is often characterized by proteins. Evidently, wines have no proteins. Therefore it was hypothesized that they would be rich in amino acids, and particularly rich in glutamic acid (GLU) which is known to be an important enhancer of flavor in many other products. The general term used for this kind of flavor richness is 'umami'. To verify the link between corner 7 and GLU, ten wines were selected which were supposed to represent different profiles of amino acids, and in particular the level of GLU. Chemical analysis confirmed the presence of GLU as expected. Regression analysis showed a strong relation between wines with high amounts of GLU and flavor richness. When manually added to wines, these wines were also regarded as being richer in flavor. As mouthfeel is balanced at a high level, the classification of these wines in corner 7 is correct.

Next to these explicit results in support of the concept that flavor can be classified, leading to flavor styles grouped in the flavor styles cube, there is an implicit line of reasoning. It concerns the use of flavor styles. The proposed classification of flavor is based on the multi-sensory experience, and offers a level of abstraction that goes beyond products or their principal components, like sweetness, saltiness, bitterness, acidity, fattiness, etc. Classification systems should give a better understanding of complex subjects by making it possible to treat non-identical components as equivalent. This implies that if the proposed classification of flavor should do just that, this can be considered as 'supportive evidence'. This is one of the results of chapter 4 . It describes the result of studies that deal with the subject of palatability. This is defined as the successful combination of product characteristics, which are liked by the consumer. To assess the concept of palatability a study was executed in which 
prominent chefs were asked to describe their most successful dishes. Comparison of these dishes was possible by making use of the level of abstraction of the proposed classification of flavor. Without prior training the chefs were able to use the terms 'contracting', 'coating', and 'flavor richness', and it was possible to formulate six Culinary Success Factors (CSFs) that determine palatability. These results were confirmed in a study where CSF dishes were evaluated by a tasting panel. Three sets of dishes were created. One of the three complied with all CSFs, the other two were slightly modified. In each of the three sets of dishes the CSF dish was preferred and found to be more paiatable than the other two. These results shed an interesting light on palatability and could be achieved by making use of the parameters of the flavor styles cube.

In chapter 7 these results are discussed in a wider perspective. In this chapter examples are mentioned of studies on flavor of specific products that also support the view that mouthfeel and flavor richness are important aspects. In flavor intrinsic and extrinsic components can be distinguished. The intrinsic components are 'tasted'; the extrinsic components influence food choice and ultimately flavor itself. Flavor styles may help consumers to make 'better' choices, especially in the case of food products where reliable sensory information is limited or not available. Flavor styles communicate to the consumer what kind of flavor can be expected. The theorem of flavor styles is therefore formulated as 'the function of flavor styles increases as the amount of reliable sensory information decreases'. Liking a certain flavor is closely related to making the 'right' choice, which in turn implies that 'expectation' is strongly related to liking. The proposed classification of flavor can serve a purpose in that respect to food professionals. The 'behavioral process of food choice' is presented as a model of food selection.

A principal question is whether there is sufficient evidence presented to accept the described concept of flavor styles, as is introduced in the introduction. The dimensions 'contracting', 'coating', and 'flavor richness' were formulated in daily practice where they proved to be very useful in getting a better understanding of flavor and flavor reactions, for instance wines and foods. This thesis is a next step in trying to find a scientific base for this supposition. Strong indications were found in support of the acceptance of the concept of flavor styles to classify flavors. Further research is encouraged. 


\section{Acknowledgements}

For more than 20 years now I have been active in the hedonistic part of the world. We own a well-known restaurant, 2 gastronomic shops, and we do our own wine imports. My Academy for Gastronomy was founded to train the service and kitchen staffs of restaurants and hotels, and I have written several books on gastronomy. Interest in flavor is a family heritage. Building stones were supplied by my father. Through his, and later my own activities I became more and more interested in the science behind flavor. I wanted to know more about how our taste sense really works and the underlying principals of liking and not liking certain foods and drinks.

Flavor reactions triggered this interest. It is a well-known fact that for instance wine and food react to each other and that certainly not all reactions are considered favorable. It appears that our positive or negative judgment on these changes is rather universal. This aspect alone enticed my enthusiasm: the predominant opinion is that flavor is a personal and therefore subjective matter. I have come to the conclusion that in regard to flavor, the human and the product side are often mixed. Food and wines have flavor, it is the sum of all kinds of volatile and non-volatile components which can objectively be assessed. Humans do the tasting and form a judgment. This implies that even a good tasting food product needs not necessarily be appreciated. Liking is in the mind of the ever capricious and seemingly unpredictable consumer. Yet, it pays to try to understand the factors that influence appreciation; in the restaurant business as well as in the food industry.

To serve people is in the heart of every restaurateur; and it is true: one can survive in the hedonistic world even without study or writing a doctoral thesis. Studying, writing and teaching can be considered as personal hobby's. At the same time these hobby's have proven to be very rewarding and complementary to my vocation as restaurateur: why not also serve people with knowledge?

A central theme of this work is that people enjoy flavor that corresponds to their good choice. In a similar way, I have been in the lucky circumstance to be able to choose the work and do the things that I like to do. I realize that this is a privilege that can only be granted if other people do the work that has to be done. My wife gave me this opportunity, just as the staff of restaurant De Echoput. l owe them much as they gave me the chance to start this work in the first place.

Secondly, Bob Cramwinckel needs to be mentioned. He introduced me in sensory science. More specifically he introduced me in the 'other way' of looking at flavor, and the necessity to study humans in natural settings if you want to study flavor. His 'contrarian' attitude led to many new views that form the basis of this work.

Lastly, Wim Saris and Coen Hemker gave me the opportunity to embark on my scientific journey. They took the risk of granting permission to a hedonist, not knowing if they could mould him into an academic. I thank them for giving me this confidence. The fact that both are hedonists in their spare time may have contributed to their confidence.

Peter Klosse 


\section{Curriculum Vitae}

\section{Personal}

name:

address:

city:

born:

marital status:

2. Education

$1975-1979$

$1979-1981$

1983

other:
Peter Ronaid Klosse

Amersfoortseweg 86

NL-7346 AA Hoog Soeren

3 February 1956

married, 5 children e-mail: info@echoput.nl

www.echoput.nl

www.academiegastronomie.nl

\section{Professional activities}

1979 - 1981 Instituut Praehep, Den Haag:

management assistant and tutor Internal Organization en Marketing

1983 - present manager, director, owner Restaurant De Echoput (* Michelin), Hoog Soere de Echoput Wijnen \& Foods (gastronomical shops and wine imports), founder-owner Academy for Gastronomy (research, Sommelier training ; courses on wine and food pairing)

author: Wildgerechten, de vier seizoenen van de Echoput (1995)

Smaak, het handboek voor het combineren van wijnen en gerechten (19 Smaakstijlen, de nieuwste visie op het combineren van wijnen en gerechten (2000)

De Echoput, 80 Wild- en Paddestoelengerechten (2002)

Het Proefboek, de essentie van smaak (2003)

The concept of Flavor Styles to classify flavors (2004, thesis)

Various columns, articles and chapters in hotel/restaurant study books

currently: a basic book on wine: how and where it is made.

tutor: Wijnacademie (lesson Gastronomy)

own courses Wine and Food and Sommelier Training

courses for Wageningen Business School 